\title{
The Role of Tobacco Cessation Counseling in Physical Therapist Practice and Education
}

Rose M. Pignataro

West Virginia University

Follow this and additional works at: https://researchrepository.wvu.edu/etd

\section{Recommended Citation}

Pignataro, Rose M., "The Role of Tobacco Cessation Counseling in Physical Therapist Practice and Education" (2013). Graduate Theses, Dissertations, and Problem Reports. 4988.

https://researchrepository.wvu.edu/etd/4988

This Dissertation is protected by copyright and/or related rights. It has been brought to you by the The Research Repository @ WVU with permission from the rights-holder(s). You are free to use this Dissertation in any way that is permitted by the copyright and related rights legislation that applies to your use. For other uses you must obtain permission from the rights-holder(s) directly, unless additional rights are indicated by a Creative Commons license in the record and/ or on the work itself. This Dissertation has been accepted for inclusion in WVU Graduate Theses, Dissertations, and Problem Reports collection by an authorized administrator of The Research Repository @ WVU.

For more information, please contact researchrepository@mail.wvu.edu. 
The Role of Tobacco Cessation Counseling in Physical Therapist Practice and Education

Rose M. Pignataro, PT, DPT

\author{
Dissertation submitted to the School of Public Health \\ at West Virginia University \\ in partial fulfillment of the requirements \\ for the degree of
}
Doctor of Philosophy
in

Public Health Sciences

Anne K. Swisher, PT, PhD, Chair

Ruth Kershner, RN, EdD, MCHES, Co-Chair

Matthew Gurka, PhD

Dina L. Jones, PT, PhD

William Stauber, PT, PhD

Morgantown, West Virginia

2013

Keywords: physical therapy, smoking cessation, evidence-based practice

Copyright 2013 Rose M. Pignataro 


\section{ABSTRACT}

\section{The Role of Tobacco Cessation Counseling in Physical Therapist Education and Practice}

\section{Rose M. Pignataro}

Purpose: Smoking is the leading preventable cause of mortality and chronic disease. Therefore, smoking cessation is one of the highest global health priorities. Within the United States, approximately 443,000 deaths and 8.6 million cases of chronic illness can be linked to the direct and indirect effects of smoking.

Evidence-based clinical guidelines for tobacco cessation counseling (TCC) established by the Agency for Health Care Quality and Research (AHRQ) and the United States Department of Health and Human Services (USDHHS) are considered the "gold standard" for effective smoking cessation. However, dissemination and adoption of these guidelines within standard clinical practice is lacking. Less than $25 \%$ of people who smoke received cessation advice during their last visit with a medical provider. It is estimated that widespread implementation of these evidence-based guidelines would result in 5 million fewer smokers each year, with prevention of more than 3 million premature deaths. Chances of cessation are doubled when smokers are counseled by more than one type of health care provider, stressing the importance of an interprofessional approach.

People with disabilities have higher smoking rates and receive less targeted interventions for smoking cessation when compared with their non-disabled peers, constituting a greater need for tobacco cessation services among physical therapy clientele. As instrumental members of the health care team, it is essential for physical therapists to join efforts to end the tobacco epidemic.

The goal of this research was to promote the use of evidence-based TCC guidelines in physical therapist practice and education by applying principles of knowledge translation as defined by the National Institute on Disability and Rehabilitation Research (NIDRR). According to the NIDDR, research should be framed so that knowledge gained is ultimately applied in a manner geared towards improving the lives of people with disabilities.

Methods and Results: Knowledge translation requires the exchange and utilization of research through dissemination, diffusion, and implementation, as well as the need to base professional practice and education on the best available evidence. Within this dissertation, the process of knowledge translation was represented by three inter-related research studies. 
Study 1 resulted in a perspectives paper which established a sound clinical rationale for the inclusion of TCC as a component of physical therapist practice. This rationale is based on the pathophysiologic effects of smoking on all systems of the body, and the potential for smoking cessation to enhance treatment outcomes in all areas described by the Guide to Physical Therapist Practice, including cardiovascular, pulmonary, neuromuscular, musculoskeletal, and integumentary health. The paper derived from study 1 also provided a template for implementation of the AHRQ clinical guidelines for TCC within the context of physical therapist patient assessment and management. Methodology for Study 1 included a targeted review of the literature, with dissemination of findings through the premier journal of the American Physical Therapy Association.

Study 2 consisted of an assessment of the existing need for TCC training in entry-level physical therapist education, and examined the prevalence and scope of TCC training, as well as the opinions of physical therapy educators towards the inclusion of TCC in the academic and clinical environment. Methodology for Study $\mathbf{2}$ involved a cross-sectional survey of faculty at accredited entry-level physical therapist programs across the United States. Data were analyzed using frequency counts and percentages. Logistic regression was employed to assess factors that influence curricular inclusion of TCC training in entry-level physical therapist education, such as perceived barriers and facilitators to TCC in the clinical environment, and the perceived relevance of TCC within the physical therapist's scope of practice and professional obligations.

Findings from Study 2 indicated that TCC training was absent in 60\% of programs which provided responses to the survey. Based on the need for further dissemination and implementation of TCC in entry-level physical therapist education, the dissertation research culminated with a feasibility study involving the application of a tailored curriculum designed to promote the application of AHRQ/ USDHHS clinical guidelines as a component of physical therapy patient care.

Study 3 involved pilot testing of a curricular blueprint for TCC training as a component of entrylevel physical therapist education. Methodology for Study 3 centered on a pre-test/ post-test design and involved a small sample of student physical therapists at two entry-level programs in the United States. Results of Study 3 demonstrated the feasibility and impact of TCC training for student physical therapists in producing positive changes in knowledge, skill, and intention to apply evidence-based TCC guidelines when working with physical therapy clientele.

Results: Due to higher prevalence of smoking among people with disabilities, and the negative influence of tobacco use on physical therapy treatment outcomes, TCC is an important element 
in physical therapist practice. Barriers to the implementation of TCC clinical guidelines in the clinical environment include limited training for entry-level physical therapists. A tailored TCC training program for student physical therapists was successful in improving knowledge, skill, and intention to apply AHRQ/ USDHHS evidence-based TCC guidelines during subsequent clinical practice.

Conclusions: There is a need for dissemination and adoption of evidence-based TCC guidelines in physical therapist practice and education. Study 1 resulted in a perspectives paper that described the scientific rationale for TCC as a component of physical therapist practice based on the detrimental impact of tobacco use on all aspects of rehabilitative care. Study $\mathbf{2}$ provided data highlighting the existing need for evidence-based TCC training in entry-level physical therapist education. Study $\mathbf{3}$ consisted of a pilot training program. Results of Study 3 supported the efficacy of a tailored curricular blueprint specifically designed to enhance the knowledge, skills, and intentions of student physical therapists towards the application of TCC guidelines as a component of future practice.

Further research is required to assess widespread implementation of tailored training both in larger groups of student physical therapists, and among experienced professionals. Future studies should examine the adoption of guidelines in clinical practice, based on the intentions of trained clinicians. Outcome studies will also be needed to gauge the impact of TCC by physical therapists on patient smoking behaviors, as well as the impact of smoking cessation on physical therapy outcomes, including healing rates, functional recovery, and recurrence of illness or injury. 


\section{Acknowledgements}

Throughout my career as a physical therapist, I have consistently sought to have a meaningful impact on the lives of my patients. This dissertation reflects the impact of many important people on my own life. I would like to take this opportunity to acknowledge my appreciation for their encouragement and support.

Special thanks to the co-chairs of my committee, Drs. Anne Swisher and Ruth Kershner.

"The mediocre teacher tells; the good teacher explains; the superior teacher demonstrates ... the great teacher inspires." (William Arthur Ward) Thank you both for inspiring me.

I would also like to extend my appreciation to the other members of my committee, Drs. Matthew Gurka, Dina Jones, and William Stauber. Your guidance has allowed me to put my ideas into action, and expand my clinical knowledge into scientific research and application.

To Dr. Patricia Ohtake (University at Buffalo, Department of Rehabilitation Science) - I am incredibly grateful for the opportunity to work with someone of your stature, and I have gained so much from your input as an expert consultant. Thank you for your generosity in giving your time and sharing your knowledge.

To Dr. Keith Zullig and Dr. Fred Minnear - Your assistance and counsel have made all the difference. As a non-traditional graduate student, I deeply appreciate the care and concern you have shown in helping me navigate the challenges of blending research, education, and professional practice.

To my amazing colleagues at University of South Florida School of Physical Therapy and Rehabilitation Sciences - this past year has been a stunning example of the value of professional collaboration.

- Dr. William Quillen - it is an honor to work under your leadership and example. "(S)he who dares wins!" (David Stirling - British Special Air Service)

- Drs. Dolly Swisher and Gina Musolino - As leaders in our profession, your mentorship means the world to me.

- Dr. Heather Hartsell - Your calm demeanor and balanced perspective have been such a major source of comfort.

- Drs. Aimee Klein and Rebecca Edgeworth - Your editorial services and professional expertise were essential in helping me write with clarity. Aimee, thank you for keeping me well supplied with caffeine, and Becca, thank you for sustaining my enthusiasm and sense of humor! 
To the life-long friends I have made while at West Virginia University, and to my fellow students at the School of Public Health - a special thank you for being a strong network of brilliant, dedicated minds.

- Drs. Sarah Geiger, Molly Matthews-Ewald and Laura Kurth - BCE forever! Lock the four of us in a room, and we will conquer the world! You were, by far, the best part of this journey.

- To my soul sisters, Kate McCarthy, Karen Manzo, Mousumi Banikya Leasburg and Ruchi Bhandari - I thank God for giving me such good friends, study partners, and general life support. You are amazing people, and I am so grateful for everything you have done to help me achieve my dreams.

And finally, to my loving family - thank you for making sure I never lost heart -

- Rose A. Pignataro and Anthony Pignataro - Mom and Dad, God picked the very best parents anyone could ever ask for when He gave me the two of you! Dad, after 40 years of checking my homework, you may now officially enjoy your retirement!

- My Nana - Rose M. Pignataro - you are the strongest, most intelligent woman I know! Thank you for setting such a wonderful example.

- My siblings - Natalie Giambra and Anthony Pignataro - many thanks to you and your beautiful families for bringing me so much joy.

- To my nieces and nephews - Ariella, Kelly, Brian, William, Nicole, Dominic, and Antonella - Aunt Rosie loves you very much. Dream big and don't ever let anything stop you!

- My BFF and head cheerleader - Nicole Green - so often, you were the glue that held me together and the compass that kept me on course. I can never thank you enough.

- My partner in life - Jack D. Murry, Jr. - "Two are better than one ... for if either of them falls, the one will lift up his companion." (Ecclesiastes 4:10) Thank you for lifting me up, for being my comfort and consolation, and for always believing in me. 


\section{Table of Contents}

Acknowledgments

i.

Table of Contents

iii.

Chapter 1: Introduction

p.1

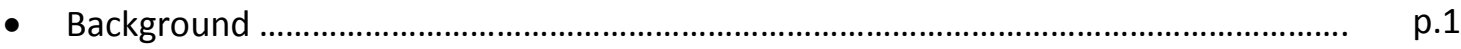

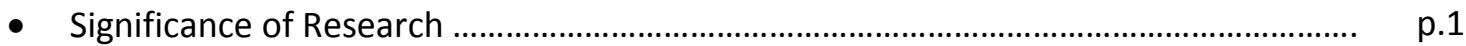

- Purpose of Research .................................................................................................... p

- Experimental Design and Methods .............................................................................. p. p.

- Summary ............................................................................................................... p

- References ................................................................................................................. p.11

Chapter 2: The Role of Physical Therapists in Smoking Cessation: Opportunities for Improving $\quad$ p.20

Treatment Outcomes

- Abstract ............................................................................................................ p p. 21

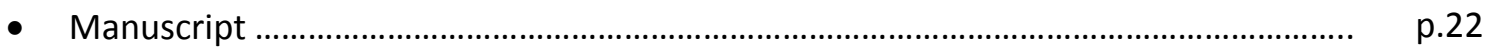

- References ................................................................................................................. p.31

Chapter 3: Tobacco Cessation Counseling Training in US Entry-Level Physical Therapist Education Curricula: Prevalence, Content, and Associated Factors

p.39

- Abstract ...................................................................................................... p.

- Introduction .................................................................................................... p.

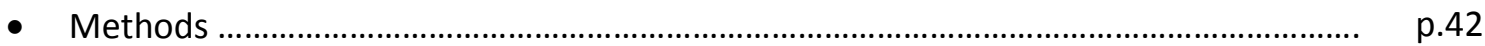

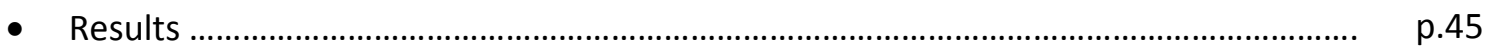

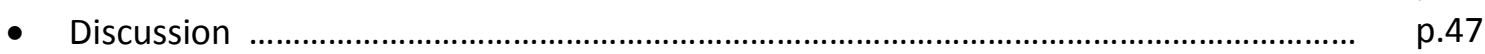

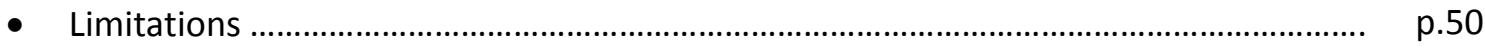

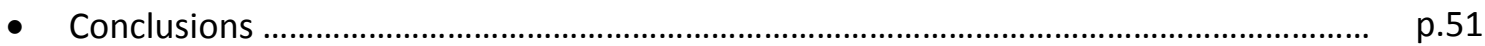

- References ............................................................................................................... p.

Chapter 4: Tobacco Cessation Counseling Training for Student Physical Therapists: Feasibility and

Preliminary Outcomes ............................................................................................................... p. p

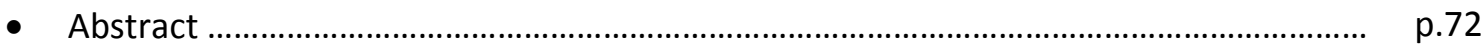

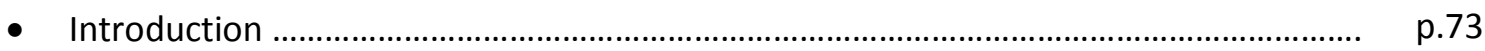

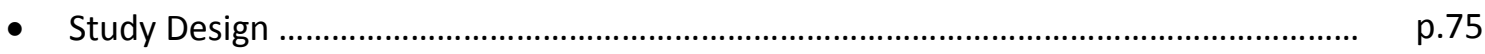

- Outcome Assessment ............................................................................................ p p

- Data Analysis ....................................................................................................... p p.78

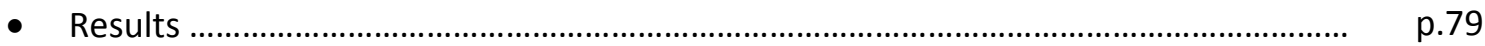

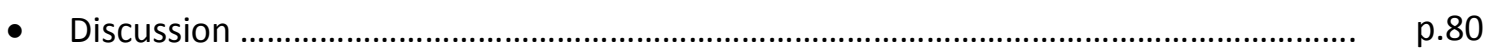

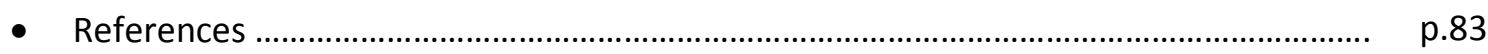

Chapter 5: Summary and Conclusions …........................................................................................ p

- References ......................................................................................................... p.104 


\section{Chapter 1}

\section{Background}

Tobacco use is the leading preventable cause of premature mortality and chronic disease in the United States. ${ }^{1}$ Each year, approximately 443,000 deaths and 8,600,000 cases of chronic illness can be linked to the direct and indirect effects of smoking. ${ }^{2}$ Smoking cessation has been identified as one of the country's top priorities, as defined by the national health agenda, Healthy People, 2020. ${ }^{3}$ Due to elevated risk of disease and disability, brief tobacco cessation counseling (TCC) based on evidence-based clinical guidelines is one of the most effective preventive services a health care professional can offer. ${ }^{4}$

According the United States Public Health Service (USPHS), tobacco dependence is a chronic condition that requires repeated interventions from multiple provider types for successful treatment. ${ }^{5}$ Unfortunately, a survey of ambulatory care patients found that less than $25 \%$ of people who smoked received any cessation advice during their most recent medical visit. ${ }^{6}$ This information is particularly pertinent given further research that indicates approximately $70 \%$ of current smokers would like to quit and are amenable to receiving cessation advice within a health care setting. ${ }^{7}$ While many providers anticipate patient resistance towards TCC, research has also demonstrated a clear patient preference towards TCC delivered by a healthcare provider versus tobacco cessation interventions delivered via support groups, self-help materials, and telephone counseling. ${ }^{8}$ Furthermore, TCC has been linked with improved patient satisfaction due to greater perceived interest and communication on the part of the health care provider. ${ }^{9}$ Approximately $40 \%$ of people who are counseled by a medical provider will make a quit attempt in response to the intervention, ${ }^{10}$ with some studies demonstrating a $76 \%-87 \%$ increase in cessation for patients counseled by providers following a training intervention to improve the provider's knowledge and skill. ${ }^{11}$

\section{Significance of Research}

Despite the development and dissemination of evidence-based guidelines for TCC through the Agency for Health Care Quality and Research (AHRQ) more than a decade ago, the lack of adequate smoking interventions among health care practitioners persists. ${ }^{12}$ Several types of health care professionals, including physicians, ${ }^{13}$ nurses, ${ }^{14}$ pharmacists, ${ }^{15}$ chiropractors, ${ }^{16}$ dentists, ${ }^{4}$ and dental hygienists, ${ }^{4}$ have identified a lack of education in TCC as the primary reason for this deficiency. ${ }^{17}$ Training in TCC techniques has been shown to generate positive changes in providers' behavior. ${ }^{18}$ Therefore, improved training is likely to increase the number

of patients that receive evidence-based smoking cessation interventions. ${ }^{18}$ Long term, the expected results would be an increase in cessation rates and a decrease in the prevalence of 
tobacco-related disease. ${ }^{18}$ Application of evidence-based TCC techniques is especially pertinent for special populations distinguished by elevated tobacco use and decreased access to cessation interventions. According to available research, people with disabilities are twice as likely to smoke as their non-disabled peers, ${ }^{19}$ and less likely to receive specific cessation advice during medical encounters. ${ }^{20,21}$

Targeted training has been shown to increase the skill and likelihood of TCC by physicians, ${ }^{10,22}$ dentists, ${ }^{22}$ dental hygienists, ${ }^{23}$ pharmacists, ${ }^{22}$ psychologists, ${ }^{11}$ and nurses. ${ }^{11}$ The physical therapy profession is in a prime position to optimize treatment outcomes and advance prevention by joining these efforts. ${ }^{7}$ As demonstrated by a survey conducted in 2004, TCC is not currently employed as standard practice in physical therapy. ${ }^{24}$ Results showed that only $17 \%$ of therapists in California, New York, and Tennessee reported the inclusion of tobacco screening and intervention as a usual component of patient care. ${ }^{24}$ Among nurses, ${ }^{17}$ dental hygienists, ${ }^{25}$ osteopathic physicians, ${ }^{26}$ and medical students, ${ }^{27}$ a lack of training has been linked to the unavailability of tailored TCC education programs. It is likely that the same issues exist within physical therapist practice and education, where the absence of curricular and content guidelines for evidence-based TCC perpetuates the lack of tobacco cessation interventions in the clinical environment. ${ }^{7}$

\section{Purpose of the Research}

The primary goal of this dissertation project was to promote the application of evidencebased TCC guidelines in physical therapist practice through tailored training for entry-level physical therapy students.

This project centered on the evidence-based TCC clinical guidelines established by the AHRQ and the United States Department of Health and Human Services (USDHHS), commonly known as the " 5 A's" and the " 5 R's.",28 The " 5 A's: Ask, Advise, Assess, Assist, and Arrange" outline important strategies for addressing smoking cessation in patients who may be considering cessation, or are open to behavioral change regarding tobacco use. The first step is for health providers to ask patients about their tobacco use during the initial clinical encounter, and document the patient's smoking status. If the patient is an active smoker, the provider should advise him or her that smoking cessation is a crucial step in improving their health. Advice should be strong, but non-judgmental, and should be personalized to reflect the patient's goals and objectives in seeking a health care consultation. Next, the health care provider should assess the patient's willingness to quit. This will help guide subsequent interventions. If the patient is willing to consider steps towards cessation, the practitioner can then assist him or her by recommending resources, or offering appropriate referrals. The last step is to arrange for follow-up so that the patient and practitioner can review progress and potential challenges. Patients should be informed that smoking is a chronic problem, and cessation can take many 
attempts in order to achieve long-term abstinence. Relapse in smoking behaviors can be viewed as learning opportunities in order to discover and resolve barriers to breaking the habit. $^{2}$

The "5 R's: Relevance, Risks, Rewards, Roadblocks, and Repetition" are designed for patients who may not be ready to make an immediate commitment towards smoking cessation. The health care provider can use the " $5 \mathrm{R}$ 's" to help patients uncover motivation to quit smoking. The first step is to discuss relevance, or why smoking cessation is pertinent within the context of this particular individual's life, i.e. - how is smoking related to this person's unique values? Next, the practitioner and patient can discuss risks of continued tobacco use by asking the patient to identify potential concerns related to the many consequences of smoking. In addition, the patient and practitioner should review the benefits, or rewards, of quitting. Most smokers are well aware of health risks associated with tobacco use, and often, resistance towards quitting is not due to an absence of cognitive awareness, but rather, a decisional imbalance caused by concern for barriers to successful cessation. Therefore, the next step in counseling is to identify roadblocks, or the personal and environmental obstacles that can impede one's ability to quit. Finally, because everyone learns from repetition, it is important for the health care practitioner to periodically revisit the topic of cessation throughout the patient's episode of care. ${ }^{2}$ Please see Appendix A, Chapter 1 , for a graphic representation of the " 5 A's and 5 R's."

The " 5 A's and 5 R's" are considered the industry "gold standard" for tobacco cessation interventions ${ }^{29}$ and have been utilized in widespread training initiatives for other healthcare providers ${ }^{11,22}$ including physicians, ${ }^{30-33}$ nurses, ${ }^{34}$ pharmacists, ${ }^{15}$ chiropractors, ${ }^{16,35}$ dentists, ${ }^{36}{ }^{37-39}$ and respiratory therapists. ${ }^{40}$ According to the American Physical Therapy Association, as the profession advances towards the future, physical therapists will be the practitioners of choice for the diagnosis, treatment, and prevention of conditions related to movement, function, and health. ${ }^{41}$ Tobacco cessation as a component of comprehensive physical therapy assessment and intervention is consistent with the role of the profession in health promotion and wellness, through prevention as well as management of chronic disease. ${ }^{7}$ 


\section{Experimental Design and Methods}

The dissertation research centered on three primary aims:

\section{Aim 1.0: Establish a clinical rationale for inclusion of TCC as an important element of physical therapist practice and education.}

Barriers to TCC by health care professionals include failure to recognize the importance of TCC with respect to professional roles and priorities. ${ }^{42}$ Therefore, as a prelude to design and implementation of a tailored educational intervention intended to increase TCC as a component of physical therapy assessment and treatment, it was essential to outline and illustrate the impact of smoking on patient outcomes within the four major areas outlined by The Guide to Physical Therapist Practice: 1) cardiovascular/pulmonary, 2) neuromuscular, 3) musculoskeletal, and 4) integumentary health. ${ }^{43}$ This goal was accomplished through a comprehensive, structured review of the literature, which was then used to compose an evidence-based position paper geared towards increasing the awareness of this issue within the physical therapy profession, thus creating an incentive for further action. ${ }^{44}$

Aim 1.0 was the focus of Study 1, presented in the first of three papers of the dissertation, found in Chapter 2. 


\section{Aim 2.0: Determine the current state of TCC education in entry-level physical therapy programs, i.e. - prevalence of training, scope of content, and instructional format, including opportunities to apply TCC skills in a clinical setting.}

Previous research has shown that TCC is not yet a widespread component of physical therapist practice. According to a 2004 survey of physical therapists in New York, Tennessee, and California, less than $17 \%$ of respondents routinely incorporated tobacco cessation advice within standard practice. ${ }^{24}$ This deficiency has been tied to a lack of TCC training and practical skills application during the formative years of professional training. ${ }^{45,46}$ It has also been shown that TCC training in entry-level professional education can improve the provision of TCC by providers engaged in direct patient care in clinical settings. ${ }^{5}$ However, no known data were available to reflect the current state of TCC training within entry-level physical therapist education. Therefore, a needs assessment was required before any further intervention could take place.

An assessment of the need for TCC training within physical therapist education was directed through the application of the PRECEDE-PROCEED planning model developed by Green and colleagues. ${ }^{47}$ This model enabled a targeted appraisal of existing resources within the educational setting in order to guide the formation, implementation, and evaluation of the subsequent TCC training initiative. The selection of the PRECEDE-PROCEED model was based on prior research which demonstrated its effectiveness in shaping interventions geared towards addressing gaps in evidence-based practice. ${ }^{48}$ According to the PRECEDE-PROCEED model, the needs assessment should result in an initial educational diagnosis based on the characteristics of the educators, students, and the learning environment. With regards to the need for TCC training in entry-level physical therapist education, these characteristics included predisposing, reinforcing, and enabling factors such as the individual attitudes, beliefs (self-efficacy, outcome expectations), and baseline knowledge and skills of program faculty towards advancing the profession's role in smoking cessation. ${ }^{22}$ Data gathered during these preliminary stages were used to assess organizational support for the proposed change in student education order to identify potential barriers, obtain a realistic starting point, and gauge the potential for successful program implementation and sustainability. ${ }^{49}$ Each aspect of the PRECEDE-PROCEED model, i.e. - the educational diagnosis, intervention design, and subsequent program assessment, were previously employed by Tremblay and colleagues in creating an intervention to promote increased TCC among Canadian physicians. ${ }^{50}$

The PRECEDE-PROCEED planning model is closely related to the Theory of Reasoned Action (TRA) formed by Ajzen and Fishbein. ${ }^{51}$ Based on the TRA, intervention design is most effective in promoting changes in action when it targets the causal determinants of the behavior of interest. ${ }^{52}$ Throughout this dissertation research, the behavior of interest was knowledge 
translation, ${ }^{53}$ defined as the application of evidence-based TCC guidelines in physical therapist education and practice.

Methods to promote increased application of evidence-based TCC guidelines in physical therapist practice focused on principles of knowledge translation defined by the National Institute on Disability and Rehabilitation Research (NIDRR), "the multidimensional, active process of ensuring that new knowledge gained through the course of research ultimately improves the lives of people with disabilities." ${ }^{54}$ People with disabilities are twice as likely to smoke when compared with members of the general population. ${ }^{1,20}$ They are also less likely to be screened for tobacco use or receive cessation counseling, and are subject to clustering of risk factors which increase likelihood of chronic disease, including limited access to health care, obesity, and a sedentary lifestyle. ${ }^{20,55,56}$ Throughout their professional history, physical therapists have demonstrated an enduring commitment towards addressing the health care needs of people with disabilities, and are thereby obligated to increase their involvement in TCC.

Aim 2.0 was the focus of study 2 . Study 2 explored the following research questions:

What is the current state of TCC training in physical therapist education, i.e. - what is the scope and content of TCC currently covered by entry-level programs throughout the United States?

What are the perceived barriers and facilitators towards the inclusion of evidence-based TCC as a component of entry-level physical therapist education?

Results of Study 2 are presented in the second of three papers of the dissertation, found in Chapter 3. Paper 2 presented cross-sectional data from a survey of physical therapy faculty. Survey items focused on the prevalence and scope of TCC training among entry-level physical therapist education programs throughout the United States. Data from Study 2 were used to assess whether TCC is covered as a component of entry-level curricula, as well as the number of hours, and teaching methods employed in conveying the materials. Faculty members were also asked to provide their opinions regarding TCC and the professional roles of the physical therapist, as well as potential challenges to the application of TCC in the clinical environment. A list of possible barriers was based on findings from surveys of other health professionals. These potential impediments included lack of time and competing priorities, ${ }^{57}$ anticipated resistance among patients, ${ }^{58}$ lack of reimbursement for counseling/ patient education services, ${ }^{8,59}$ and perceived lack of efficacy of TCC in achieving successful smoking abstinence. ${ }^{59}$

Information regarding the barriers and facilitators for inclusion of TCC as a component of entrylevel physical therapist educational curricula was subsequently used in shaping the educational initiative - a pilot training program designed to increase the knowledge, skill, outcome 
expectations, self-efficacy and intention of student physical therapists towards the application of evidence-based TCC guidelines during subsequent clinical practice. The design and results of this initiative are outlined in Aim 3.0, Study 3.

Aim 3.0: Assess the knowledge, attitudes, self-efficacy, and intentions of physical therapy students towards TCC before and after a specifically-tailored educational module to teach TCC skills.

\section{A: Conduct a baseline survey of physical therapy students (pre-test)}

\section{B: Develop and deliver a tailored educational module for PT students}

\section{C: Conduct a post-educational survey of physical therapy students (post-test)}

Results of the educational needs assessment, outlined in Chapter 3 (Study 2), indicated a lack of curricular content for evidence-based TCC as a component of physical therapist education. According to prior studies involving other health care professions, one of the most significant barriers to TCC is the lack of TCC education during the formative years of training. ${ }^{58}$ Past research also shows that tobacco treatment training programs for health care professionals are essential in improving cessation rates among people who smoke. ${ }^{60}$ Tailored training increases the provider's confidence in being able to offer effective interventions, and enhances the likelihood and quality of patient education. ${ }^{61}$

Challenges to TCC training for entry-level physical therapists and the subsequent integration of TCC as a component of practice include the perceptions and attitudes of the student clinicians in shaping future behavior. The Theory of Reasoned Action (TRA) ${ }^{51}$ has been successfully utilized in order to promote changes in evidence-based practice by enhancing the intention to apply evidence-based guidelines during subsequent clinical practice. ${ }^{62}$ The TRA described the likelihood of a particular course of action (i.e. - the application of evidence-based TCC guidelines) based upon an individual's knowledge and skill, as well as his or her self-efficacy, attitudes, and intention towards the behavior of interest. ${ }^{51}$ As intention increases, so does the probability of the specific course of action. Therefore, intention is viewed as the proximal determinant of behavior. ${ }^{63} \mathrm{~A}$ systematic review examining application of evidence-based clinical practice guidelines found positive correlations between the self-reported intentions and actual behaviors of medical professionals. ${ }^{64}$ These findings show promise for the application of TRA in promoting changes in physical therapist practice. Therefore, the TRA was selected as a basis for improving the integration of evidence-based TCC within entry-level physical therapist education, in order to encourage greater application of TCC during future patient management.

The TRA also postulates that intentions are shaped by an individual's attitudes towards the behavior of interest. These attitudes include the individual's outcome expectations, defined as 
the perceived value of the anticipated results relative to the prescribed behavior. ${ }^{63}$ Behavioral intentions are also influenced by other internal factors such as knowledge, skill, and perceived control, also known as self-efficacy. ${ }^{51}$ Self-efficacy is an individual's confidence in his or her own ability to successfully perform the prescribed course of action. ${ }^{65}$ The relationship between selfefficacy and intention is strongest when accompanied by favorable expected outcomes. ${ }^{66}$ In a study of clinical behaviors of primary care physicians, the provision of lifestyle counseling had been linked to higher levels of outcome expectations and self-efficacy. ${ }^{67}$ Specific to evidencebased TCC, behaviors among physicians were also directly correlated with self-efficacy and perceived knowledge and skill. ${ }^{68}$ Thus, it was determined that tailored training designed to promote increased TCC in physical therapist practice should center on factors identified by the TRA, namely, behavioral intention, as a product of the learner's knowledge, skills, attitudes, and self-efficacy. Please see Figure 1 for a schematic representation of this relationship.

Design of the educational initiative for entry-level physical therapy students was guided by previous research regarding training in other healthcare disciplines, including data that suggest training should incorporate elements of active learning, and incorporate scenarios and case studies to facilitate collaboration ${ }^{42}$ as well as the practical application of knowledge. ${ }^{46}$ Learning objectives for TCC training in student physical therapists were similar to the training goals established for TCC education of medical residents: systematically identify patients who smoke; clearly advise all smokers to quit using individually tailored counseling techniques; assess smokers' readiness to change; apply evidence-based TCC strategies; and engage in short and long-term follow-up. ${ }^{69}$ Curricular content was also modeled after TCC training objectives previously employed by other health professions. Training content for student physical therapists included epidemiological data identifying groups in highest need of tobacco cessation interventions, ${ }^{70}$ the general consequences of tobacco use, pathophysiologic changes in each major body system (cardiopulmonary/ vascular, musculoskeletal, neuromuscular, and integument) that occur as a consequence of smoking, the stages of change model as it impacts smoking behaviors, assessment of smoking history and screening for nicotine addiction, elements of the AHRQ/USDHHS evidence-based guidelines for TCC, and referral mechanisms to assist patients in achieving successful cessation. ${ }^{37,71}$

Study 3 focused on the following research questions:

Is tailored training in evidence-based TCC effective in improving the knowledge, skills, outcome expectations, perceived barriers and facilitators, and self-efficacy of physical therapy students?

Does training result in an increase in intention to provide TCC in a clinical setting? 
Baseline measurements and changes in knowledge, skills, attitudes (perceived barriers, facilitators, outcome expectations), self-efficacy and intention to perform TCC following the implementation of a tailored educational module, were assessed using a prospective pre-test/ post-test research design. Data were collected using a survey instrument specifically designed to capture each of these domains. Similar techniques have been used to assess impact of TCC training within nursing and medical education curricula. ${ }^{42,46,72,73}$

Aim 3.0 served as the focus of the third study. Results are presented as the final paper of the dissertation, found in Chapter 4. Data from Study 3 were used to demonstrate the positive impact of evidence-based TCC training on the knowledge, skill, attitudes, and behavioral intentions of student physical therapists in incorporating evidence-based TCC guidelines as a usual component of patient care. Results of this study strengthen the application of a curricular blueprint in response to previous research which demonstrates that an established training model facilitates the widespread implementation of TCC guidelines in entry-level education for health care practitioners. ${ }^{14}$

\section{Summary}

The primary focus of this dissertation research was to promote training to enhance the application of evidence-based TCC within the physical therapy profession, in order to ultimately decrease rates of smoking, particularly among people with disabilities. As a whole, the project involved some necessary delimitations and assumptions. Although there are inherent health risks from other forms of smokeless tobacco such as snuff, dip and chew, ${ }^{74}$ statistics show that, within the United States, cigarettes are, by far, the most prevalent form of tobacco use. ${ }^{12}$ Other forms of smoking, for example, pipes and cigars, also exceed the use of smokeless tobacco. 8 AHRQ/ USDHHS evidence-based TCC guidelines (The " 5 A's" and " 5 R's") and the design and implementation of the TCC training initiative for physical therapy students mainly addressed cigarette use.

In addition, by employing the TRA, this research focused on intention as a proximal measure of behavior. Ideally, it would have been best to examine the actual rate of TCC within the clinical setting among student physical therapists who had been trained in the application of evidencebased guidelines. Although the exploration of subsequent clinical behaviors of student physical therapists trained in TCC is a topic that will require further research, the scope of this dissertation was limited to a pilot educational intervention designed to promote increased knowledge and skill in the use of evidence-based TCC guidelines within an academic environment. This initial research forms the basis future studies involving deeper inquiry into the clinical behaviors of physical therapists with regards to the application of AHRQ/ USDHHS guidelines for smoking cessation through the application of skills gained during their entry-level education. 
The significance of this dissertation research stemmed from the role of physical therapists in the national health agenda, and the need for the profession to assume a more active role in prevention of chronic disease and disability. Historically, the physical therapy profession has been well-recognized for its responsiveness to the needs of society. ${ }^{75}$ Although evidence-based TCC is not yet considered a primary standard of care within most rehabilitative settings, patient education has always been a central component of physical therapy interventions, with a strong emphasis on personal empowerment through effective self-management. ${ }^{76}$ People with disabilities are $50 \%$ more likely to smoke than the general population. ${ }^{1,20}$ People with disabilities also tend to exhibit higher smoking intensity and greater signs and symptoms of nicotine addiction. ${ }^{1,19}$ The ill effects of smoking may be magnified in people with disabilities due to clustering of other risk factors for chronic disease such as sedentary lifestyle, obesity, and limited access to healthcare. ${ }^{77}$ Research has also found that people with disabilities who smoke have lower health-related quality of life than people with disabilities who do not smoke. ${ }^{55}$ These epidemiologic data indicate that the prevalence and consequences of smoking are higher among typical physical therapy clientele where the need for successful TCC is even greater than in the non-disabled population.

It has been projected that future physical therapist practice will be shaped by the quest for cost-effective interventions that can improve health without inflating cost of care. ${ }^{78}$ There are approximately 45 million smokers in the United States. ${ }^{2}$ It is anticipated that more than half of these people will die prematurely from a smoking-related illness. Costs of care due to smoking are estimated at $\$ 96$ billion per year in direct expenditures and $\$ 97$ billion in lost productivity. ${ }^{2}$ For these reasons, the AHRQ/USDHHS clinical guidelines for TCC have been recognized as the nation's most cost-effective means of improving adult health. ${ }^{42}$ Smoking cessation interventions delivered by other health care professionals such as psychologists, physicians, and nurses, have already proven effective in reducing the number of people who smoke. ${ }^{79}$ In addition, interprofessional approaches to smoking cessation have the greatest chances of success. ${ }^{79}$ When two or more professionals from different disciplines counsel patients regarding tobacco use, the likelihood of a cessation attempt triples. ${ }^{80}$ It is time for physical therapists to contribute their expertise in addressing health consequences resulting from tobacco use. Further research is needed in order to determine the best way for the physical therapy profession to achieve the goals of promoting smoking cessation among people with disabilities as well as the population at large. 


\section{References}

1. Moorhouse M, Pomeranz, J., Barnett, T., Yu, N., Curbow, B. Tobacco Cessation Intervention for People with Disabilities: Survey of Center for Independent Living Directors. Rehabilitation Counseling Bulletin. 2011;54(2):118-121.

2. Fiore $M$, Croyle R, Curry S, et al. Preventing 3 Million Premature Deaths and Helping 5 Million Smokers Quit: A National Action Plan for Tobacco Cessation. American Journal of Public Health. 2004;94(2):205-210.

3. United States Department of Health and Human Services. The National Prevention Strategy: America's Plan for Better Health and Wellness. 2011; http://www.healthcare.gov/news/factsheets/2011/06/prevention06162011a.html. Accessed 12/6/12, 2012.

4. O'Donnell J, Hamilton M, Markovic N, Close J. Overcoming Barriers to Tobacco Cessation Counseling in Dental Students. Oral Health and Preventive Dentistry. 2010;8:117-124.

5. Rankin K, Jones D, Crews K. Tobacco Cessation Education for Dentists: An Evaluation of the Lecture Format. Journal of Cancer Education. 2010;25:282-284.

6. Heaton P, Frede, S. Patients' Need for More Counseling on Diet, Exercise, and Smoking Cessation: Results from the National Ambulatory Medical Care Survey. Journal of the American Pharmacists Association. 2006;46:364-369.

7. Bodner M, Dean, E. Advice as a Smoking Cessation Strategy: A Systematic Review and Implications for Physical Therapists. Physiotherapy Theory and Practice. 2009;25(56):369-407.

8. Walsh M, Ellison J. Treatment of Tobacco Use and Dependence: The Role of the Dental Professional. Journal of Dental Education. 2005;69(5):521-537.

9. Walsh S, Singelton, J., Worth, C., Krugler, J., Moore, R., Wesley, G., Mitchell, C. Tobacco Cessation Counseling Training with Standardized Patients. Journal of Dental Education. 2007;71(9):1171-1178.

10. Hu S, Pallonen, U., McAllister, A., Howard, B., Kamisnki, R., Stevenson, G., Servos, T. Knowing How to Help Tobacco Users: Dentists' Familiarty and Compliance with the Clinical Practice Guideline. Journal of the American Dental Association. 2006;137:170179.

11. Lancaster T, Stead, L. Individual Behavioral Counselling for Smoking Cessation. The Cochrane Library. 2008(4).

12. United States Department of Health and Human Services. Ending the Tobacco Epidemic: A Tobacco Control Strategic Action Plan for US Department of Health and Human Services2010.

13. Bloom B. Effects of Continuing Medical Education on Improving Physician Clinical Care and Patient Health: A Review of Systematic Reviews. International Journal of Technology Assessment in Health Care. 2005;21(3):380-385.

14. Wewers M, Kidd, K., Armbruster, D., Sarna, L. Tobacco Dependence Curricula in U.S. Baccalaureate and Graduate Nursing Education. Nursing Outlook. 2004;52(2):95-101.

15. Prohkorov A, Hudmon K, Marani S, et al. Engaging Physicians and Pharmacists in Providing Smoking Cessation Counseling. Archives of Internal Medicine. 2010;170(18):1640-1646. 
16. Gordon J, Istavan J, Haas M. Tobacco Cessation Via Doctors of Chiropractic: Results of a Feasibility Study. Nicotine \& Tobacco Research. 2010;12(3):305-308.

17. Shishani K, Stevens K, Dotson J, Reibe C. Improving Nursing Students' Knowledge Using Online Education and Simulation to Help Smokers Quit. Nurse Education Today. 2012;in press(in press):in press.

18. Sheffer C, Barone, C., Anders, M. Training Nurses in the Treatment of Tobacco Use and Dependence: Pre- and Post-Training Results. Journal of Advanced Nursing. 2011;67(1):176-183.

19. Brawarsky P, Brooks, D., Wilber, N., Gertz, R., Walker, D. Tobacco Use Among Adults with Disabilities in Massachusetts. Tobacco Control. 2002;11 (Suppl):ii29-ii33.

20. Armour B, Campbell, V., Crews, J., Malarcher, A., Maurice, E., Richard, R. State-Level Prevalence of Cigarette Smoking and Treatment Advice, by Disability Status, United States, 2004. Preventing Chronic Disease: Public Health Research, Practice and Policy. 2007;4(4):1-11.

21. Becker H, Brown A. Disparities in Smoking Behaviors Among Those With and Without Disabilities From 2001 to 2005. Public Health Nursing 2008;25(6):526-535.

22. Gorin S, Heck, J. Meta-Analysis of the Efficacy of Tobacco Counseling by Health Care Providers. Cancer Epidemiology, Biomarkers and Prevention. 2004;13(12):2012-2022.

23. Davis J, Stockdale, M., Cropper, M. Evaluation of a Comprehensive Tobacco Cessation Curriculum for Dental Hygeine Programs. Journal of Dental Education. 2010;74(5):472479.

24. Rea B, Marshak, H., Neish, C., Davis, N. The Role of Health Promotion in Physical Therapy in California, New York and Tennessee. Physical Therapy. 2004;84(6):510-523.

25. Harris J, Patton, L., Wilder, R., Peterson, C., Curran, A. North Carolina Dental Hygeine Students' Opinions About Tobacco Cessation Education and Practices in Their Programs. Journal of Dental Education. 2009;73(5):539-549.

26. Montaldo N, Ferry L, Stanhiser T. Tobacco Dependence Curricula in Undergraduate Osteopathic Medical Education. Journal of the American Osteopathic Association. 2004;104(8):317-323.

27. Richmond R, Zwar N, Taylor R, Hunnisett J, Hyslop F. Teaching About Tobacco in Medical Schools: A Worldwide Study. Drug and Alcohol Review. 2009;28:484-497.

28. Fiore M, Bailey W, Cohen S. Treating Tobacco Use and Dependence: Quick Reference Guide for Clinicians. In: Services USDoHaH, ed. Rockville, Maryland: Public Health Service; 2000.

29. Hartmann K, Espy A, McPheeters M, Kinsinger L. Physicians Taught as Residents to Conduct Smoking Cessation Intervention: A Follow-Up Study. Preventive Medicine. 2004;39:344-350.

30. Bernstein S, Boudreax E, Cabral L, et al. Efficacy of a Brief Intervention to Improve Emergency Physicians' Smoking Cessation Counseling Skills, Knowledge, and Attitudes. Substance Abuse. 2009;30:158-181.

31. Brown R, Pfeifer J, Gjerde C, Seibert C, Haq C. Teaching Patient-Centered Tobacco Intervention to First-Year Medical Students. Journal of General Internal Medicine. 2004;19:534-539. 
32. Geller A, Zapka, J., Brooks, K., Dube, C., Powers, C., Rigotti, N., O'Donnell, J., Ockene, J. Tobacco Control Competencies for US Medical Students. American Journal of Public Health. 2005;95(6):950-955.

33. Leong S, Lewis, P., Curry, W., Gingrich, D. Tobacco World: Evaluation of a Tobacco Cessation Training Program for Third-Year Medical Students. Academic Medicine. 2008;83(10):S25-S28.

34. Barta S, Stacy R. The Effects of a Theory-Based Training Program on Nurses' Self-Efficacy and Behavior for Smoking Cessation Counseling. The Journal of Continuing Education in Nursing. 2005;36(3):117-123.

35. Evans M, Hawk C, Strasser S. An Educational Campaign to Increase Chiropractic Intern Advising Roles on Patient Smoking Cessation. Chiropractice and Osteopathy. 2006;14(24):1-9.

36. Koerber A, Crawford J, O'Connell K. The Effects of Teaching Dental Students Brief Motivational Interviewing for Smoking Cessation Counseling: A Pilot Study. Journal of Dental Education. 2003;67(4):439-447.

37. Gelsky S. Impact of a Dental/ Dental Hygeine Tobacco-Use Cessation Curriculum on Practice. Journal of Dental Education. 2002;66(9):1074-1078.

38. Arnett M, Baba N, Cheek D. Improving Tobacco Dependence Education for Dental and Dental Hygeine Students at Loma Linda University School of Dentistry. Journal of Dental Education. 2012;76(4):472-478.

39. Geboy M. Dental School-Based Continuing Education in Tobacco Use Cessation Counseling for Oral Health Care Providers. Journal of Dental Education. 1990;54(12):736-738.

40. Jordan T, Khubchandani J, Wilblishauser M, Glassman T, Thompson A. Do Respiratory Therapists Receive Training and Education in Smoking Cessation? A National Study of Post-Secondary Training Programs. Patient Education and Counseling. 2011;85:99-105.

41. American Physical Therapy Association. Vision 20202000.

42. Sarna L, Bialous, S., Rice, V., Wewers, M. Promoting Tobacco Dependence Treatment in Nursing Education. Drug and Alcohol Review. 2009;28:507-516.

43. American Physical Therapy Association. Guide to Physical Therapist Practice: Second Edition2003.

44. Pignataro R, Ohtake P, Swisher A, Dino G. The Role of Physical Therapists in Smoking Cessation: Opportunities for Improving Treatment Outcomes. Physical Therapy. 2012;92:757-766.

45. Bodner M, Miller, W., Rhodes, R., Dean, E. Smoking Cessation and Counseling: Knowledge and Views of Canadian Physical Therapists. Physical Therapy. 2011;91(7):1051-1062.

46. Schmelz A, Nixon, B., McDaniel, A., Hudmon, K., Zillich, A. Evaluation of an Online Tobacco Cessation Course for Health Professions Students. American Journal of Pharmaceutical Education. 2010;74(2):1-9.

47. Green L. From Reseach to "Best Practices" in Other Settings and Populations. American Journal of Health Behavior Research. 2001;25(3):165-178.

48. Grol R, Wensing M. What Drives Change? Barriers to and Incentives for Achieving Evidence-Based Practice. Medical Journal of Australis. 2004;180(6):54-57. 
49. Gilmore G, Campbell M. Needs and Capacity Assessment Strategies for Health Education and Health Promotion. Sudbury, MA: Jones and Bartlett; 2005.

50. Tremblay M, Gervais, A., Lacroix, C., O'Loughlin, J., Makni, H., Paradis, G. Physicians Taking Action Against Smoking: An Intervention Program to Optimize Smoking Cessation Counselling by Montreal General Practitioners. Canadian Medical Association Journal. 2001;165(5):601-607.

51. Ajzen I. The Theory of Planned Behavior. Organizational Behavior and Human Decision Processes. 1991;50:179-211.

52. Michie S, Johnston M, Abraham C, et al. Making Psychological Theory Useful for Implementing Evidence Based Practice: A Consensus Approach. Quality and Saefty in Health Care. 2005;14:26-33.

53. Estabrooks C, Thompson, D., Lovely, J., Hofmeyer, A. A Guide to Knowledge Translation Theory. The Journal of Continuing Education in the Health Professions. 2006;26:25-36.

54. Sudaswad P. Knowledge Translation: Introduction to Models, Strategies, and Measures. In: Madison TUoW-, ed. Madison, Wisconsin: The National Center for the Dissemination of Disability Research; 2007.

55. Mitra M, Chung, M., Wilber, N., Walker, D. Smoking Status and Quality of Life: A Longitudinal Study Among Adults with Disabilities. American Journal of Preventive Medicine. 2004;27(3):258-260.

56. Rimmer J, Chen M, Hseih K. A Conceptual Model for Identifying, Preventing and Managing Secondary Conditions in People with Disabilities. Physical Therapy. 2011;91(12):1728-1739.

57. Tong E, Strouse, R., Hall, J., Kovac, M., Schroeder, S. National Survey of U.S. Health Professionals' Smoking Prevalence, Cessation Practices, and Beliefs. Nicotine \& Tobacco Research. 2010;12(7):724-733.

58. Monson A, Engeswick, L. Promotion of Tobacco Cessation through Dental Hygeine Education. Journal of Dental Education. 2005:901-911.

59. Sheffer C, Barone, C., Anders, M. Training Health Care Providers in the Treatment of Tobacco Use and Dependence: Pre- and Post-Training Results. Journal of Evaluation in Clinical Practice. 2009;15:607-613.

60. Rigotti N, Bitton, A., Richards, A., Reyen, M., Wassum, K., Raw, M. An International Survey of Training Programs for Treating Tobacco Dependence. Addiction. 2009;104:288-296.

61. Dent L, Harris, K., Noonan, C. Randomized Trial Assessing the Effectiveness of a Pharmacist-Delivered Program for Smoking Cessation. The Annals of Pharmacotherapy. 2009;43:194-201.

62. Perkins M, Jensen, P., Jaccard, J., Gollwitzer, P., Oettinger, G., Pappadopulous, E., Hoagwood, K. Applying Theory-Driven Approaches to Understanding and Modifying Clinicians' Behaviors: What Do We Know? Psychiatric Services. 2007;58(3):342-348.

63. Ajzen I, Madden T. Prediction of Goal-Directed Behavior: Attitudes, Intentions, and Perceived Behavioral Control. Journal of Experimental Social Psychology. 1986;22:453474. 
64. Eccles M, Hrisos, S., Franic, J., Kaner, E., Dickninson, H., Beyer, F., Johnston, M. Do SelfReported Intentions Predict Clinicians' Behaviour: A Systematic Review. Implementation Science. 2006;1(28).

65. Bandura A, ed Social Foundations of Thought and Action: A Social Cognitive Theory. Engelwood Cliffs, New Jersey: Prentice Hall; 1986.

66. Bagozzi R, Kimmel S. A Comparison of Leading Theories for the Prediction of GoalDirected Behaviors. British Journal of Social Psychology. 1995;34(4):437-461.

67. Laws R, Kemp L, Harris M, Davies G, Williams A, Eames-Brown R. An Exploration of How Clinician Attitudes and Beliefs Influence the Implementation of Lifestyle Risk Factor Management in Primary Healthcare: A Grounded Theory Study. Implementation Science. 2009;4(66).

68. Mas F, Alberola J, Brogger J, Hsu C. Tobacco Control: Are We Appropriately Training Future Professionals? American Journal of Health Studies. 2005;20(2):115-123.

69. Cornuz J, Humair, J., Seematter, L., Stolanov, R., van Melle, G., Stadler, H., Pecoud, A. Efficacy of Resident Training in Smoking Cessation: A Randomized, Controlled Trial of a Program Based on Application of Behavioral Theory and Practice with Standardized Patients. Annals of Internal Medicine. 2002;136:429-437.

70. Ferry L, Grissino, L., Runfola, P. Tobacco Dependence Curricula in US Undergraduate Medical Education. Journal of the American Medical Association. 1999;282(9):825-829.

71. Humair J, Cornuz, J. A New Curriculum Using Active Learning Methods and Standardized Patient to Train Residents in Smoking Cessation. Journal of General Internal Medicine. 2003;18:1023-1027.

72. Matten P, Morrison, V., Rutledge, S., Chen, T., Chung, E., Wong, S. Evaluation of Tobacco Cessation Classes Aimed at Hospital Staff Nurses. Oncology Nursing Forum. 2011;38(1):67-73.

73. Kelley F, Heath, J., Crowell, N. Using the Rx for Change Tobacco Curriculum in Advanced Practice Nursing Education. Critical Care Nursing Clinics of North America. 2006;18:131138.

74. Centers for Disease Control and Prevention. CDC Fact Sheets - Smokeless Tobacco. Atlanta, Georgia2009.

75. Threlkeld A, Pachal K. Entry-Level Physical Therapist Education in the United States of America. Physical Therapy Reviews. 2007;12:156-162.

76. Rindflesch A. A Grounded-Theory Investigation of Patient Education in Physical Therapy Practice. Physiotherapy Theory and Practice. 2009;25(3):193-202.

77. Rimmer J, Rowland, J. Health Promotion for People with Disabilities: Implications for Empowering the Persona and Promoting Disability-Friendly Environments. American Journal of Lifestyle Medicine. 2008:1-12.

78. Sullivan K, Wallace, J., O'Neill, M., Musolino, G., Mandich, M., Studer, M., Bottomley, J., Cormack, J., Nicholson, S., Jensen, G. A Vision for Society: Physical Therapy as Partners in the National Health Agenda. Physical Therapy. 2011;91(11):1-9.

79. Mojica W, Suttorp, M., Sherman, S., Morton, S., Roth, E., Maglione, M., Rohdes, S., Shekelle, P. Smoking-Cessation Interventions by Type of Provider: A Meta-Analysis. American Journal of Preventive Medicine. 2004;26(5):391-401. 
80. An L, Foldes, S., Alesci, N., Bluh, J., Bland, P., Davern, M., Schillo, B., Ahluwalia, J., Manley, M. The Impact of Smoking-Cessation Intervention by Multiple Health Professionals. American Journal of Preventive Medicine. 2008;34(1):54-60. 
Figure 1: Expected relationship between elements of the Theory of Reasoned Action/ Planned Behavior (i.e. - knowledge, attitudes, self-efficacy, and intention) and the likelihood of TCC behaviors.

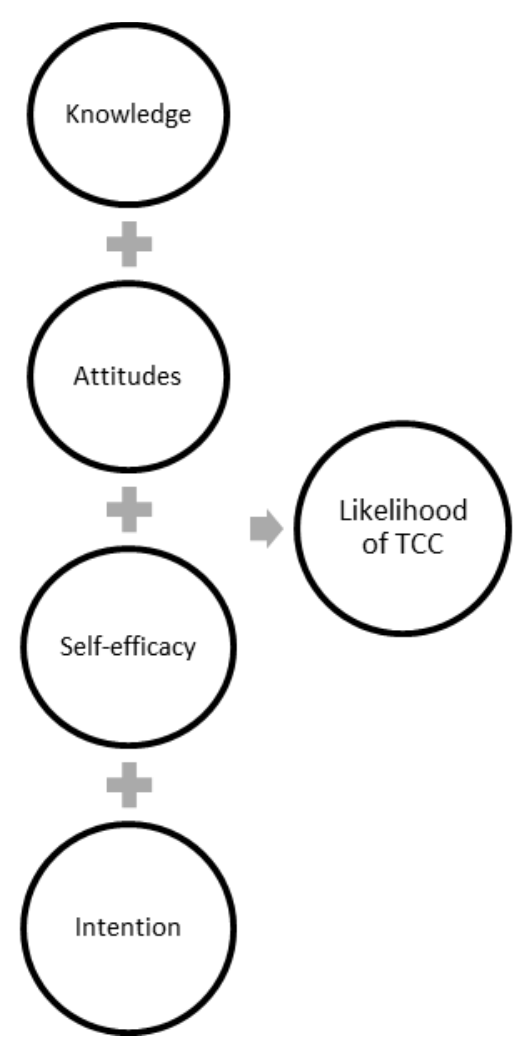


Appendix A - The "5 A's" and 5 R's"

The "5 A's":

\section{At initial evaluation:}

ASK :

"Do you smoke?"

"How often?"

"How many cigarettes per day?"

"How many cigarettes per week?"

$\downarrow$

(At an early point in the episode of care after the therapeutic alliance has been established, initiate smoking cessation counseling.)

ADVISE:

"In your initial evaluation, you mentioned that you smoke. As your physical therapist, I strongly recommend that you stop smoking. It is one of the best things you can do to improve your health, including the reason you are coming for physical therapy." Specifically explain why smoking cessation will improve the outcomes of the patient's physical therapy diagnosis.

EXAMPLES:

"Quitting smoking will improve your rate of wound healing."

"People who stop smoking tend to get better results in reducing their pain."

"Smoking can Interfere with bone growth - if you quit now, you will be less likely to experience complications from your spinal surgery."

\section{ASSESS:}

"How interested are you in quitting smoking right now?"

"Would you be willing to quit in the next 30 days?"

\section{$\sqrt{ }$}

ASSIST:

If patient is ready to quit within the next 30 days, proceed with recommedations for immedicate cessation (action phase).

If the patient is not yet ready to quit, proceed for recommendations for contemplation phase.

$\downarrow$

\section{ARRANGE:}

"Can we call you to see how you are doing with your quit attempt? "

" When would be a good time to reach you?" 
The "5 R's":

Relevance: Explain how smoking impacts the person's individual health, e.g. - for patients with an orthopedic injury, it can interfere with bone healing, contribute to osteoporosis, exacerbate pain, and effect muscle strength and endurance.

Rewards: Ask your patient to identify some of the makjor benefits of cessation, i.e. - better health, optimal recovery and improved physical functioning, money saved, improved sense of taste and smell ...

Risks: Include both acute and long-term risks of smoking, e.g. - disability, reduced quality of life.

Also discuss environmental risks such as increased health risks to spouses, children and others exposed to secondhand smoke, including pets.

Roadblocks: Spend time asking the patient about the percived barriers to cessation, e.g. - withdrawal symptoms, weight gain, fear of failure ... and brainstorm possible solutions.

Repetition: Reinforce your commitment and interest in helping the patient stop smoking. Continue to gauge his or her motivation to quit during subsequent office visits, or arrange for follow-up phone contact. 
Chapter 2 


\title{
The Role of Physical Therapists in Smoking Cessation: Opportunities for Improving Treatment Outcomes
}

\begin{abstract}
Tobacco use is the largest preventable cause of mortality and chronic disease, resulting in approximately 443,000 deaths and 8,600,000 cases of chronic illness each year. Smoking and second-hand smoke exposure impacts all areas of physical therapist practice, including cardiovascular, musculoskeletal, neuromuscular, and integumentary health. Research has demonstrated the positive influence of tobacco cessation counseling by other health care practitioners including physicians, nurses, dentists, and pharmacists. Physical therapists can play an important role in this interdisciplinary initiative, particularly in light of epidemiologic data that shows people with disabilities have almost a ten percent greater smoking prevalence over the general population. The depth of our inter-personal relationships with our patients, and our history of successfully serving the greater public good, places physical therapists and physical therapist assistants in a prime position to have a serious impact on this important issue. In order to optimize treatment outcomes and advance preventive care, we must recognize our role in addressing the ill-effects of smoking and work to incorporate tobacco cessation counseling strategies as part of a comprehensive treatment approach. Brief advice and referral can take as little as five minutes, and should not be difficult to integrate into current practice patterns. Therefore, the aim of this article is to identify impairments commonly managed by physical therapists that are negatively affected by tobacco use, and to provide a rationale and guidelines for the profession, so that physical therapists and physical therapist assistants can effectively engage in smoking cessation interventions.
\end{abstract}


Tobacco use constitutes one of the greatest threats to public health worldwide. As a preventable cause of mortality and chronic disease, tobacco use in the United States results in an estimated 443,000 deaths each year through both direct exposure and secondhand smoke. ${ }^{1}$ An additional 8,600,000 people across the nation have chronic illness due to smoking. ${ }^{1} \mathrm{As}$ physical therapists, we must realize that tobacco use impacts all areas of our practice, including cardiovascular, musculoskeletal, neurological, and integumentary health throughout the lifespan. In order to provide optimal care for the clients we serve, it is essential for physical therapists to screen for tobacco use and incorporate cessation strategies as part of our interventions. ${ }^{2}$ There is a substantial unmet demand and opportunity for our profession to promote tobacco cessation. ${ }^{2}$ Despite evidence that links successful cessation to counseling by health care providers, fewer than $40 \%$ of insured adults report receiving such advice. ${ }^{3}$ In addition, receiving advice from two or more health care practitioners more than doubles the odds of successful cessation, ${ }^{4}$ further supporting the need for physical therapists and physical therapist assistants to contribute our skills and expertise as part of the interdisciplinary health care team. Successful cessation efforts have been demonstrated by other health care professionals, including physicians, dentists, dental hygienists, nurses and pharmacists, and are an important component of preventive medicine and population health. ${ }^{5}$ According to the United States Medical Expenditure Panel Survey, in 2007, physical therapists conducted a total of 88 million ambulatory visits for approximately 9 million adults aged 18 and over. ${ }^{6}$ The number of visits (an average of 9.6 per patient, per episode), ${ }^{6}$ and nature of our interactions, which include extended, personalized one-on-one care, present a unique opportunity for physical therapists and physical therapist assistants to provide support for tobacco cessation ${ }^{2}$ as a means of enhancing treatment outcomes and health-related quality of life. In addition, due to the nature of our clientele, physical therapists are in a prime position to address serious health care disparities. People with disabilities have limited access to health care and follow-up visits, and have an average smoking prevalence of $30.5 \%$ compared with a rate of $21.7 \%$ for those without disabilities. ${ }^{7}$ Furthermore, the health effects of tobacco use may be magnified in people with disabilities due to the clustering of other risk factors, such as obesity and tendency towards a sedentary lifestyle. ${ }^{7}$

According to the Guide to Physical Therapist Practice, the physical therapist's scope of services includes assessment and intervention designed to "promote not only optimal physical function but optimal wellness ... and optimal quality of life." ${ }^{8}$ Furthermore, as we advance toward the attainment of "Vision 2020,"8 and direct access enables physical therapists to become practitioners of choice for people seeking better health, the profession needs to become more proactive and skilled in recognizing and promoting behavioral changes that have widespread effects at all levels of the International Classification of Functioning, Disability and Health (ICF model) from pathophysiology to impaired individual capacity and performance. ${ }^{9}$ Tobacco cessation counseling is consistent with the role of our profession in promoting wellness, improving immediate health, and preventing secondary complications of chronic disease. ${ }^{2,10}$ Therefore, the aim of this manuscript is to identify the impairments commonly managed by physical therapists that are negatively impacted by tobacco use, and to provide a rationale and guidelines to enable physical therapists and physical therapist assistants to successfully engage in smoking cessation interventions. 


\section{The Impact of Smoking on Physiologic Systems}

The adverse effects of tobacco use on cardiopulmonary function are well established and recognized. ${ }^{11}$ Less evident, but equally important, is its impact on all aspects of physical therapist practice including integumentary, musculoskeletal, and neuromuscular health. Adverse effects of smoking occur throughout the lifespan, from prenatal exposure, through childhood, adolescence, and all phases of adulthood. Since tobacco use has the potential to impact multiple physiologic systems, it is likely that cessation efforts will improve outcomes for many of the conditions and impairments treated by physical therapists.

\section{General Physiologic Effects of Smoking}

Many pathophysiologic changes caused by tobacco use can be traced to the pro-inflammatory effects of cigarette smoke. This inflammation is a product of oxidative tissue injury and is evidenced by increased levels of inflammatory cytokines such as IL-6 and TNF-alpha, and Creactive protein in smokers. ${ }^{12}$ At the cellular level, smoking contributes to mutations in proteins that can later manifest as tumors. ${ }^{13}$ Smoking can also lead to adverse changes in the mitochondria and impaired function along the respiratory chain, causing increased cellular stress and decreasing the ability to produce new, healthy tissue. ${ }^{13}$ In addition, hemoglobin's affinity for carbon monoxide in cigarette smoke is 200 times higher than its affinity for oxygen. ${ }^{14}$ Due to this effect, increased levels of carbon monoxide within the bloodstream decrease oxygen saturation, ${ }^{15}$ and interfere with the electron transport chain within the mitochondria, leading to a decrease in cytochrome $\mathrm{C}$ oxidase. ${ }^{16}$ This effect can be especially pronounced in tissues with a high metabolic rate, such as skeletal muscle, and the central nervous system. ${ }^{16}$ Smoking also interferes with oxygen transport by reducing the proliferation of red blood cells. ${ }^{14}$ In addition, as part of this cycle, smoking decreases concentrations of antioxidant vitamins and nutrients such as folate and riboflavin, ${ }^{17}$ vitamins $\mathrm{E}$ and $\mathrm{C},{ }^{18}$ and melatonin. ${ }^{19}$ Melatonin is not only an important anti-oxidant, but it also functions as an anticarcinogenic. $^{19}$

Smokers also experience impaired lipid metabolism. The oxidation of low density lipoproteins (LDLs) leads to a cytotoxic environment and may promote platelet adhesion, DNA damage and apoptosis. ${ }^{20}$ Metabolic disturbances in smokers also include impaired glycolysis. ${ }^{20}$ These factors are particularly harmful given the tendency for smokers to engage in other unhealthy behaviors such as the consumption of a high-fat diet, which is often rich in simple carbohydrates and deficient in anti-oxidant nutrients, ${ }^{20}$ and can result in a clustering of dangerous risk factors for chronic illness.

Smoking also leads to tissue damage through accelerated vascular aging. In addition to its impact on the cardiac system, accelerated vascular aging has been implicated in increased risk of cerebrovascular accident (CVA) and vascular dementia. ${ }^{13}$ This is due to the presence of heavy metals and toxins within cigarette smoke, ${ }^{13}$ and the effects of nicotine. ${ }^{21}$ Nicotine increases systemic blood pressure by stimulating sympathetic nerve endings, leading to vasoconstriction and increased vascular resistance, ${ }^{21}$ which contributes to tissue hypoxia throughout the body. Peripheral vascular disease and reduced blood flow also increase the risk 
of other health problems including metabolic syndrome, ${ }^{22}$ a precursor to diabetes. Cessation is an important step in limiting systemic inflammation and oxidative tissue injury, thereby enhancing current healing and future health.

\section{Effects of Tobacco on the Integumentary System}

Tobacco use impedes tissue healing through several mechanisms. Smoking not only causes transient deficiencies in tissue oxygenation, but once oxygen delivery has been restored, reperfusion injury may also occur. ${ }^{16}$ At the integumentary level, smoking has been shown to reduce cutaneous blood flow by as much as $40 \%$ due to the effect of nicotine on cholinergic fibers which supply the vascular bed. ${ }^{23}$ Nicotine also suppresses immune response and decreases the proliferation, viability, and function of lymphocytes, ${ }^{23}$ increasing the likelihood of infection. In neutrophils, nicotine stimulates the release of proteases, which may accelerate tissue destruction and further inhibit repair. ${ }^{24}$ During the proliferative phase, tobacco use reduces the ability of fibroblasts to migrate and interferes with wound contraction. ${ }^{23}$ It also decreases plasma levels of vitamin $\mathrm{C}$ needed for collagen formation. ${ }^{23}$ Furthermore, nicotine not only lowers the formation of collagens, but it decreases synthesis of procollagens I and II and hydroxyproline, ${ }^{14}$ all of which are required for production of ground substance. Overall, for those who use tobacco, collagen production is slowed, scar tissue is weaker, and healed tissues break down more easily, ${ }^{14,23}$ increasing risk of recurrent injury.

\section{Effects of Tobacco on the Musculoskeletal System}

Smoking has been shown to contribute to musculoskeletal problems in many different ways. It results in reduced quadriceps strength, ${ }^{25}$ and increased muscle fatiguability. ${ }^{26}$ In a study comparing the strength of back extensors among male athletes, smokers had a higher rate of perceived exertion as well as fatigue, ${ }^{27}$ and these effects were observed in subjects as young as 18 years. ${ }^{27}$ It has been speculated that these problems may be due to oxidative damage to muscle proteins, ${ }^{25}$ and mitochondrial impairment. ${ }^{26}$

As people age, smoking may lead to increased weakness and reduced balance. One study examining physical functioning in women aged 65 years and older found that smokers had less strength, poorer balance, and lower physical performance scores for agility, coordination, and gait when compared with their non-smoking counterparts. ${ }^{28}$ In another population of older females, smokers had impaired performance on timed rise, walk tests and grip strength. ${ }^{29}$ It is speculated that atherosclerotic damage in the lower extremities may perpetuate these functional limitations by reducing tolerance to physical activity. ${ }^{28}$

Through its effects on metabolism and circulation, tobacco use also leads to bone demineralization. Smoking can increase fracture risk by depleting estrogen which can contribute to osteoporosis. ${ }^{13}$ Tobacco use has also been shown to interfere with the absorption of calcium and vitamin D. ${ }^{30}$ Elevated cortisol levels ${ }^{31}$ associated with smoking contribute to bone reabsorption. ${ }^{31}$ Additionally, smoking inhibits the differentiation of osteoclasts, leading to the reduced formation of new bone. ${ }^{13}$ These factors work collectively to decrease bone density and increase fracture risk, ${ }^{32}$ as well as a greater risk of fracture nonunion. ${ }^{33}$ For clients typically 
seen in physical therapy settings, tobacco cessation limits damage to muscles and bones, preventing future decline and optimizing current recovery of function.

\section{Effects of Tobacco on the Neuromuscular System}

Toxic effects of tobacco use have also been established within the neuromuscular system. Nicotine readily crosses the blood-brain barrier, ${ }^{14}$ and has a detrimental effect on cerebral circulation. Smokers were shown to have a 1.8 times greater risk of silent cerebral infarct when compared with nonsmokers. ${ }^{34}$ Risk increased with higher doses of tobacco. ${ }^{34}$ The lifetime accumulation of heavy metals due to smoking, such as lead, has been associated with lower levels of language processing, hand-eye coordination, executive functioning, verbal and visual memory, learning and global function, and higher rates of white matter lesions and cerebral atrophy in older adults. ${ }^{34}$ Among the heavy metals contained in cigarette smoke, vinyl chloride has been implicated as a causative agent for brain tumors. ${ }^{34}$ Heavy smoking in midlife is associated with a higher risk of dementia and Alzheimer's disease, ${ }^{35}$ and a $150 \%$ increased risk of amyotrophic lateral sclerosis (ALS) over non-smokers. ${ }^{36}$ In animal studies, prenatal exposure to carbon monoxide lead to decreased deposition of myelin in peripheral nerves, ${ }^{37}$ possibly increasing likelihood of neuropathy. It has been suggested that nicotine, free radicals, and other toxins in cigarette smoke may cause degeneration or interfere with axonal conduction, particularly in fibers that have already been damaged or demyelinated. ${ }^{37}$ Chronic exposure to carbon monoxide from smoking increases levels of hemeoxygenase within the bloodstream, a factor which may contribute to development of neuropathic pain. ${ }^{38}$ Smoking may also enhance excitatory transmission in the dorsal horn of the spinal cord by stimulating nicotinic acetylcholine receptors, thereby increasing the intensity of neuropathic pain. ${ }^{39}$

In terms of other neuropathologic impairments, people who smoked 20-40 cigarettes per day had twice the risk of developing multiple sclerosis (MS) than non-smokers. ${ }^{40}$ In those who already had MS, smokers were more likely to have the more severe form of primary progressive disease and present with more severe symptoms and functional disability. ${ }^{40}$ Due to links between smoking and cognitive function, as well as neuropathic pain and impairment, tobacco cessation should be a key element in physical therapy interventions to address prevention and restoration of neuromuscular pathologies.

Smoking has also been linked to an increased likelihood of autoimmune diseases such as rheumatoid arthritis (RA) and systemic lupus erythmatosis (SLE). ${ }^{12}$ The relative risk of RA in current smokers is 3.8 times higher than nonsmokers, ${ }^{12}$ and for those with the disease, smokers are less likely to respond to anti-TNF alpha pharmacotherapy, ${ }^{12}$ such as infliximab. The link between smoking and RA is thought to be related to the production of pro-inflammatory cytokines within the synovium. ${ }^{41}$ The association between tobacco use, RA, and SLE should be reflected in our clinical practice patterns when planning for care of people with these conditions.

There are also links between smoking and increased likelihood of chronic pain ${ }^{38}$ resulting from conditions such as fibromyalgia, ${ }^{42,43}$ and low back dysfunction. ${ }^{44,45}$ Research demonstrated that smokers with fibromyalgia had higher levels of substance $P$ in their cerebrospinal fluid when 
compared with non-smokers. ${ }^{43}$ The intensity of smoking in the sample ranged from less than 1 pack per day to more than 2 packs per day, with $60 \%$ of smokers averaging 1-2 packs per day, duration of use unknown. ${ }^{43}$ In terms of low back pain, it is thought that other health impairments may exacerbate the problem, such as chronic coughing, ${ }^{27,46}$ which increases intrabdominal pressure and places additional stress on the spine. Nicotine may also cause cell damage in the nucleus and annulus of the intervertebral disc, ${ }^{47}$ a contributing factor in degenerative spinal changes. ${ }^{48}$

In general, by increasing pro-inflammatory cytokines, smoking likely amplifies pain signals, ${ }^{48}$ and nicotine may lower the pain threshold within the central nervous system. ${ }^{45}$ In studies investigating treatment of chronic pain, smokers were more likely to use opioid medications than non-smokers, as well having higher use of analgesic medication, in general. ${ }^{42}$ Although smokers were more likely to use more pain medication, they were also less likely to be satisfied with resulting levels of relief. ${ }^{49}$ In one study, smokers with chronic pain demonstrated more intense symptoms than non-smokers on all domains of the brief pain index (BPI), including functional impairment, and had lower scores on the short-form 36, reflecting greater deficits in health-related quality of life. ${ }^{42}$ Additionally, nicotine dependence was associated with greater disturbance in affect and mood, less ability to perform normal work, and less overall enjoyment of life. $^{42}$

There is a dose-response relationship between smoking and prevalence of chronic pain. ${ }^{50}$ Therefore, clinicians working with this population need to prioritize smoking cessation during their treatment planning. Cessation should be approached with care and support, since smokers deprived of nicotine will initially have less pain tolerance, ${ }^{37,38}$ and tobacco use likely involves a complex relationship between smoking as a coping strategy, and its simultaneous effect in exacerbating pain. ${ }^{46}$

The Unique Role of Physical Therapists and Physical Therapist Assistants in Smoking Cessation Intervention

As we advance toward the attainment of "Vision 2020,"8 and direct access enables physical therapists to become practitioners of choice for people seeking better health, our profession needs to become more proactive and skilled in recognizing and promoting behavioral changes that have widespread effects at all levels of the International Classification of Functioning, Disability and Health (ICF model) pathophysiology to impaired individual capacity and performance. ${ }^{2,9}$ Furthermore, it is essential that our quest towards evidence-based practice is focused on priorities that are consistent with epidemiologic data suggesting highest need. Tobacco use represents the greatest preventable cause for illness and disability. Reducing its use can have a substantial impact on the health and wellness of a significant component of the population, including those who do not use cigarettes but are subject to the effects of secondhand smoke, such as infants and children. As practitioners dedicated towards using noninvasive measures to promote and maintain optimal wellness, tobacco cessation intervention is consistent with the role of our profession in improving immediate health, and preventing secondary complications of chronic disease. People who smoke have $44 \%$ fewer years of healthy life than those who have never used tobacco. ${ }^{51}$ In addition, because people 
with disabilities tend to have higher smoking rates than those without, ${ }^{52}$ physical therapists and physical therapist assistants are in a key strategic position for providing intervention to those with greatest need. Importantly, practice patterns for physical therapists provide ample opportunity for many components of successful cessation counseling. ${ }^{10,53}$ Visits with clients are personalized, with frequent follow-ups that enable us to build rapport and tailor advice to each individual patient, as well as provide on-going support throughout the course of someone's cessation efforts.

While providing care for a condition that is potentially exacerbated by tobacco use, the physical therapist and physical therapist assistant may encounter opportunities that serve as "teachable moments" to encourage smoking cessation. ${ }^{10,53}$ This is true not only for outpatient settings, but in the acute care and in-patient rehabilitation environment as well. The Joint Commission for Accreditation of Healthcare Organizations (JCAHO) operating guidelines for acute care facilities requires documentation of smoking status and provision of cessation counseling in patients hospitalized due to 3 chronic diseases: community-acquired pneumonia, acute myocardial infarction, and congestive heart failure. ${ }^{54}$ In the rehabilitation setting, patients who smoke are often transitioning from acute care, and therefore have likely been through a period of forced abstinence. The rehabilitation environment can provide an opportunity to capitalize on this period of abstinence through continued counseling and support. ${ }^{55}$

In a 2002 survey of ambulatory care physicians, $78.6 \%$ of patients who smoked did not receive any counseling advice regarding cessation during their visit. ${ }^{56}$ With direct access, physical therapists are increasingly becoming the entry-portal for persons accessing the health care system. In addition, the depth of our relationships with our patients enhances our ability to perform detailed assessments and create interventions that best suit the unique needs of each individual.

There are several potential barriers to providing tobacco cessation counseling which must be addressed. One is the lack of training and practical skills in providing such services. ${ }^{53}$ Other perceived challenges include time constraints and overriding responsibilities to care for the client's primary condition. ${ }^{43}$ In general, health care practitioners also site a decreased awareness of resources and effective treatment options, anticipated resistance to advice among patients who smoke, and a lack of reimbursement for cessation counseling as reasons for not providing this service as part of their standard care. ${ }^{4}$ Specific to physical therapists, a survey conducted in 2004 collecting data from physical therapists in New York, California, and Tennessee, found that barriers to providing tobacco cessation interventions included a lack of self-efficacy as well as limited outcome expectations. ${ }^{2}$ A survey conducted by Bodner and colleagues in 2010 reported that key barriers among Canadian physical therapists were lack of time and lack of resources. ${ }^{10}$

It is important to recognize that $60 \%$ of current smokers would like to quit, ${ }^{57}$ but are hampered by addiction. As integral members of the interdisciplinary care team, the physical therapist and physical therapist assistant play an essential role in addressing this dilemma. Studies have demonstrated that when cessation advice is received by two or more health care professionals, smokers are nearly three times more likely to make a quit attempt. ${ }^{4}$ Persistence is key since it is 
likely to take many unsuccessful attempts before someone is able to achieve sustained cessation. $^{57}$

Tobacco Use Management Strategies for Physical Therapists and Physical Therapist Assistants

The Agency for Healthcare Research and Quality (AHRQ) recommends that all patients who smoke be offered options to promote cessation such as nicotine replacement therapy, social support, and skills training, including nutritional counseling and physical activity. ${ }^{58}$ The expertise of the physical therapist in tailoring and monitoring response to physical activity is an essential part of this formula. Through coordinated care and treatment planning, the physical therapist and physical therapist assistant can work together towards meeting goals for tobacco cessation through continued monitoring, support, and encouragement. With respect to patient autonomy, the decision to quit must originate with the person who smokes. ${ }^{59}$ However, there are steps that can be taken to foster and support cessation efforts. According to the United States Department of Health and Human Services (USDHHS) reference guide for clinicians "Treating Tobacco Use and Dependence, ${ }^{59}$ these steps include counseling the patient to set a quit date and make a plan that will allow them to cope with the expected withdrawal. The quit date should fall within a month of the decision to quit, and it can be associated with a special occasion such as a birthday or anniversary. Maintaining smoking abstinence involves rewards, as well as periodic review of the benefits of cessation and the reasons for wanting to succeed.

Brief advice has been shown to have a positive impact on cessation and quit attempts. ${ }^{53}$ In the physical therapy setting, smoking questionnaires can help identify smokers, their level of addiction, and the intention to quit. ${ }^{53}$ The USDHHS has published Clinical Guidelines for Treating Tobacco Use and Dependence. Guidelines for providing brief advice includes the " 5 $A^{\prime} \mathrm{s}^{\prime \prime}$ : asking about tobacco use, advising people to quit, assessing willingness to quit, assisting the quit attempt through counseling and/ or referral, and arranging for follow-up. ${ }^{60}$ In terms of time management, the " $5 \mathrm{~A}^{\prime} \mathrm{s}$ " can take as little as 3 minutes. ${ }^{61} \mathrm{~A}$ shortcut consisting of only three steps: asking, advising and referral, can take even less time and still be effective. ${ }^{54}$ For those people who are not yet ready to quit, clinicians may employ the " $5 \mathrm{R}$ ' $\mathrm{s}^{\text {": reviewing }}$ relevance of smoking and the role it plays in someone's life, discussing risk through the impact of smoking on health, identifying roadblocks and rewards by inquiring about the pros \& cons of smoking relative to the advantages of cessation and the potential impact of secondhand smoke on the health of family members and friends, and repetition - offering a follow-up appointment or opportunities to discuss quitting in more detail. ${ }^{60}$ Figure 1 provides a flowchart for use in providing tobacco cessation counseling for patients who are willing to quit, or may be considering quitting in the future. Whereas assessment should be part of the physical therapist's initial evaluation and treatment plan, together the physical therapist and physical therapist assistant can create a united front in implementing strategies such as reinforcement and follow-up, as well as individualized approaches to communication.

There is some evidence that exercise and other physical therapy interventions that stimulate endorphin release can help mitigate symptoms of nicotine withdrawal. ${ }^{62}$ Exercise and increased physical activity may help reduce cravings, negative changes in mood, and withdrawal symptoms as an aid to cessation. ${ }^{63}$ In smokers who were trying to quit, exercise increased self- 
efficacy and confidence for success. ${ }^{64}$ When used in combination with nicotine replacement therapy, exercise has been shown to facilitate cessation, increase functional capacity, and delay weight gain in female smokers. ${ }^{65}$ In addition, increased physical activity may help decrease insomnia, ${ }^{66}$ and serve as a replacement activity ${ }^{67}$ or diversion for those working towards breaking their addiction.

Although cessation is the optimal outcome, exercise offers a way of counteracting at least some of the deleterious effects of tobacco use. Physical activity can help to reduce oxidative stress by increasing concentrations of endogenous anti-oxidants, improving clearance of lipids and triglycerides, and enhancing glucose metabolism. ${ }^{20}$ This is especially pertinent given the increased likelihood for smokers versus non-smokers to lead a sedentary lifestyle. ${ }^{64}$ Smokers who are physically active live longer than sedentary smokers and reduce their risk of cerebrovascular disease and cancer of the lung, colon and rectum. ${ }^{68}$ Smokers who exercise also have better peripheral blood flow and less vascular resistance, as well as lower resting heart rates. $^{22}$

Physical therapists and physical therapist assistants should closely monitor smokers during exercise due to reduced tolerance when compared with age-matched non-smoking cohorts. ${ }^{69,70}$ During treadmill testing, young, healthy male smokers aged 20-25 showed higher heart rates and systolic blood pressure as well as shorter maximal duration when compared with their nonsmoking counterparts. ${ }^{69}$ In a similar study of smokers ages 13 to 36, lower cardiovascular fitness was also observed. ${ }^{70}$ It is important to emphasize the potential for recovery when encouraging people to stop smoking: in the study by Bernaards and colleagues, ${ }^{70}$ detrimental effects of smoking on physical activity appeared reversible in participants who had stopped smoking before the age of 36 .

Sometimes, the best service provided by a clinician in terms of supporting cessation is patient referral. We do not always possess all the resources and skills necessary to meet each individual's need. Additional resources for aiding cessation can be found through the Surgeon General's website: www.surgeongeneral.gov/tobacco/tobagrg.htm. One option is the use of quit lines as an adjunct to brief advice. In the United States, there is a national number: 1-800QUITNOW that will refer callers to local services. Quit lines have been shown to enhance cessation rates by $30 \%,{ }^{60}$ and smokers have been found to be 4 times more likely to use a quit line than seek face-to-face-counseling. ${ }^{60}$ Additional resources are shown in Figure 1.

\section{Working toward the Future}

Simply put, smoking negatively impacts all of the body's systems. Physical therapists and physical therapist assistants have a unique opportunity to help people quit. As a profession, our first step is to recognize that cessation is indeed part of our role as health care providers. We also need to find ways to expand our education in this regard, since training has been shown to increase provider confidence, as well as the likelihood and quality of cessation counseling. ${ }^{71}$ In other health care professions, such as dentistry and dental hygiene, training workshops in evidence-based interventions have been proven effective for increasing cessation counseling by practitioners. ${ }^{72}$ In terms of training format, web-based platforms and self-study may help reach 
practitioners who are unable to attend workshops in person. ${ }^{72}$ Training should target positive outcome expectations by demonstrating that our profession can make an enormous impact by providing brief advice regarding tobacco cessation. ${ }^{2}$ Training should also stress self-efficacy, or the practitioner's belief that he or she can provide effective counseling. ${ }^{2}$ Initial studies examining barriers to smoking cessation counseling among physical therapy students found that lack of confidence in one's ability to communicate with patients who smoke could be improved by a seminar on smoking cessation counseling skills. ${ }^{73}$

Physical therapists and physical therapist assistants have an obligation as well as a successful history in providing public service. As outlined in The American Physical Therapy Association's guiding document, "Vision 2020,"74 physical therapists and physical therapist assistants are dedicated to providing services consistent with core values of altruism, caring and respect by working with other professionals to promote optimal health and wellness in individuals and communities. Smoking cessation counseling is a key expression of these goals. While some may be concerned that cessation counseling detracts from the main focus for physical therapy intervention, in reality, the multiple physiologic effects of smoking make tobacco cessation a key factor in prevention and restoration of neuromuscular, musculoskeletal, and integumentary impairments. Therefore, tobacco cessation counseling must be included in clinical treatment planning for patients who smoke. While further research is needed regarding the role of specific physical therapy modalities, such as exercise, in promoting successful cessation, we already recognize the success of other clinicians in providing services based on the USDHHS guidelines (the $5 \mathrm{~A}^{\prime}$ 's and $5 \mathrm{R}^{\prime} \mathrm{s}$ ), as well as the use of quit lines as a referral source. Use of these techniques should be adopted as a component of evidence-based physical therapist practice designed to serve the best interests of our clients. Counseling and referral can take as little as 5 minutes, and should not be difficult to integrate in physical therapist practice, a profession that places such emphasis on tailored, individualized patient education. Our own education, in entry-level and post-professional forums, will also need to evolve to best meet these demands, so that we may continue to refine and expand our skills as practitioners of choice for noninvasive, holistic physical wellness. 


\section{References}

1. United States Department of Health and Human Services. Ending the Tobacco Epidemic: A Tobacco Control Strategic Action Plan for US Department of Health and Human Services, 2010.

2. Rea, B., Marshak, H., Neish, C., Davis, N. The Role of Health Promotion in Physical Therapy in California, New York and Tennessee. Physical Therapy. 2004;84(6):510-523.

3. Gollust, S., Schroeder, S., Warner, K. Helping Smokers Quit: Understanding the Barriers to Utlization of Smoking Cessation Services. The Milbank Quarterly. 2008;86(4):601-627.

4. An, L., Foldes, S., Alesci, N., Bluh, J., Bland, P., Davern, M., Schillo, B., Ahluwalia, J., Manley, M. The Impact of Smoking-Cessation Intervention by Multiple Health Professionals. American Journal of Preventive Medicine. 2008;34(1):54-60.

5. Zenzano, T., Allan, J., Bigley, M., Bushardt, R., Garr, D., Johnson, K., Lang, W., Maeshiro, R., Meyer, S., Shannon, S., Spolsky, V., Stanley, J. The Roles of Healthcare Professionals in Implementing Clinical Prevention and Population Health. American Journal of Preventive Medicine. 2011;40(2):261-267.

6. Machlin, S., Chevan, J., Yu, W., Zodet, M. Determinants of Utlization and Expenditures for Episodes of Ambulatory Physical Therapy Among Adults. Physical Therapy. 2011;91(7):1-12.

7. Rimmer, J., Rowland, J. Health Promotion for People with Disabilities: Implications for Empowering the Persona and Promoting Disability-Friendly Environments. American Journal of Lifestyle Medicine. 2008:1-12.

8. American Physical Therapy Association. Guide to Physical Therapist Practice: Second Edition,2003.

9. World Health Organization. Towards a Common Language for Functioning, Disability and Health: ICF,2002.

10. Bodner, M., Miller, W., Rhodes, R., Dean, E. Smoking Cessation and Counseling: Knowledge and Views of Canadian Physical Therapists. Physical Therapy. 2011;91(7):1051-1062.

11. Leone, A. Interactive Effect of Combined Exposure to Active and Passive Smoking on the Cardiovascular System. Recent Patents on Cardiovascular Drug Discovery. 2011;6(1):6169.

12. Harel-Meir,M., Sherer ,Y., Shoenfeld, Y. Tobacco Smoking and Autoimmune Rheumatic Diseases. Nature: Clinical Practice: Rheumatology. 2007;3(12):707-715.

13. Bernhard, D., Backovic, A., Wick, G. Cigarette Smoke: An Aging Accelerator? . Experimental Gerontology. 2007;42:160-165.

14. Ahn,C., Mulliga ,P., Salicido, R. Smoking - the Bane of Wound Healing: Biomedical Interventions and Social Influences. Advances in Skin and Wound Care. 2008;21:227236.

15. Palmer,K., Syddall, H., Cooper, C., Coggon, D. Snoking and Musculoskeletal Disorders: Findings from a British National Survey. Annals of Rheumatic Diseases. 2003;62:33-36.

16. Alonso, J., Cardellach, F., Lopez, S., Casademont, J., Miro, O. Carbon Monoxide Specifically Inhibits Cytochrome C Oxidase of Human Mitochondrial Respiratory Chain. Pharmacology and Toxicology. 2003;2003:142-146. 
17. Ulvick, A., Midttun, O., Nygard, O., Vollset, S., Bonaa, K., Nordrehaug, J. Nilsen, D., Schrimer, H., Ueland, P. Long- and Short-Term Effects of Tobacco Smoking on Circulating Concentrations of B Vitamins. Clinical Chemistry. 2010;56(5):755-763.

18. Kosecik, M., Erel, O., Sevinc, E., Selek, S. Increased Oxidative Stress in Children Exposed to Passive Smoking. International Journal of Cardiology. 2005;100(1):61-64.

19. Ozguner,F., Cesur, G. Active Smoking Causes Oxidative Stress and Decreases Blood Melatonin Levels. Toxicology and Industrial Health. 2005;21:21-26.

20. Bloomer, R., Fisher-Wellman, K. The Role of Exercise in Minimizing Postprandial Oxidative Stress in Cigarette Smokers. Nicotine \& Tobacco Research. 2009;11(1):3-11.

21. Jaimes, E., Raij, L. Nicotine: The Link Between Cigarette Smoking and the Progression of Renal Disease. American Journal of Physiology. 2007;292:H76-H82.

22. Anton, M., Cortez-Cooper, M., DeVan, A., Neidre, D., Cook, J., Tanaka, H. Cigarette Smoking, Regular Exercise, and Peripheral Blood Flow. Atherosclerosis. 2006;185:201205.

23. Rayner,R. Effects of Cigarette Smoking on Cutaneous Wound Healing. Primary Intention. 2006;14(3):100-102, 104.

24. Morita, A. Tobacco Smoke Causes Premature Skin Aging. Journal of Dermatological Science. 2007;48:169-175.

25. Barreiro, E., Peinado, V., Galdiz, J., Ferrer, E., Marin-Corral, J., Sanchez, F., Gea, J., Barbera, J. Cigarette-Smoke Induced Oxidative Stress: A Role in COPD Skeletal Muscle Dysfunction. American Journal of Respiratory Critical Care Medicine. 2010;182(4):477488.

26. Wust, R., Morse, C., Haan, A., Rittweger, J., Jones, D., Degens, H. Skeletal Muscle Properties and Fatigue Resistance in Relation to Smoking History. European Journal of Applied Physiology. 2008;104(103-110).

27. Adedoyin, R., Mbada, C., Odiachi, A., Adegoke, A., Awotidebe, T. Differences in Back Extensor Muscles Fatiguability for Smoking and Non-Smoking Athletes. Isokinetics and Exercise Science. 2010;18:149-155.

28. Nelson, H., Nevitt, M., Scott, J., Stone, K., Cummings, S. Smoking, Alcohol and Neuromuscular and Physical Function of Older Women. Journal of the American Medical Association. 1994;272(23):1825-1831.

29. Rapuri, P., Gallagher, J., Smith, L. Smoking Is a Risk Factor for Decreased Physical Performance in Elderly Women. Journal of Gerontology. 2007;62A(1):93-100.

30. Krall, E., Dawson-Hughes, B. Smoking Increases Bone Loss and Decreases Intestinal Calcium Absorption. Journal of Bone and Mineral Research. 1999;14(2):215-220.

31. Law, M., Hackshaw, A. A Meta-Analysis of Cigarette Smoking, Bone Mineral Density and Risk of Fracture: Recognition of a Major Effort. British Medical Journal. 1997;315(7112):841-852.

32. Jenkins, M., Denison A. Smoking Status as a Predictor of Hip Fracture Risk in Postmenopausal Women of Northwest Texas. Preventing Chronic Disease: Public Health Research, Practice and Policy. 2008;5(1):1-8. 
33. Castillo, R., Bosse, M., MacKenzie, E., Patterson, B. Impact of Smoking on Fracture Healing and Risk of Complications in Limb-Threatening Open Tibia Fracture. Journal of Orthopedic Trauma. 2005;19:151-157.

34. Swan, G., Lessov-Schlaggar, C. The Effects of Tobacco Smoke and Nicotine on Cognition and the Brain. Neuropsychology Review. 2007;17(3):259-273.

35. Rusanen, M., Quesenbery, C., Zhou, J., Whitmer, R. Heavy Smoking in Midlife and Longterm Risk of Alzheimer Disease and Vascular Dementia. Archives of Internal Medicine. 2010.

36. Sutjeda, N., Fischer, K., Kromhout, H., Wolke, J., Huisman, M., Heederik, D., Van den Berg, L. Lifetime Occupation, Education, Smoking and Risk of ALS. Neurology. 2007;69:1508-1514.

37. Carratu, M., Coluccia, A., Borracci, P., Fasano, A., Riccio, P., Cuomo, V. Smoking During Pregnancy: A Risk Factor for Peripheral Neuropathy? Developmental Neuroscience. 2008;30:224-230.

38. Shi ,Y., Weingarten, T., Mantilla, C., Hooten, W., Warner, D. Smoking and Pain: Pathophysiology and Clinical Implications. Anesthesiology. 2010;113:977-992.

39. Richards, J,, Kogos, S., Mess ,T., Oleson, C. Effects of Smoking on Neuropathic Pain in Two People with Spinal Cord Injury. The Journal of Spinal Cord Medicine. 2005;28(4):330-332.

40. Zivadonov ,R., Weinstock-Guttman, B., Hashmi, K., Abdelrahman, N., Stosic, M., Dwyer, S., Hussein, J., Ramanathan, D., Ramanathan, M. Smoking Is Associated with Increased Lesion Volumes and Brain Atrophy in Multiple Sclerosis. Neurology. 2009;73(7):504-510.

41. Onozaki, K. Etiological and Biological ASpects of Cigarette Smoking in Rheumatoid Arthritis. Inflammation and Allergy - Drug Targets. 2009;8:364-368.

42. Weingarten, T., Moeschler, S., Ptaszynski, A., Hooten, M., Bebbe, T., Warner, D. An Assessment of the Association Between Smoking Status, Pain Intensity, and Functional Interference in Patients with Chronic Pain. Pain Physician. 2008;11:643-653.

43. Yunus, M., Arslan, S., Aldag, J. Relationship Between Fibromyalgia Features and Smoking Scandanavian Journal of Rheumatology. 2002;31:301-305.

44. Goldberg, M., Scott, S., Mayo, N. A Review of the Association Between Cigarette Smoking and the Development of Nonspecific Back Pain and Related Outcomes. Spine. 2000;25(8):995-1014.

45. Fogelholm, R., Alho, A. Smoking and Intervertebral Disc Degeneration. Medical Hypotheses. 2001;56(4):537-539.

46. Zvolensky, M., Mc Millan, K., Gonzalez, A., Asmundson, G. Chronic Pain and Cigarette Smoking and Nicotine Dependence Among a Representative Sample of Adults. Nicotine \& Tobacco Research. 2009;11(12):1407-1414.

47. Akmal, M., Kesani, A., Anand, B., Singh, A., Wiseman, M., Goodship, A. Effect of Nicotine on Spinal Disc Cells: A Cellular Mechanism for Disc Degeneration. Spine. 2004;29(5):568575.

48. Shiri,R., Karpinnen J, Leino-Arjas P, Solovieva S, Viikari-Juntura, E. The Association Between Smoking and Low Back Pain: A Meta-Analysis. The American Journal of Medicine. 2010;123:87.e87. 
49. Hooten, M., Townsend, C., Bruce, B., Warner, D. The Effects of Smoking Status on Opioid Tapering Among Patients with Chronic Pain. Anesthesia and Analgesia. 2009;108(308315).

50. Andersson, H., Ejlertsson, G., Leden, I. Widespread Musculoskeletal Chronic Pain Associated with Smoking: An Epidemiological Study in a General Rural Population. Scandanavian Journal of Rehabilitation Medicine. 1998;30:185-191.

51. Dean, E. Physical Therapy in the 21st Century (Part I): Toward Practice Informed by Epidemiology and the Crisis of Lifestyle Conditions. Physiotherapy Theory and Practice. 2009;25(5-6):330-353.

52. Centers for Disease Control and Prevention. Health Disparities Persist Among People with Disabilities, 2007.

53. Bodner, M., Dean, E. Advice as a Smoking Cessation Strategy: A Systematic Review and Implications for Physical Therapists. Physiotherapy Theory and Practice. 2009;25(56):369-407.

54. Schroeder,S. What to Do with a Patient Who Smokes. Journal of the American Medical Association. 2005;294(4):482-487.

55. Guilmette, T., Motta, S., Shadel, W., Mukand, J., Niaura, R. Promoting Smoking Cessation in the Rehabilitation Setting. American Journal of Physical Medicine and Rehabilitation. 2001;80(8):560-562.

56. Heaton, P., Frede, S. Patients' Need for More Counseling on Diet, Exercise, and Smoking Cessation: Results from the National Ambulatory Medical Care Survey. Journal of the American Pharmacists Association. 2006;46:364-369.

57. Zhou, X., Nonnemaker, J., Sherrill, B., Gilsenan, A., Coste, F., West, R. Attempts to Quit Smoking and Relapse: Factors Associated with Success or Failure from the ATTEMPT Cohort Study. Addictive Behaviors. 2009;34:365-373.

58. Agency for Healthcare Research and Quality. Treating Tobacco Use and Dependence: 2008 Update,2008.

59. Fiore, M., Bailey, W., Cohen, S., et al. Treating Tobacco Use and Dependence: Quick Reference Guide for Clinicians. In: Services USDoHaH, ed. Rockville, Maryland: Public Health Service; 2000.

60. Fiore, M., Croyle, R., Curry, S., Cutler, C., Davis, R., Gordon, C., Healton, C., Koh, H., Orleans, C., Richling, D., Satcher, D., Seffrin, J., Williams, C., Williams, L., Keller, P., Baker, T. Preventing 3 Million Premature Deaths and Helping 5 Million Smokers Quit: A National Action Plan for Tobacco Cessation. American Journal of Public Health. 2004;94(2):205-210.

61. Mclvor, A., Kayser, J., Assaad, J., Brosky, G., Demarest, P., Desmarais, P., Hampson, C., Khara, M., Pathammavong, R., Weinberg, R. Best Practices for Smoking Cessation Interventions in Primary Care. Canadian Respiratory Journal. 2009;16(4):129-134.

62. Wai, E., Rodriguez, S., Dagenais, S., Hall, H. Evidence-Informed Management of Chronic Low Back Pain with Physical Activity, Smoking Cessation, and Weight Loss. The Spine Journal. 2008;8:195-202.

63. Taylor, A., Ussher, M., Faulkner, G. The Acute Effects of Exercise on Cigarette Cravings, Withdrawal Symptoms, Affect and Smoking Behaviour: A Systematic Review. Addiction. 2007;102:534-543. 
64. Boudreaux, E., Francis, J., Taylor, C., Scarinci, I., Brantley, P. Changing Multiple Health Behaviors: Smoking and Exercise. Preventive Medicine. 2003;36:471-478.

65. Prapavessis, H., Cameron, L., Baldi, J., Robinson, S., Borrie, K., Harper, T., Grove, J. The Effects of Exercise and Nicotine Replacement Therapy on Smoking Rates in Women. Addictive Behaviors. 2007;32:1416-1432.

66. Grove, J., Wilkinson, A., Dawson, B., Eastwood, P., Heard, P. Effects of Exercise on Subjective Aspects of Sleep During Tobacco Withdrawal. Australian Psychologist. 2006;41(1):69-76.

67. Olchowski ,A., Graham, J., Beverly, E., Dupkanick, C. Cigarette Smoking, Physical Activity and the Health Status of College Students. Journal of Applied Social Psychology. 2009;39(3):683-706.

68. Perez C. Prescribing Exercise in Tobacco Smoking Cessation Therapy. Archivos de Bronchoneumologia. 2009;45(11):556-560.

69. Papathanasiou, G., Georgakopoulos, D., Georgoudis, G., Spyropoulos, P., Perrea, D., Evangelou, A. Effects of Chronic Smoking on Exercise Tolerance and on Heart RateSystolic Blood Pressure Product in Young Healthy Adults. European Journal of Cardiovascular Prevention and Rehabilitation. 2007;14:646-652.

70. Bernaards, C., Twisk, J., Van Mechelen, W., Snel, J., Kemper, H. A Longitudinal Study on Smoking in Relationship to Fitness and Heart Rate Response. Journal of the American College of Sports Medicine. 2003;35(5):793-800.

71. Dent, L., Harris, K., Noonan, C. Randomized Trial Assessing the Effectiveness of a Pharmacist-Delivered Program for Smoking Cessation. The Annals of Pharmacotherapy. 2009;43:194-201.

72. Studts, J., Burris, J., Kearns, D., Worth, C., Sorrell, C. "Providers Practice Prevention": Promoting Dental Hygenists' Use of Evidence-Based Treatment of Tobacco Use and Dependence. Journal of Dental Education. 2009;73(9):1069-1081.

73. Ohtake, P., Homish, G. Smoking Cessation Counseling Skills and Confidence Are Increased in DPT Students Following Communication Skills Education. Cardiopulmonary Physical Therapy Journal. 2010; 21(4):27.

74. American Physical Therapy Association. Vision 2020,2000. 
Figure 1: Physical therapist practice guide to tobacco cessation counseling

\section{Tobacco Cessation Counseling Guidelines}

- Every patient should be asked about tobacco use.

- For people who smoke, an outline of the " $5 A^{\prime} s$ " and 5 R's are listed below.

\section{At initial evaluation:}

ASK :

"Do you smoke?"

"How often?"

"How many cigarettes per day?"

"How many cigarettes per week?"

(At an early point in the episode of care after the therapeutic alliance has been established, initiate smoking cessation counseling.)

\section{ADVISE:}

"In your initial evaluation, you mentioned that you smoke. As your physical therapist, I strongly recommend that you stop smoking. It is one of the best things you can do to improve your health, including the reason you are coming for physical therapy." Specifically explain why smoking cessation will improve the outcomes of the patient's physical therapy diagnosis.

EXAMPLES:

"Quitting smoking will improve your rate of wound healing."

"People who stop smoking tend to get better results in reducing their pain."

"Smoking can Interfere with bone growth - if you quit now, you will be less likely to experience complications from your spinal surgery."

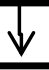

ASSESS:

"How interested are you in quitting smoking right now?"

"Would you be willing to quit in the next 30 days?"

\section{ASSIST:}

If patient is ready to quit within the next 30 days, proceed with recommedations for immedicate cessation (action phase).

If the patient is not yet ready to quit, proceed for recommendations for contemplation phase.

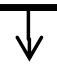

\section{ARRANGE:}

"Can we call you to see how you are doing with your quit attempt? "

"When would be a good time to reach you?" 
ACTION PHASE: Patient reports he or she is ready to quit smoking within the next 30 days.

- Commend the patient on his or her willingness to quit \& express empathy towards making such a difficult decision, for example, "I know that quitting is difficult, but I am really happy that you've made such an important decision. Quitting now will help you heal faster. Let's make sure that you receive more information about smoking cessation before you leave."

- Encourage the patient to get rid of tobacco products, put away ashtrays if quitting today.

- If the patient is not ready to quit today, ask them to select a quit date in the next week or two.

- Encourage patient to make some immediate changes in smoking behaviors to facilitate future cessation: cutting back on how much they smoke, limiting where they smoke, tell others they want to quit so that they can gather social support, writing down reasons they want to quit to serve as a reminder and ongoing motivation.

- Recommend materials for patient that will assist cessation.

Internet sites: American Cancer Society www.cancer.org, 1-800-ACS-2325

American Legacy Foundation www.americanlegacy.org, 1-202-454-5555

American Lung Association www.lungusa.org, 1-800-LUNG-USA

Toll-Free Quit Lines: American Cancer Society, 1-800-ACS-2345

American Lung Association, 1-800-LUNG-USA

National Quit Line: 1-800-QUITNOW (will refer caller to local resources)

- Ask the patient if she or he is interested in pharmacotherapy - if yes, offer to contact the patient's medical provider/ physician. 


\section{CONTEMPLATION PHASE:}

- Acknowledge difficulties in making a quit decision, e.g. “That's OK. Most people who smoke aren't ready to quit right away. I'd like for you to give it more thought. The decision to quit can only be made by you, but I am willing to help any way that I can. "

- Follow the 5 R's.

Relevance: Explain how smoking impacts the person's individual health, e.g. - for patients with an orthopedic injury, it can interfere with bone healing, contribute to osteoporosis, exacerbate pain, and effect muscle strength and endurance.

Rewards: Ask your patient to identify some of the makjor benefits of cessation, i.e. - better health, optimal recovery and improved physical functioning, money saved, improved sense of taste and smell ...
Risks: Include both acute and long-term risks of smoking, e.g. - disability, reduced quality of life.

Also discuss environmental risks such as increased health risks to spouses, children and others exposed to secondhand smoke, including pets.

Roadblocks: Spend time asking the patient about the percived barriers to cessation, e.g. - withdrawal symptoms, weight gain, fear of failure ... and brainstorm possible solutions.

Repetition: Reinforce your commitment and interest in helping the patient stop smoking. Continue to gauge his or her motivation to quit during subsequent office visits, or arrange for follow-up phone contact. 


\section{Chapter 3}




\title{
Tobacco Cessation Counseling Training in U.S. Entry-Level Physical Therapist Education Curricula: Prevalence, Content, and Associated Factors
}

\begin{abstract}
Introduction: The United States Public Health Service recommends tobacco cessation counseling (TCC) training for all healthcare professionals. Smoking impairs functional outcomes in all areas of physical therapist practice, and people with disabilities have elevated smoking rates. Therefore, TCC is an important skill that should be a component of entry-level physical therapist (PT) education.

Objectives: Identify the prevalence and scope of TCC training, as well as factors associated with the inclusion of TCC training in entry-level PT education.

Design: Descriptive cross-sectional survey.

Methods: Entry-level PT programs accredited by the Commission on Accreditation in PT Education ( $N=204$ ) were surveyed in 2012 , yielding a $71.5 \%$ response rate. Logistic regression and Fisher's exact test were used to examine likelihood of TCC training, based on program characteristics, and the opinions of the faculty.

Results: Forty percent of participating programs report TCC curricular content. Likelihood of training was highest when faculty were familiar with evidence-based TCC guidelines (OR $=9.68$, $p<.0001)$ and had prior training $(p=0.01)$ and greater self-confidence in their own knowledge and skill (OR $=6.20, p=.02)$. TCC curricular content was positively associated with favorable opinions regarding the efficacy of TCC $(O R=5.78, p<.001)$, and the inclusion of TCC in PT practice $(O R=12.16, p<.0001)$.

Limitations: Data are derived from a relatively homogenous sample of PT educators, limited in size, but strengthened by anonymity, reducing potential for bias.

Conclusions: There is a need for TCC training in entry-level PT education. Faculty awareness, knowledge and skill and positive opinions towards the physical therapist's role in smoking cessation counseling are associated with increased likelihood of TCC curricular content as a component of entry-level training.
\end{abstract}




\section{Introduction}

Smoking cessation is the leading preventable cause of chronic disease and premature mortality in the United States and worldwide. ${ }^{1,2}$ Approximately $21 \%$ of American adults currently use tobacco, and rates are even higher among people with disabilities. ${ }^{1}$ When compared with their non-disabled peers, people with disabilities are less likely to receive tailored cessation counseling (TCC), and less likely to make a quit attempt. ${ }^{1,3}$ Unfortunately, people with disabilities are also more likely to experience detrimental effects of tobacco use, since smoking can exacerbate pre-existing health conditions. ${ }^{3}$ Physical therapists are uniquely positioned to provide TCC for people with disabilities due to elements of physical therapist practice that are closely compatible with tailored, individualized patient education, including the opportunity to establish a close rapport through frequent communication across a single episode of care. ${ }^{4,5}$ Furthermore, the impact of smoking on treatment outcomes in all aspects of physical therapist practice provides a strong incentive for increased professional involvement in TCC.,

Results of the National Ambulatory Medical Care survey (2008) revealed that less than 20\% of patients who smoke received TCC during their most recent encounter with a healthcare provider. ${ }^{6}$ Specific to physical therapy, a practitioner survey conducted among clinicians in New York, Tennessee and California demonstrated TCC rates of 17 percent. ${ }^{7}$ One reason behind this persistent shortcoming is that many health care professionals lack the knowledge and confidence to apply TCC skills in clinical practice. ${ }^{8}$ It is known that training increases TCC and improves provider performance, ${ }^{9-11}$ and patients who receive counseling are $60 \%$ more likely to make a quit attempt. ${ }^{12}$ Receiving advice from two or more health care practitioners more than doubles the odds of successful cessation, further supporting the need for physical therapists to join in an interprofessional approach to end smoking. ${ }^{13}$

Based on a growing awareness of the importance of TCC and the need for proper training, several health professions have begun to incorporate use of evidence-based clinical guidelines for smoking cessation as a component of their entry-level curricula. Evidence-based clinical guidelines for TCC developed by the Agency for Health Care Quality and Research (AHRQ) ${ }^{14}$ have been successfully employed in training in pharmacy students, ${ }^{10}$ dental students, ${ }^{11}$ chiropractic students, ${ }^{11}$ and medical students. ${ }^{15,16}$ However, based on results of the 2005-2007 Global Health Professions Student Survey (GHPSS), there is a continued need for widespread implementation: less than $40 \%$ of dental, medical, nursing and pharmacy students reported prior TCC training, although the majority of respondents believed that TCC was part of their professional roles and should be included in their entry-level education. ${ }^{17}$ Preliminary data investigating the impact of training for student physical therapists showed that student confidence in providing advice for smoking cessation can be improved through education and skills practice. ${ }^{18}$ 
While previous studies have examined the prevalence and scope of knowledge regarding TCC among physical therapy practitioners, ${ }^{19}$ no known data were available to reflect the current rates of TCC training among student physical therapists. Therefore, the primary objective of this research was to determine the prevalence of evidence-based TCC training among entrylevel physical therapist education programs within the United States, and explore the characteristics of programs and faculty that are associated with the inclusion of TCC as a component of student training.

This study is designed as a needs assessment in order to acquire data that can be used to inform curricular development, with the ultimate goal of improving knowledge and skill in evidence-based TCC among entry-level physical therapists.

\section{Methods}

Data were collected using a cross-sectional descriptive survey.

The survey developed for this study (Appendix) was distributed in 2012 to faculty at all entrylevel professional education programs accredited by the Commission on Accreditation in Physical Therapy Education (CAPTE), $\mathrm{N}=204 .{ }^{20}$ The study was approved by the institutional review board of the sponsoring universities. With the exception of program name, individual responses were anonymous.

\section{Study Participants}

The director of each physical therapist educational program was contacted via electronic mail (email) describing the goals and purpose of the research, along with a request for participation. Each director was asked to designate an appropriate faculty member who might be willing and able to answer questions regarding curricular content for TCC training, and provide opinions regarding the physical therapist's professional role in promoting smoking cessation. This procedure was selected in lieu of direct faculty contact due to variations in curricular design at each individual program, and the likelihood that TCC content may fall under one or more course categories.

Once a faculty member had been designated, he or she was sent an email with a consent letter and link to the online survey. Faculty were advised that they were free to abstain from answering any questions and could choose to withdraw at any time during the survey. A chance to receive a $\$ 50$ gift certificate was offered as an incentive to participate.

Following the first distribution, less than $20 \%$ of programs had provided a response. Follow-up emails were then sent to program directors and/ or the Academic Coordinators/ Directors of Clinical Education (ACCE/ DCE). The ACCE/ DCE was used as an alternate contact, because, like 
the program director, the responsibilities of an ACCE/ DCE require communication with the entire faculty, and familiarity with the overall student curriculum, including content on health promotion and wellness. ${ }^{21}$ When possible, if a contact person had already been designated, follow-ups were directed towards the faculty member responsible for content related to smoking cessation. It was hypothesized that low initial responses may have been due to timing of the survey's launch, which coincided with the end of the spring term. Therefore, follow-up emails and phone calls were deferred until the start of the fall academic term, 2012. Data collection concluded in November, 2012, with a final response rate of $71.5 \%$.

\section{Procedure}

The survey was administered using Qualtrics Online Survey Software (Provo, Utah). Items focused on existing curricular content for evidence-based tobacco cessation interventions, specifically, aspects of the AHRQ TCC Clinical Practice Guidelines, i.e. - "The 5 A's": ask, advise, assess, assist, and arrange. ${ }^{19,22,23}$ Content modifications specific to physical therapy were based on a preliminary review of the literature regarding the physical therapist's professional role and the impact of smoking on physical therapy treatment outcomes. ${ }^{5}$ Respondents were asked if topics related to TCC were covered, how many hours were devoted to the content, and what teaching methods were employed, including whether students were given the opportunity to apply the techniques in a simulated and/ or clinical setting. ${ }^{22,23}$ Survey items also included questions about content covering the physiological effects of tobacco use, methods for assessing nicotine dependence, and use of the Transtheoretical Model (i.e. - Prochaska's Stages of Change). ${ }^{24}$

Along with demographic information (e.g. - age, sex, level of experience as a physical therapist and educator), the survey incorporated elements of social and behavioral theory, i.e. - The Theory of Reasoned Action. ${ }^{25}$ According to this theory, decisions, such as whether to include TCC as a component of practice and education, are a direct product of behavioral intention. In turn, intentions are shaped by an individual's attitudes and opinions, as well as confidence in his or her ability to achieve the expected outcomes. Within this research study, the Theory of Reasoned Action was used to construct questions regarding potential barriers and facilitators towards the inclusion of the AHRQ TCC Clinical Guidelines in physical therapist education and practice. ${ }^{26}$ These factors included an awareness of TCC guidelines, ${ }^{19}$ knowledge and agreement with the content of the guidelines, ${ }^{27}$ having sufficient time to apply the guidelines in a clinical practice setting, ${ }^{27}$ having sufficient opportunity and resources to establish training, ${ }^{28}$ and the perceived importance and efficacy of TCC in promoting smoking cessation. ${ }^{29}$

Face validity and content validity of the survey instrument were assessed via information gathered from a preliminary search of the literature. Content validity was also assessed via expert review $(\mathrm{N}=7)$ by professionals with backgrounds in physical therapy, public health, 
cardiopulmonary pathology and treatment, health promotion, and graduate education in substance abuse and counseling. Prior to widespread distribution, wording and format of the survey instrument were pre-tested using a small sample of physical therapist clinicians and academic faculty $(\mathrm{N}=10)$. Following the pre-test, minor modifications were made to consolidate items and provide space for text responses, allowing respondents to elaborate on certain topics, such as clinical specialty, reasons for opinions towards TCC as a component of education and practice, and methods used in delivery of TCC content.

Data analyses were conducted using SPSS software, Version 16 (IBM Corporation, Armonk, NY) and SAS software, Version 9.3 (SAS Institute, Cary, NC). Primary analysis included program characteristics and faculty member demographics calculated by frequencies and percentages. Program characteristics included whether the program was located at a public versus private institution, whether it was located in a tobacco-growing state, and whether the program's campus had a smoke-free policy. Faculty demographics included age, sex, years of experience as a physical therapist and educator, entry level and highest earned degree, membership in the American Physical Therapy Association (APTA), smoking status, prior training in TCC, familiarity with TCC clinical guidelines, primary teaching responsibility, and primary clinical specialty. Faculty were also asked about their opinions regarding the physical therapist's role in TCC, and whether they supported TCC training as a component of entry-level physical therapist education.

Data were initially analyzed in order to address the first research question: What is the prevalence of evidence-based TCC training among entry-level physical therapist education programs within the United States? For programs that included elements of TCC, frequencies and percentages provided an overview of the number of hours, and whether training covered each of the three distinct aspects prescribed by the AHRQ: the $5 \mathrm{~A}^{\prime} \mathrm{s}, 5 \mathrm{R}^{\prime} \mathrm{s}$, and relapse prevention. Respondents were also asked whether students had the opportunity to practice TCC skills in classroom, laboratory, or clinical settings.

Further analysis explored the second research question: Which characteristics of programs and faculty are associated with the inclusion of TCC as a component of student training? Categorical data regarding the inclusion of TCC training in entry-level physical therapy program curricula were compared to categorical data reflecting program demographics using logistical regression. The dependent variable was defined as whether the program included TCC training. Independent variables for each separate model are listed below:

1. Program is located at a public institution

2. Program is located on a smoke-free campus

3. Program is located within a tobacco growing state 
Next, categorical data regarding the inclusion of TCC training in entry-level physical therapist program curricula were compared to data reflecting faculty demographics and opinions regarding the physical therapist's role in providing TCC for patients who smoke. For categories with sufficient sample size, associations were explored using logistic regression. When categories resulted in contingency tables with cell counts less than 5, Fisher's exact test was utilized. The dependent variable was defined as whether the program included TCC training. Independent variables for each separate model are listed below:

1. Faculty member's gender (reference $=$ female)

2. Faculty member's age

3. Faculty member performs direct patient care in addition to teaching

4. Faculty member has an entry-level doctorate in physical therapy (DPT)

5. Faculty member has a PhD or equivalent (e.g. - DSc, EdD)

6. Faculty member is familiar with USDHHS TCC clinical guidelines

7. Faculty member has the self-rated knowledge and skill needed to implement the USDHHS TCC guidelines for people who are willing to consider quitting, i.e. - "The 5 $A^{\prime} s^{\prime \prime}$

8. Faculty member has the self-rated knowledge and skill needed to implement the USDHHS TCC guidelines for people who are not immediately willing to commit to smoking cessation, i.e. - "The $5 \mathrm{R}^{\prime} \mathrm{s}$ "

9. Faculty member believes brief TCC can be effective

10. Faculty member believes that patients who smoke are not interested in TCC

11. Faculty member believes lack of reimbursement is a barrier to TCC

12. Faculty member believes that time constraints are a barrier to TCC

As in the first analysis, for categories with sufficient sample size, associations were explored using logistic regression. When categories resulted in contingency tables with cell counts less than 5 , Fisher's exact test was utilized. Statistical significance for each of these procedures was defined as a $p$-value $\leq 0.05$.

\section{Results}

Final survey response rate was $71.5 \%(\mathrm{~N}=146)$. Analysis revealed no distinct pattern in program size or location when examining the distribution of non-respondents. Response rates for each of the 10 regions defined by CAPTE criteria were as follows: East North Central, 59\%; East South Central, 60\%; Middle Atlantic, 61\%; Mountain, 55\%; New England, 56\%; Pacific, 61\%; South Atlantic, 74\%; West South Central, 41\%; West North Central, 61\%. Data regarding program size (class size, by year), were available for 184 programs nationwide. The average 
class size for respondents was 42 students. The average class size for non-respondents was 41 students.

\section{Program and Faculty Demographics:}

There are 204 CAPTE accredited physical therapy programs. Of these programs, $41 \%$ are located within the sixteen states that have tobacco farms. A total of 146 programs responded to the survey; of these, 116 of respondents specified program name: $53 \%$ of programs providing necessary data are located in tobacco growing states, $53 \%$ of programs are located at public universities, and $83 \%$ are located at universities with smoke-free campus policies.

Faculty respondents were primarily female (68\%), had a mean age of 52 years (SD 8, range 3269 years), 26 years of experience as a physical therapist (SD 9, range 6-46 years), and 17 years of experience in an academic environment (SD 9, range 1-40 years). Primary teaching responsibilities were weighted towards cardiopulmonary content, with multiple areas represented, including neurological and musculoskeletal physical therapy, consistent with the underlying premise that TCC is relevant to all areas of physical therapist practice. Primary clinical specialties also represented a broad range, with $58 \%$ of respondents continuing to provide direct patient care in addition to teaching. Nearly all respondents $(97 \%)$ were members of the American Physical Therapy Association (APTA), 34\% were familiar with TCC clinical guidelines, and of those who were familiar with guidelines, $40 \%$ reported prior training in TCC methods. None of the respondents were current smokers, although $14 \%$ had previously smoked more than 10 cigarettes within their lifetime. Program and faculty respondent demographics can be found in Table 1 and Table 2, respectively.

\section{Prevalence and Content of TCC Training:}

Approximately $40 \%$ (57/146) of programs responding to the survey reported the inclusion of TCC as a component of entry-level PT training within the classroom setting, with $5 \%$ of programs (6/119) also reporting TCC as a component of training within the clinical environment. Mean number of training hours was 1.4 (SD 1.1, range 1-6 hours). A summary of TCC curricular content can be found in Figure 1 and Table 3.

Associations between program characteristics and inclusion of TCC training were not statistically significant. With regard to faculty characteristics, data analyses revealed greater likelihood of TCC training in programs where faculty members were familiar with USDHHS TCC guidelines (OR $=9.68, p<0.01)$, had the self-rated knowledge and skill to implement USDHHS TCC guidelines, the " 5 A's" (OR 6.20, $p=0.02$ ), believed TCC is effective (OR $=5.78, p<0.01$ ), and supported the role of physical therapists in providing TCC for patients who smoke $(\mathrm{OR}=12.16$, $p<0.01)$. These associations can be found in Table 4 . 
Faculty Characteristics Associated with Positive Opinions towards the Role of Physical Therapists in TCC:

Likelihood of TCC curricular content was greater in programs where faculty members expressed favorable opinions towards the physical therapist's role in smoking cessation (OR 12.16, $\mathrm{p}<$ 0.01). Therefore, secondary data analyses explored factors which enhanced faculty members' support for TCC as a component of physical therapy clinical practice. These relationships can be found in Table 5.

Support for TCC as a component of entry-level physical therapist practice was higher among younger faculty members, and was lowest among those with greatest age $(O R=0.92, p=0.01)$. A very small sample of respondents had an entry-level doctorate in physical therapy $(\mathrm{N}=3)$, however, all of them supported the role of physical therapists in TCC. A belief that smokers are not interested in TCC ( $N=19)$, and a belief that time constraints are a barrier to TCC in the clinical environment $(\mathrm{N}=33)$ both reduced the likelihood of support for the physical therapist's role in TCC (OR $=0.16, p \leq 0.01 ; \mathrm{OR}=0.10, \mathrm{p} \leq 0.01$, respectively).

\section{Qualitative Data}

Faculty were given a space on the survey to provide comments regarding TCC in their curricula. Common themes included occasional difficulty ascertaining whether certain topics related to TCC were taught due to limited familiarity with the exact content of every course within the curriculum. Several participants expressed concern regarding the physical therapist's scope of practice, stating that referral to another health care practitioner with greater counseling expertise might be best. One respondent wrote that TCC should not interfere with the client's physical therapy treatment, i.e. - the primary reason for physical therapy intervention, and another questioned the use of the term "counseling" in the context of patient education regarding the harmful effects of smoking and benefits of cessation.

\section{Discussion}

This study provides valuable information regarding the current prevalence and scope of TCC training within entry-level physical therapist education. Results revealed that TCC training is included in the curricula of $40 \%$ of programs within the United States and Puerto Rico which responded to this survey. This percentage is similar to the number of general health professions students worldwide (pharmacy, nursing, dentistry and medicine), where $40 \%$ of respondents indicated prior TCC training as an element of entry-level education. ${ }^{17}$ TCC training for student physical therapists averaged 1 to 2 hours, with less than $20 \%$ of programs providing an opportunity to practice TCC in a simulated or laboratory-based setting, and only $5 \%$ of programs including practice in a clinical setting. Content hours for TCC training in physical therapist education are in contrast with some medical degree programs which include 4-6 
hours, but are consistent with studies examining TCC content in undergraduate osteopathic education where $64.7 \%$ of respondents reported less than 3 hours of training, ${ }^{23}$ and nearly $33 \%$ of US medical programs which reported 3 hours or less. ${ }^{30}$

Previous studies have shown the benefits of TCC training for health professions students. Approximately $88 \%$ of dentists and $98 \%$ of dental hygienists who were trained as students routinely advised their patients to quit smoking. ${ }^{31}$ Within physical therapist practice, implementation of evidence-based TCC guidelines can enhance treatment outcomes in all areas including cardiovascular and pulmonary health, neuromuscular and musculoskeletal health, and wound management. Evidence-based TCC guidelines developed by the AHRQ, commonly known as "The 5 A's and 5 R's," are closely compatible with existing patient education methods currently employed by physical therapists. ${ }^{5}$ The " $5 A^{\prime} \mathrm{s}^{\prime}$ are designed to guide tobacco cessation interventions for patients who may be willing to quit smoking within the near future. Steps include asking the patient about his or her smoking status; advising the patient to quit using a strong, personalized message; assessing the patient's willingness to quit; assisting the patient in identifying successful cessation strategies; and arranging for follow-up contact. ${ }^{14}$ For patients who may not be contemplating cessation, application of "The 5 R's" can assist in uncovering additional motivation to stop smoking. According to "The $5 \mathrm{R}$ 's," the physical therapist should encourage patients to consider the personal relevance of quitting based on individual values and circumstances. The patient should also be counseled in identifying potential risks, or negative consequences of smoking, along with the rewards, or benefits of cessation. The physical therapist can also help patients identify roadblocks, or barriers, to cessation, and should be prepared to repeat counseling at other opportunities within the episode of care.

According to prior research, physicians are the most likely type of provider to offer TCC services. ${ }^{13}$ However, utilization of rehabilitative services by people with disabilities provides a valuable opportunity for physical therapists to have a greater impact on smoking-related health disparities through supportive counseling. Supportive counseling can encourage patients to consider quitting, based on personal risk and likelihood of improved physical therapy treatment outcomes. Physical therapists can achieve these goals by communicating care and concern for the patient's well-being, congratulating successes, and expressing empathy for difficulties encountered during the cessation attempt. ${ }^{14}$

While people with disabilities have higher utilization of medical services overall, this does not typically result in increased access to preventive services. ${ }^{32}$ Although many medical professionals screen for tobacco use, for people with disabilities, other issues may take precedence over smoking cessation during routine medical visits. Therefore, an interdisciplinary approach is essential in increasing access and efficacy of TCC services. 
Receiving advice from two or more health care practitioners more than doubles the odds of successful smoking cessation. ${ }^{13}$ It has been estimated that national implementation of the AHRQ TCC guidelines would result in 5 million less smokers each year, with the prevention of more than 3 million premature deaths. ${ }^{33}$

In a health care environment plagued by escalating expenditures, scarce resources, and increasing rates of chronic disease and disability, the role of physical therapists in health promotion and wellness through effective TCC is an important aspect of health care reform. Cost savings as a result of effective TCC are estimated at approximately $\$ 883-\$ 3590$ per year of life preserved. ${ }^{34}$ Tenets of TCC are aligned with all physical therapy practice patterns. Many elements of physical therapy patient interactions are closely compatible with evidence-based TCC guidelines, including a strong emphasis on patient education, and individualized tailored attention that occurs during multiple visits within a single episode of care. ${ }^{5}$ Among medical residents, TCC training increased the likelihood of counseling and improved the efficacy of provider advice in promoting smoking cessation. ${ }^{35}$ In pharmacy students, training increased intention to perform TCC, with $97 \%$ of students reporting a belief that TCC training would improve the quality of their patient interactions. ${ }^{10}$ Within physical therapist education, possible reasons for lack of TCC training should be considered so that feasible strategies for improved training may be designed and implemented. Among other health professions, potential barriers towards inclusion of TCC education has included a lack of awareness, training and/ or perceived relevance of TCC among program faculty, along with a lack of curricular resources. ${ }^{23}$ Within this sample of entry-level physical therapist programs, likelihood of TCC curricular content was higher when faculty reported favorable attitudes and opinions towards the efficacy of TCC and the importance of TCC relative to the physical therapist's professional roles and responsibilities. The design, implementation, and adoption of TCC training within entry-level physical therapist education will have a greater likelihood of success when these potential barriers and facilitators are adequately addressed.

Several respondents expressed opinions that TCC is outside the physical therapist's scope of practice, and a belief that "there are other professionals far better equipped to do counseling." Therefore, it will be particularly important for educational initiatives to incorporate the clinical rationale for TCC based on the impact of smoking across treatment outcomes in all aspects of physical therapy. ${ }^{4,5}$ The addition of material to an already weighty curriculum requires careful deliberation. Lack of time during physical therapist education programs to provide TCC training was mentioned by several respondents in this survey, and was also discovered during similar inquiry regarding medical student education. ${ }^{30}$

Professional organizations can provide incentive for TCC education by developing content guidelines and incorporating TCC-related competencies into national licensing criteria. ${ }^{23}$ Within 
this survey of physical therapy faculty, one respondent wrote, "I would encourage educators to consider that this content be included in the Normative Model for Physical Therapy Education as well as CAPTE criteria." Another wrote, "This is an important topic, and I would love to see a specific stance taken by the APTA on what the physical therapist's role should be with this." An example of professional initiatives in smoking cessation can be found in the American Society of Health-System Pharmacists (ASHP) therapeutic position statement on tobacco cessation. ${ }^{36}$ Through this statement, the ASHP encourages educators and practitioners to enact guidelines that effectively and consistently identify patients who smoke, provide access to entry-level training and continuing education designed to equip practitioners to offer evidence-based TCC, and support public policy to promote smoking restrictions in order to further encourage cessation and limit exposure to secondhand smoke. ${ }^{36}$ Rationale for involvement in smoking cessation for pharmacists is highlighted using core professional values. ${ }^{36}$

Future research should examine the prevalence of TCC training for physical therapist assistants (PTAs), since PTAs are an integral part of the patient care team and can play a pivotal role when physical therapists and assistants work cooperatively in addressing patients' needs for behavioral change. In addition, further information regarding the results of TCC training and impact of training on TCC behaviors among practicing physical therapists will be valuable in assessing the value of implementation of evidence-based TCC guidelines. Patient education delivered by chiropractors following tailored evidence-based TCC training yielded a $22.4 \%$ abstinence rate at 12-month follow-up for patients who smoked. ${ }^{37}$ Impact of TCC by dental students following appropriate training yielded a $22 \%$ quit rate among patients who smoked. ${ }^{38}$ This is in contrast to a $5 \%$ cessation rate among adults who attempt to quit unaided. ${ }^{39}$ Physical therapists are already highly skilled in patient education. It is likely that tailored TCC training for physical therapists could achieve similar results in assisting smoking cessation, particularly among people with disabilities.

\section{Limitations}

Limitations of this study include a small sample size despite a $71.5 \%$ return rate. Previous surveys of professional faculty examining professional training in TCC have yielded a $73 \%$ return rate for respiratory therapy program directors, ${ }^{40}$ and a return rate of $89.5 \%$ for schools of osteopathic medicine. ${ }^{23}$ Additional limitations include the possible bias based on social desirability. This was potentially mitigated by the anonymous response. A direct assessment of the actual knowledge level of the participating faculty member relative to the curricular content and hours dedicated to TCC at each physical therapist education program was not possible, and was noted as a potential limiting factor by one of the survey respondents who wrote that "it was very difficult to complete this survey without knowing the exact content of every single course in our program." 


\section{Conclusions}

Despite greater need for tobacco cessation interventions for people with disabilities, ${ }^{1}$ and the impact of smoking on physical therapy intervention outcomes in all areas of practice, ${ }^{4,5}$ training in TCC is not currently a widespread component of entry-level physical therapist education. This study demonstrates strong associations between favorable faculty attitudes and opinions towards the professional role of physical therapists in smoking cessation and the likelihood of physical therapist program curricular content regarding TCC. Familiarity with evidence-based TCC guidelines, prior training, and self-rated knowledge and skill in applying guidelines within a clinical setting were positively associated with program inclusion and favorable opinions towards the physical therapist's professional role. Based on this information, it would be helpful for future initiatives designed to promote a changes in educational content to first begin with developing positive attitudes and opinions among program faculty towards the inclusion of TCC as a component of physical therapist practice. 


\section{References}

1. Armour B, Campbell, V., Crews, J., Malarcher, A., Maurice, E., Richard, R. State-Level Prevalence of Cigarette Smoking and Treatment Advice, by Disability Status, United States, 2004. Preventing Chronic Disease: Public Health Research, Practice and Policy. 2007;4(4):1-11.

2. Mokdad A, Marks J, Stroup D, Gerberding J. Actual Causes of Death in the United States, 2000. JAMA: The Journal Of The American Medical Association. 2004;291(10):12381245.

3. Becker H, Brown A. Disparities in Smoking Behaviors Among Those With and Without Disabilities From 2001 to 2005. Public Health Nursing 2008;25(6):526-535.

4. Bodner M, Dean, E. Advice as a Smoking Cessation Strategy: A Systematic Review and Implications for Physical Therapists. Physiotherapy Theory and Practice. 2009;25(56):369-407.

5. Pignataro R, Ohtake P, Swisher A, Dino G. The Role of Physical Therapists in Smoking Cessation: Opportunities for Improving Treatment Outcomes. Physical Therapy. 2012;92:757-766.

6. Sheffer C, Barone, C., Anders, M. Training Health Care Providers in the Treatment of Tobacco Use and Dependence: Pre- and Post-Training Results. Journal of Evaluation in Clinical Practice. 2009;15:607-613.

7. Rea B, Marshak, H., Neish, C., Davis, N. The Role of Health Promotion in Physical Therapy in California, New York and Tennessee. Physical Therapy. 2004;84(6):510-523.

8. Fiore $M$, Croyle R, Curry S, et al. Preventing 3 Million Premature Deaths and Helping 5 Million Smokers Quit: A National Action Plan for Tobacco Cessation. American Journal of Public Health. 2004;94(2):205-210.

9. Koerber A, Crawford J, O'Connell K. The Effects of Teaching Dental Students Brief Motivational Interviewing for Smoking Cessation Counseling: A Pilot Study. Journal of Dental Education. 2003;67(4):439-447.

10. Corelli R, Kroon, L., Chung, E., Sakamoto, L., Gundersen, B., Fenlon, C., Hudmon, K. Statewide Evaluation of a Tobacco Cessation Curriculum for Pharamacy Students. Preventive Medicine. 2005;40:888-895.

11. Evans M, Hawk C, Strasser S. An Educational Campaign to Increase Chiropractic Intern Advising Roles on Patient Smoking Cessation. Chiropractice and Osteopathy. 2006;14(24):1-9.

12. Hu S, Pallonen, U., McAllister, A., Howard, B., Kamisnki, R., Stevenson, G., Servos, T. Knowing How to Help Tobacco Users: Dentists' Familiarty and Compliance with the Clinical Practice Guideline. Journal of the American Dental Association. 2006;137:170179.

13. An L, Foldes, S., Alesci, N., Bluh, J., Bland, P., Davern, M., Schillo, B., Ahluwalia, J., Manley, M. The Impact of Smoking-Cessation Intervention by Multiple Health Professionals. American Journal of Preventive Medicine. 2008;34(1):54-60.

14. Agency for Healthcare Research and Quality. Treating Tobacco Use and Dependence: 2008 Update2008. 
15. Geller A, Zapka, J., Brooks, K., Dube, C., Powers, C., Rigotti, N., O'Donnell, J., Ockene, J. Tobacco Control Competencies for US Medical Students. American Journal of Public Health. 2005;95(6):950-955.

16. Davis J, Stockdale, M., Cropper, M. Evaluation of a Comprehensive Tobacco Cessation Curriculum for Dental Hygeine Programs. Journal of Dental Education. 2010;74(5):472479.

17. Warren C, Jones N, Chauvin J, Peruga A. Tobacco Use and Cessation Counselling: CrossCountry Data from the Global Health Professions Student Survey (GHPSS), 2005-2007. Tobacco Control. 2008;17(4):238-247.

18. Ohtake $P$, Homish, G. Smoking Cessation Counseling Skills and Confidence Are Increased in DPT Students Following Communication Skills Education. Cardiopulmonary Physical Therapy Journal. 2010;21(4):27.

19. Bodner M, Miller, W., Rhodes, R., Dean, E. Smoking Cessation and Counseling: Knowledge and Views of Canadian Physical Therapists. Physical Therapy. 2011;91(7):1051-1062.

20. Commission on Accreditation in Physical Therapy Education. Accredited Physical Therapist Education Programs 2010; http://apps.apta.org/Custom/wscapte.cfm?cfml=accreditedschools/Index.cfm\&cfmltitle =Accredited\%20Schools\&process=3\&type=PT\&navID=10737421958. Accessed November 18, 2011, 2011.

21. Association APT. Model Position Description for the Academic Coordinator/ Director of Clinical Education (ACCE/ DCE): PT Program. Curriculum Resources 2012. Accessed 5/21/13, 2013.

22. Wewers M, Kidd, K., Armbruster, D., Sarna, L. Tobacco Dependence Curricula in U.S. Baccalaureate and Graduate Nursing Education. Nursing Outlook. 2004;52(2):95-101.

23. Montaldo N, Ferry L, Stanhiser T. Tobacco Dependence Curricula in Undergraduate Osteopathic Medical Education. Journal of the American Osteopathic Association. 2004;104(8):317-323.

24. Prochaska J, DiClemente C. Stages and Processes of Self-Change of Smoking: Toward an Integrative Model of Change. Journal of Consulting and Clinical Psychology. 1983;51(3):390-395.

25. Ajzen I, Madden T. Prediction of Goal-Directed Behavior: Attitudes, Intentions, and Perceived Behavioral Control. Journal of Experimental Social Psychology. 1986;22:453474.

26. Hudmon K, Prokhorov, A., Corelli, R. Tobacco Cessation Counseling: Pharmacists' Opinions and Practices. Patient Education and Counseling. 2006;61:152-160.

27. Feifer C, Fifield J, Ornstein S, et al. From Research to Daily Clinical Practice: What Are the Challenges in "Translation"? Joint Commission Journal on Quality and Safety. 2004;30(5):235-245.

28. Harris J, Patton, L., Wilder, R., Peterson, C., Curran, A. North Carolina Dental Hygeine Students' Opinions About Tobacco Cessation Education and Practices in Their Programs. Journal of Dental Education. 2009;73(5):539-549.

29. Flocke S, Litaker D. Physician Practice Patterns and Variation in the Delivery of Preventive Services. Society of General Internal Medicine. 2007;22:191-196. 
30. Richmond R, Zwar N, Taylor R, Hunnisett J, Hyslop F. Teaching About Tobacco in Medical Schools: A Worldwide Study. Drug and Alcohol Review. 2009;28:484-497.

31. Barker G, Williams K, Taylor T, Barker B. Practice Behaviors of Alumni Trained as Students in Tobacco Use Cessation Interventions. The Journal of Dental Hygeine. 2001;75(11):165-169.

32. Dejong G, Palsbo S, Beatty P. The Organization and Financing of Health Services for Persons with Disabilities. Milbank Quarterly. 2002;80(2):261-301.

33. An L, Bluhm J, Foldes S, et al. Clinical System Elements and Patient Reports of Tobacco Cessation Counseling. Journal of Clinical Outcomes Management. 2008;15(10):485-492.

34. Curry S, Keller P, Orleans C, Fiore M. The Role of Health Care Systems in Increased Tobacco Cessation. Annual Reviews in Public Health. 2008;29:411-428.

35. Cornuz J, Humair, J., Seematter, L., Stolanov, R., van Melle, G., Stadler, H., Pecoud, A. Efficacy of Resident Training in Smoking Cessation: A Randomized, Controlled Trial of a Program Based on Application of Behavioral Theory and Practice with Standardized Patients. Annals of Internal Medicine. 2002;136:429-437.

36. Hudmon K, Corelli R. ASHP Therapeutic Position Statement on the Cessation of Tobacco Use. American Journal of Health Systems Pharmacy. 2009;66:291-307.

37. Gordon J, Istavan J, Haas M. Tobacco Cessation Via Doctors of Chiropractic: Results of a Feasibility Study. Nicotine \& Tobacco Research. 2010;12(3):305-308.

38. Shilby O. Effect of Tobacco Counseling by Dental Students on Patient Quitting Rate. Journal of Dental Education. 2009;74(2):140-148.

39. Messer K, Trinidad D, Al-Delaimy W, J. P. Smoking Cessation Rates in the United States: A Comparison of Young Adult and Older Smokers. American Journal of Public Health. 2008;98(2):317-322.

40. Jordan T, Khubchandani J, Wiblishauser M, Glassman T, Thompson A. Do Respiratory Therapists Receive Training and Education in Smoking Cessation? A National Study of Post-Secondary Training Programs. Patient Education and Counseling. 2011;85:99-105. 
Table 1: Program demographics and faculty characteristics Note: $146 / 204$ programs responded to the survey $-71.5 \%$ response rate 116 respondents provided program name

\begin{tabular}{|c|c|}
\hline Program in located in a tobacco growing state & $53 \%(61 / 116)$ \\
\hline Program is located on a smoke-free campus & $83 \%(114 / 138)$ \\
\hline Program is located at a public institution & $53 \%(61 / 116)$ \\
\hline Program includes TCC training & $40 \%(59 / 146)$ \\
\hline $\begin{array}{l}\text { Respondent's age (in years) } \\
(\mathrm{N}=135 ; 11 \text { missing responses) }\end{array}$ & 51.65 (SD 8.35, range 32-69) \\
\hline Respondent's sex & $68 \%$ female $(96 / 141)$ \\
\hline $\begin{array}{l}\text { Respondent's years of experience as a physical } \\
\text { therapist }\end{array}$ & 26.32 (SD 8.97, range 6-46) \\
\hline Respondent's years of academic experience & 16.59 (SD 8.80 range $1-40$ ) \\
\hline \multirow[t]{4}{*}{ Respondent's entry-level degree } & BS: $60 \%(84 / 140)$ \\
\hline & Certificate: $6 \%$ ( $8 / 140)$ \\
\hline & MS: $28 \%(39 / 140)$ \\
\hline & DPT: $4 \%(5 / 140)$ \\
\hline \multirow[t]{6}{*}{ Respondent's terminal degree } & BS: $0 \%(0 / 142)$ \\
\hline & MS: $12 \%(17 / 142)$ \\
\hline & PhD or equivalent: $51 \%(73 / 142)$ \\
\hline & DPT: $7 \%(10 / 142)$ \\
\hline & PhD(or equivalent) and DPT: 0.01\% (1/142) \\
\hline & Other: $3 \%(4 / 142)$ \\
\hline Respondent is a member of APTA & $96 \%(135 / 140)$ \\
\hline \multirow[t]{2}{*}{ Respondent's smoking status } & Non-smoker $100 \%(143 / 143)$ \\
\hline & Former smoker 13\% (19/143) \\
\hline
\end{tabular}


Table 2 - Primary Teaching Responsibilities of Academic Faculty ( $N=140)$

\begin{tabular}{|c|c|c|}
\hline Topic Area & Percentage & (Frequency) \\
\hline Cardiopulmonary Physical Therapy & $28 \%$ & $(39 / 140)$ \\
\hline Clinical Education & $20 \%$ & $(28 / 140)$ \\
\hline Professional Practice/ Ethics & $9 \%$ & $(13 / 140)$ \\
\hline $\begin{array}{l}\text { Other } \\
\text { (e.g. - Health Promotion and Wellness, Women's Health, } \\
\text { Geriatrics ...) }\end{array}$ & $9 \%$ & $(12 / 140)$ \\
\hline Neurology/ Neurological Rehabilitation & $7 \%$ & $(10 / 140)$ \\
\hline Basic Sciences - e.g - pathology, histology ... & $6 \%$ & $(9 / 140)$ \\
\hline Research/Critical Inquiry & $6 \%$ & $(8 / 140)$ \\
\hline Musculoskeletal Physical Therapy/ Orthopedics & $4 \%$ & $(6 / 140)$ \\
\hline $\begin{array}{l}\text { Physical Therapy Interventions } \\
\text { (e.g. - modalities, therapeutic exercise, manual therapy ...) }\end{array}$ & $4 \%$ & $(5 / 140)$ \\
\hline Wound Management & $3 \%$ & $(4 / 140)$ \\
\hline Kinesiology/ Movement Science & $2 \%$ & $(3 / 140)$ \\
\hline Pediatric Physical Therapy & $1 \%$ & $(2 / 140)$ \\
\hline Practice Management & Less than $1 \%$ & $(1 / 140)$ \\
\hline
\end{tabular}


Figure 1 - Training Content for Entry-Level Physical Therapist Programs That Include TCC: $40 \%$ total $(59 / 146)$

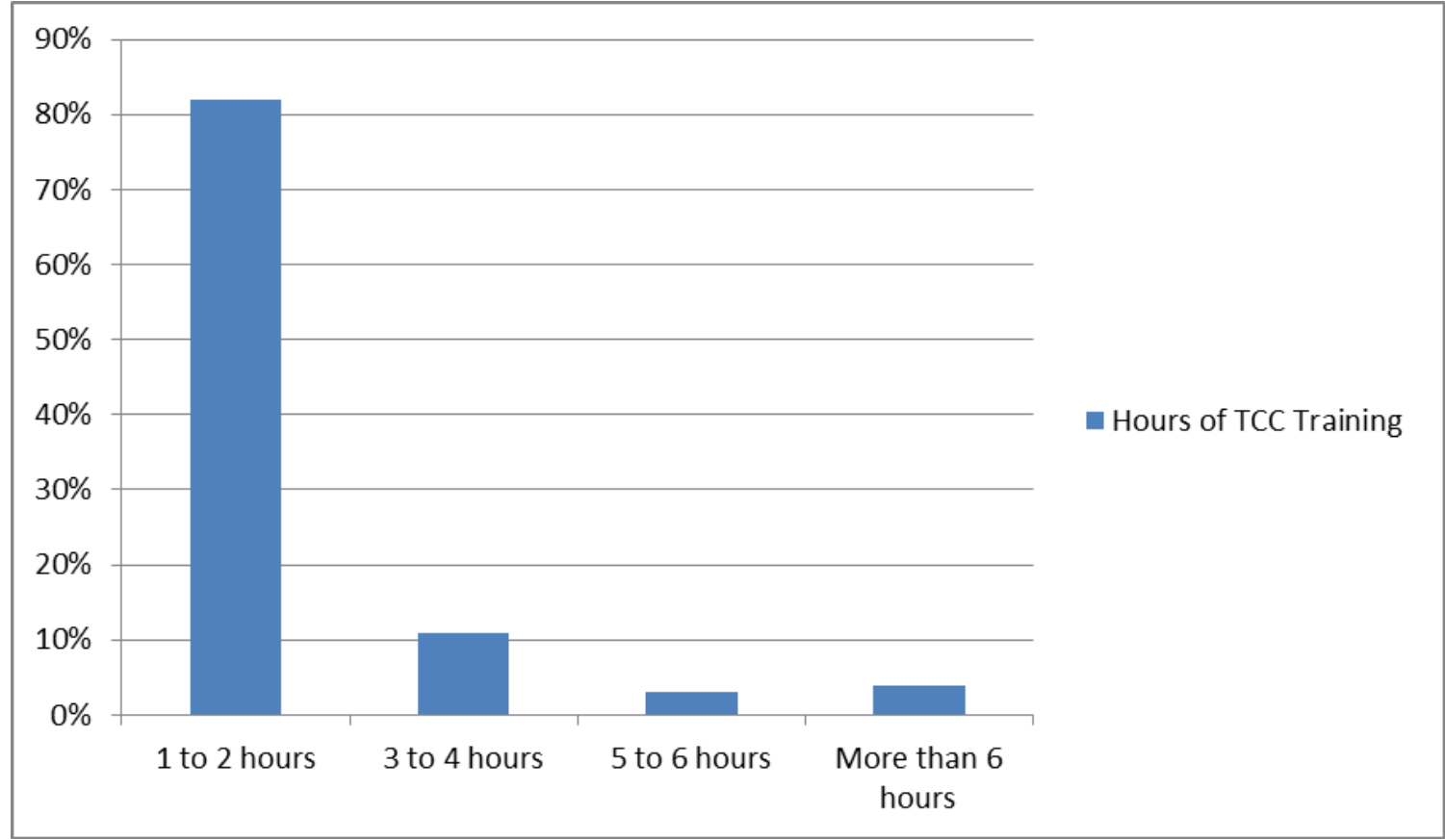

Table 3 - Training Content for Tobacco Cessation Counseling in Physical Therapy Education

\begin{tabular}{|l|cl|}
\hline Content Material/ Training Setting & Percentage & (Frequency) \\
\hline Program includes TCC practice in a laboratory setting & $18 \%$ & $(23 / 126)$ \\
\hline Program includes TCC practice in a clinical setting & $6 \%$ & $(7 / 126)$ \\
\hline Program includes TCC training using the “5 A's and 5 R's" & $23 \%$ & $(33 / 146)$ \\
\hline
\end{tabular}


Table 4 - Predictive Factors Associated with Curricular Content for TCC Training

\begin{tabular}{|c|c|c|c|c|}
\hline & $\begin{array}{l}\text { TCC Training is } \\
\text { Included in } \\
\text { Program } \\
\text { Curriculum }\end{array}$ & $\begin{array}{c}\text { TCC Training is NOT } \\
\text { included in Program } \\
\text { Curriculum }\end{array}$ & \multicolumn{2}{|c|}{ Measures of Association } \\
\hline $\begin{array}{l}\text { Program is located at } \\
\text { public institution }(N=61)\end{array}$ & $39 \%(24 / 61)$ & $61 \%(38 / 61)$ & $\begin{array}{l}\mathrm{OR}=0.68 \\
(0.32,1.42)\end{array}$ & $P=0.30$ \\
\hline $\begin{array}{l}\text { Program is located on a } \\
\text { smoke-free campus } \\
(\mathrm{N}=114)\end{array}$ & $44 \%(50 / 114)$ & $56 \%(64 / 114)$ & $\begin{array}{l}\mathrm{OR}=1.56 \\
(0.62,3.94)\end{array}$ & $P=0.34$ \\
\hline $\begin{array}{l}\text { Program is located within } \\
\text { a tobacco growing state } \\
(\mathrm{N}=61)\end{array}$ & $39 \%(24 / 61)$ & $61 \%(37 / 61)$ & $\begin{array}{l}\mathrm{OR}=0.78 \\
(0.37,1.63)\end{array}$ & $P=0.51$ \\
\hline $\begin{array}{l}\text { Faculty member is } \\
\text { familiar with USDHHS TCC } \\
\text { guidelines ( } \mathrm{N}=48)\end{array}$ & $75 \%(36 / 48)$ & $25 \%(12 / 48)$ & $\begin{array}{l}\text { OR }=9.68 \\
(4.31,21.76)\end{array}$ & $P<0.01$ \\
\hline $\begin{array}{l}\text { Faculty member has been } \\
\text { trained in use of the } \\
\text { USDHHS TCC guidelines } \\
(\mathrm{N}=15)\end{array}$ & $93 \%(14 / 15)$ & $7 \%(1 / 15)$ & \multicolumn{2}{|l|}{$P=0.01$} \\
\hline $\begin{array}{l}\text { Faculty member has the } \\
\text { self-rated skill and } \\
\text { knowledge needed to } \\
\text { implement USDHHS TCC } \\
\text { guidelines - } 5 A^{\prime} \text { 's } \\
(\mathrm{N}=37) \text { OR }=6.20\end{array}$ & $84 \%(31 / 37)$ & $16 \%(6 / 37)$ & $\begin{array}{l}\mathrm{OR}=6.20 \\
(1.42,27.07)\end{array}$ & $P=0.02$ \\
\hline $\begin{array}{l}\text { Faculty member has the } \\
\text { self-rated skill and } \\
\text { knowledge needed to } \\
\text { implement USDHHS TCC } \\
\text { guidelines - } 5 \mathrm{R}^{\prime} \mathrm{s} \\
(\mathrm{N}=31)\end{array}$ & $81 \%(25 / 31)$ & $19 \%(6 / 31)$ & $\begin{array}{l}\mathrm{OR}=2.27 \\
(0.60,8.64)\end{array}$ & $P=0.23$ \\
\hline $\begin{array}{l}\text { Faculty member believes } \\
\text { brief TCC can be effective } \\
(\mathrm{N}=38)\end{array}$ & $68 \%(26 / 38)$ & $32 \%(12 / 38)$ & $\begin{array}{l}\mathrm{OR}=5.78 \\
(2.23,14.98)\end{array}$ & $P<0.01$ \\
\hline $\begin{array}{l}\text { Faculty member supports } \\
\text { the role of PTs in } \\
\text { providing TCC for patients } \\
\text { who smoke }(\mathrm{N}=58)\end{array}$ & $66 \%(38 / 58)$ & $32 \%(20 / 58)$ & $\begin{array}{l}\mathrm{OR}=12.16 \\
(4.10 .36 .06)\end{array}$ & $P<0.01$ \\
\hline $\begin{array}{l}\text { Faculty member supports } \\
\text { the inclusion of TCC } \\
\text { training in PT education } \\
(\mathrm{N}=108)\end{array}$ & $48 \%(52 / 108)$ & $52 \%(56 / 108)$ & $\begin{array}{l}\text { N/A } \\
(>999.999)\end{array}$ & $P=0.97$ \\
\hline
\end{tabular}


$\underline{\text { Table } 5}$ - Predictive Factors Associated with Faculty Support for TCC as a Component of Physical Therapy Practice

\begin{tabular}{|c|c|c|c|c|}
\hline \multirow{2}{*}{$\begin{array}{l}\text { Faculty member is female } \\
(\mathrm{N}=68)\end{array}$} & \multirow{2}{*}{$\begin{array}{l}\text { Respondent Supports } \\
\text { TCC in PT Practice } \\
63 \%(43 / 68)\end{array}$} & \multirow{2}{*}{$\begin{array}{c}\text { Respondent Does } \\
\text { NOT Support TCC } \\
\text { in PT Practice } \\
37 \%(25 / 68)\end{array}$} & \multicolumn{2}{|c|}{ Measures of Association } \\
\hline & & & $\begin{array}{l}\text { OR }=1.20 \\
(0.41,3.56)\end{array}$ & $P=0.74$ \\
\hline Faculty member's age & Younger (32 yrs min) & Older (69 yrs max) & $\begin{array}{l}\text { OR }=0.92 \\
(0.86,0.98)\end{array}$ & $P=0.01$ \\
\hline $\begin{array}{l}\text { Faculty member performs } \\
\text { direct patient care in addition } \\
\text { to teaching }(N=54)\end{array}$ & $63 \%(34 / 54)$ & $37 \%(20 / 54)$ & $\begin{array}{l}\mathrm{OR}=1.13 \\
(0.49,2.63)\end{array}$ & $P=0.77$ \\
\hline $\begin{array}{l}\text { Faculty member has an } \\
\text { entry-level doctorate }(\mathrm{N}=3)\end{array}$ & $100 \%(3 / 3)$ & $(0 / 3)$ & \multicolumn{2}{|l|}{ N/A } \\
\hline $\begin{array}{l}\text { Faculty member has a PhD or } \\
\text { equivalent (e.g. - DSc, EdD) } \\
(\mathrm{N}=58)\end{array}$ & $60 \%(35 / 58)$ & $40 \%(23 / 58)$ & $\begin{array}{l}\mathrm{OR}=0.90 \\
(0.38,2.13)\end{array}$ & $P=0.81$ \\
\hline $\begin{array}{l}\text { Faculty member is familiar } \\
\text { with USDHHS TCC guidelines } \\
(\mathrm{N}=36)\end{array}$ & $78 \%(28 / 36)$ & $22 \%(8 / 36)$ & $\begin{array}{l}\mathrm{OR}=3.38 \\
(1.33,8.64)\end{array}$ & $P=0.01$ \\
\hline $\begin{array}{l}\text { Faculty member has the self- } \\
\text { rated knowledge and skill to } \\
\text { implement TCC guidelines in } \\
\text { clinical practice }\left(5 A^{\prime} \mathrm{s}\right) \\
(\mathrm{N}=30)\end{array}$ & $83 \%(25 / 30)$ & $17 \%(5 / 30)$ & \multicolumn{2}{|l|}{$P=0.11$} \\
\hline $\begin{array}{l}\text { Faculty member has the self- } \\
\text { rated knowledge and skill to } \\
\text { implement TCC guidelines in } \\
\left.\text { clinical practice ( } 5 \mathrm{R}^{\prime} \mathrm{s}\right) \\
(\mathrm{N}=28)\end{array}$ & $82 \%(23 / 28)$ & $18 \%(5 / 28)$ & \multicolumn{2}{|l|}{$P=0.34$} \\
\hline $\begin{array}{l}\text { Faculty member believes } \\
\text { brief TCC can be effective } \\
(\mathrm{N}=27)\end{array}$ & $93 \%(25 / 27)$ & $7 \%(2 / 27)$ & \multicolumn{2}{|l|}{$P>3.36$} \\
\hline $\begin{array}{l}\text { Faculty member believes } \\
\text { smokers are not interested } \\
\text { in TCC } \\
(\mathrm{N}=19)\end{array}$ & $47 \%(9 / 19)$ & $53 \%(10 / 19)$ & $\begin{array}{l}\mathrm{OR}=0.16 \\
(0.05,0.56)\end{array}$ & $P<0.01$ \\
\hline $\begin{array}{l}\text { Faculty member believes lack } \\
\text { of reimbursement is a barrier } \\
\text { to TCC } \\
(\mathrm{N}=3)\end{array}$ & $67 \%(2 / 3)$ & $33 \%(1 / 3)$ & \multicolumn{2}{|l|}{$P=0.16$} \\
\hline $\begin{array}{l}\text { Faculty member believes } \\
\text { time constraints are a barrier } \\
\text { to TCC } \\
(\mathrm{N}=33)\end{array}$ & $39 \%(13 / 33)$ & $61 \%(20 / 33)$ & $\begin{array}{l}\mathrm{OR}=0.10 \\
(0.03,0.33)\end{array}$ & $P<0.01$ \\
\hline
\end{tabular}




\section{Appendix}

\section{Survey Instrument: Tobacco Cessation Counseling Training in Entry-Level Physical Therapist Education}

1. Please list the name of the college or university where you work:

2. Which area best describes your primary teaching responsibilities? Check only one:

\begin{tabular}{|l|l|}
\hline & Basic sciences, e.g. - pathology, histology \\
\hline & Cardiopulmonary PT \\
\hline & Integumentary PT/ Wound Management \\
\hline & Kinesiology/ Movement Science \\
\hline & Musculical Imaging \\
\hline & Neurology/ Neurological Rehabilitation \\
\hline & Pediatric PT \\
\hline & Pharmacology \\
\hline & PT interventions - e.g. - modalities, therapeutic exercise, manual therapy \\
\hline & Practice management \\
\hline & Professional Practice/ ethics \\
\hline & Other \\
\hline
\end{tabular}

3. If you responded "other" to question 2, please describe your primary teaching responsibilities below: 
4. Does your campus have a smoke-free policy?

\begin{tabular}{|l|l|}
\hline & Yes \\
\hline & No \\
\hline
\end{tabular}

5. Do your teaching responsibilities include any of the following? Please check all that apply:

\begin{tabular}{|l|l|}
\hline & Classroom instruction \\
\hline & Clinical instruction \\
\hline
\end{tabular}

6. Are you familiar with the United States Department of Health and Human Services (USDHHS) practice guidelines for tobacco cessation counseling?

\begin{tabular}{|l|l|}
\hline & Yes \\
\hline & No \\
\hline
\end{tabular}

7. (This question was only displayed if the respondent answered yes to being familiar with USDHHS guidelines): Please indicate your level of agreement for each statement regarding the USDHHS practice guidelines for tobacco cessation counseling:

\begin{tabular}{|l|l|l|l|l|l|}
\hline & $\begin{array}{l}\text { Strongly } \\
\text { Agree }\end{array}$ & Agree & $\begin{array}{l}\text { Neither } \\
\text { Agree Nor } \\
\text { Disagree }\end{array}$ & Disagree & $\begin{array}{l}\text { Strongly } \\
\text { Disagree }\end{array}$ \\
\hline $\begin{array}{l}\text { I have the knowledge and skill needed to } \\
\text { implement these guidelines for physical therapy } \\
\text { clients who are interested in immediate } \\
\text { smoking cessation (ready to quit within the next } \\
30 \text { days), i.e. - the "5 A's": ask, advise, assess, } \\
\text { assist and arrange }\end{array}$ & & & & & \\
\hline $\begin{array}{l}\text { I have the knowledge and skill needed to } \\
\text { implement guidelines for physical therapy } \\
\text { clients who are NOT interested in immediate } \\
\text { cessation (not ready to quit within the next } 30 \\
\text { days), i.e. - the "5 R's": relevance, risks, } \\
\text { rewards, roadblocks, and repetition }\end{array}$ & & & & & \\
\hline
\end{tabular}


8. What is your PRIMARY clinical specialty/ area of concentration? Please choose only one response:

\begin{tabular}{|l|l|}
\hline & Acute Care \\
\hline & Cardiopulmonary Physical Therapy \\
\hline & Neurology \\
\hline & Oncology \\
\hline & Orthopedics \\
\hline & Pediatrics \\
\hline & Women's Health \\
\hline & Wound Management \\
\hline & Other - please specify below: \\
\hline
\end{tabular}

9. How many years have you been a physical therapist?

10. How many years of academic experience do you currently possess (i.e. - teaching in a university setting)? 
11. What was your first (entry-level) physical therapy degree, i.e. - prior to taking the licensing examination?

\begin{tabular}{|l|l|}
\hline & Baccalaureate degree \\
\hline & Post-baccalaureate Certificate \\
\hline & Master's Degree \\
\hline & OPT \\
\hline
\end{tabular}

12. What is the highest earned degree (or degrees) you hold in any area of study? Select only one response:

\begin{tabular}{|l|l|}
\hline & Baccalaureate degree \\
\hline & Master's degree \\
\hline & PhD or equivalent, e.g. - EdD or ScD \\
\hline & tDPT \\
\hline & PhD (or equivalent) and DPT \\
\hline & PhD (or equivalent) and tDPT \\
\hline & Other - please specify below: \\
\hline
\end{tabular}

13. Are you a member of the American Physical Therapy Association (APTA)?

\begin{tabular}{|l|l|}
\hline & Yes \\
\hline & No \\
\hline
\end{tabular}

14. Please indicate your age in years, at your last birthday: 
15. Please indicate your sex:

\begin{tabular}{|l|l|}
\hline & Male \\
\hline & Female \\
\hline
\end{tabular}

16. Please select the statement which best describes your own smoking status:

\begin{tabular}{|l|l|}
\hline & I have never smoked (or I have smoked less than 5 cigarettes in my lifetime) \\
\hline & I have previously smoked \\
\hline & I currently smoke, but am planning to quit \\
\hline & Yes, I smoke \\
\hline
\end{tabular}


17. Please indicate whether students in your program receive training in the following areas. Select all that apply:

\begin{tabular}{|c|c|c|c|c|}
\hline & $\begin{array}{l}\text { As part of } \\
\text { my course(s) }\end{array}$ & $\begin{array}{l}\text { As part of } \\
\text { other } \\
\text { course(s) }\end{array}$ & $\begin{array}{l}\text { As part of } \\
\text { clinical } \\
\text { education }\end{array}$ & $\begin{array}{l}\text { Not included as } \\
\text { part of entry-level } \\
\text { physical therapy } \\
\text { training }\end{array}$ \\
\hline Screening patients for tobacco use & & & & \\
\hline $\begin{array}{l}\text { Screening patients for nicotine } \\
\text { addiction }\end{array}$ & & & & \\
\hline Cancer risks from smoking & & & & \\
\hline $\begin{array}{l}\text { Effects of secondhand smoke } \\
\text { exposure }\end{array}$ & & & & \\
\hline $\begin{array}{l}\text { The relationship between smoking } \\
\text { and diabetes }\end{array}$ & & & & \\
\hline $\begin{array}{l}\text { The relationship between smoking } \\
\text { and arthritis }\end{array}$ & & & & \\
\hline $\begin{array}{l}\text { The relationship between smoking } \\
\text { and autoimmune disease, e.g. - RA, } \\
\text { lupus ... }\end{array}$ & & & & \\
\hline $\begin{array}{l}\text { The relationship between smoking } \\
\text { and cognitive impairments }\end{array}$ & & & & \\
\hline $\begin{array}{l}\text { The relationship between smoking } \\
\text { and neurological conditions such as } \\
\text { chronic pain, ALS, and MS }\end{array}$ & & & & \\
\hline $\begin{array}{l}\text { High risk groups/groups with the } \\
\text { highest smoking prevalence }\end{array}$ & & & & \\
\hline $\begin{array}{l}\text { How to provide smoking cessation } \\
\text { counseling for physical therapy } \\
\text { clients }\end{array}$ & & & & \\
\hline Motivational interviewing skills & & & & \\
\hline
\end{tabular}


18. Question will only appear if respondent indicates that students in his or her program receive some form of tobacco cessation counseling training): Approximately how many hours of tobacco cessation counseling training do students receive as part of the physical therapy curriculum?

\begin{tabular}{|l|l|}
\hline & 1 to 2 hours \\
\hline & 3 to 4 hours \\
\hline & 5 to 6 hours \\
\hline & 7 to 8 hours \\
\hline & 9 to 10 hours \\
\hline & More than 10 hours - please specify below: \\
\hline
\end{tabular}

19. (Question will only appear if respondent indicates that students in his or her program receive some form of tobacco cessation counseling training): What resource materials were used in developing your tobacco cessation training curriculum? Please select all that apply:

\begin{tabular}{|l|l|}
\hline & USDHHS Clinical Guidelines for Tobacco Cessation Counseling: “The 5 A's and 5 R's" \\
\hline & Review of scientific literature \\
\hline & National Cancer Institute Guideline, "How to Help Your Patient Stop Smoking” \\
\hline & \\
\hline
\end{tabular}

20. (Question will only appear if respondent indicates that students in his or her program receive some form of tobacco cessation counseling training): Does tobacco cessation counseling training for physical therapy students include any of the following topics?

\begin{tabular}{|l|l|l|}
\hline & Yes & No \\
\hline Application of tobacco cessation counseling in a simulated setting (no actual patients) & & \\
\hline Application of tobacco cessation counseling in a clinical setting with actual patients & & \\
\hline
\end{tabular}


21. (Question will only appear if respondent indicates that students in his or her program receive some form of tobacco cessation counseling training): Please indicate the extent of training physical therapy students receive in each of the following content areas. Select "covered in detail" only if instruction includes laboratory activities and evaluation of student performance:

\begin{tabular}{|c|c|c|c|}
\hline & $\begin{array}{l}\text { Not } \\
\text { Covered }\end{array}$ & $\begin{array}{l}\text { Covered } \\
\text { Briefly }\end{array}$ & $\begin{array}{l}\text { Covered in } \\
\text { Detail }\end{array}$ \\
\hline $\begin{array}{l}\text { USDHHS clinical guidelines, the " } 5 \mathrm{~A}^{\prime} \mathrm{s} \text { ": ask, advise, ass } \\
\text { arrange }\end{array}$ & & & \\
\hline $\begin{array}{l}\text { USDHHS clinical guidelines, the " } 5 \mathrm{R}^{\prime} \mathrm{s} \text { ": relevance, risks } \\
\text { roadblocks, and repetition }\end{array}$ & & & \\
\hline Relapse prevention for smokers who quit & & & \\
\hline Proachaska and DiClemente's Stages of Change Theory & & & \\
\hline
\end{tabular}

22. In addition to teaching, do you practice as a physical therapist (perform direct patient care independent of student instruction)?

\begin{tabular}{|l|l|}
\hline & Yes \\
\hline & No \\
\hline
\end{tabular}


23. (Question only displayed if respondent answered yes to question 22 - do you practice as a physical therapist?): What setting best described your primary area of patient care? Select only one response:

\begin{tabular}{|l|l|}
\hline & Acute care hospital \\
\hline & Subacute rehab hospital (inpatient) \\
\hline & Health system or hospital-based outpatient facility \\
\hline & Patient's home - home care - pediatrics \\
\hline & Patient's home - home care - adults \\
\hline & School system (preschool, primary, secondary education) - pediatrics \\
\hline & College health \\
\hline & Health and wellness facility \\
\hline
\end{tabular}


24. Please indicate your level of agreement for each of the following statements:

\begin{tabular}{|l|l|l|l|l|l|}
\hline & $\begin{array}{l}\text { Strongly } \\
\text { Agree }\end{array}$ & Agree & $\begin{array}{l}\text { Neither } \\
\text { Agree Nor } \\
\text { Disagree }\end{array}$ & Disagree & $\begin{array}{l}\text { Strongly } \\
\text { Disagree }\end{array}$ \\
\hline All PT clients should be screened for tobacco use & & & & & \\
\hline $\begin{array}{l}\text { Physical therapists should provide tobacco } \\
\text { cessation counseling for clients who smoke }\end{array}$ & & & & & \\
\hline $\begin{array}{l}\text { Smoking has adverse effects on PT treatment } \\
\text { outcomes for cardiopulmonary conditions }\end{array}$ & & & & & \\
\hline $\begin{array}{l}\text { Smoking has adverse effects on PT treatment } \\
\text { outcomes for orthopedic conditions } \\
\text { (musculoskeletal impairments) }\end{array}$ & & & & & \\
\hline $\begin{array}{l}\text { Smoking has adverse effects on PT treatment } \\
\text { outcomes for wound management }\end{array}$ & & & & & \\
\hline $\begin{array}{l}\text { Training in tobacco screening should be a part of } \\
\text { entry-level PT education }\end{array}$ & & & & & \\
\hline $\begin{array}{l}\text { Training in tobacco cessation counseling should be } \\
\text { a part of entry-level PT education } \\
\text { intervention for smoking cessation }\end{array}$ & & & & & \\
\hline $\begin{array}{l}\text { Nicotine can be as addictive as heroin or cocaine } \\
\text { Brief counseling (5 minutes) can be an effective }\end{array}$ & & & & & \\
\hline
\end{tabular}

25. Have you ever received training in how to screen patients for tobacco use (smoking, smoking intensity, use of smokeless tobacco)?

\begin{tabular}{|l|l|}
\hline & Yes \\
\hline & No \\
\hline
\end{tabular}


26. (Question will display only if respondent indicates prior training in screening): Did this training include use of the USDHHS clinical guidelines, the " 5 A's": ask, advise, assess, assist, arrange?

\begin{tabular}{|l|l|}
\hline & Yes \\
\hline & No \\
\hline
\end{tabular}

27. Have you ever received training in how to screen patients for nicotine addiction?

\begin{tabular}{|l|l|}
\hline & Yes \\
\hline & No \\
\hline
\end{tabular}

28. The following is a list of potential challenges to tobacco cessation counseling by physical therapists. Please indicate your level of agreement with each statement:

\begin{tabular}{|l|l|l|l|l|l|}
\hline & $\begin{array}{l}\text { Strongly } \\
\text { Agree }\end{array}$ & Agree & $\begin{array}{l}\text { Neither } \\
\text { Agree Nor } \\
\text { Disagree }\end{array}$ & Disagree & $\begin{array}{l}\text { Strongly } \\
\text { Disagree }\end{array}$ \\
\hline $\begin{array}{l}\text { Patients who smoke are not interested in receiving } \\
\text { cessation advice from the physical therapist }\end{array}$ & & & & & \\
\hline $\begin{array}{l}\text { Physical therapists should NOT provide tobacco } \\
\text { cessation counseling BECAUSE this service is not } \\
\text { reimbursed by third-party payers }\end{array}$ & & & & & \\
\hline $\begin{array}{l}\text { Tobacco cessation counseling is an important } \\
\text { aspect of physical therapy patient education }\end{array}$ & & & & & \\
\hline $\begin{array}{l}\text { Physical therapists do not have enough time in } \\
\text { their schedule to make tobacco cessation } \\
\text { counseling a priority }\end{array}$ & & & & & \\
\hline
\end{tabular}

29. Thank you for your participation in this survey. Your thoughts and input are greatly appreciated. If you should have any further comments about the survey, or tobacco cessation counseling training for student physical therapists, please enter these below: 
Chapter 4 


\section{Tobacco Cessation Counseling Training for Student Physical Therapists: Feasibility and Preliminary Outcomes}

\section{Abstract:}

Background: Odds of smoking are higher among people with disabilities when compared with their non-disabled peers. Smoking impairs outcomes in all areas of physical therapist practice, yet most physical therapists do not provide tobacco cessation interventions. Lack of training has been linked to deficiencies in tobacco cessation counseling (TCC) within the clinical environment and may be facilitated by TCC education for entry-level students.

Objective: This pilot study assessed changes in knowledge, attitudes, and intentions of student physical therapists towards the application of evidence-based TCC guidelines, following participation in tailored TCC training.

Design: Pre-test/ post-test design

Methods: Students from two physical therapist educational programs ( $N=16$ and $\mathrm{N}=19$ ) participated in a 3 hour TCC workshop. Anonymous online surveys were used to assess knowledge, outcome expectations, opinions, and intention to implement TCC during subsequent practice. Frequencies and percentages were used to evaluate demographic data. Changes in outcomes were assessed using the Wilcoxon Signed Rank Test to compare median scores before and after training.

Results: Complete data sets were obtained from $75 \%$ and $89 \%$ of participants at Sites 1 and 2, respectively. Tailored training in evidence-based TCC guidelines yielded statistically significant gains in median scores for knowledge in both groups $(+5.0)$, self-efficacy $(+2.0$ and +3.5 points, Sites 1 and 2, respectively), perceived facilitators (+2.0 and +4.0, Sites 1 and 2, respectively) and intention to apply TCC in clinical settings (+1.0). Site 2 also showed statistically significant gains in perceived barriers (+6.0).

Limitations: Data may not be representative of all students or programs.

Conclusion: An evidence-based curricular model enhances the intention of student physical therapists to apply evidence-based TCC guidelines in subsequent clinical practice. 


\section{Introduction}

Smoking is the leading cause of preventable morbidity and mortality in the United States. ${ }^{1}$ Approximately $21.7 \%$ of the adult population currently smoke. ${ }^{2}$ In people with disabilities, smoking prevalence can be up to $10 \%$ higher. $^{2}$ Smoking cessation is a national health priority, as demonstrated by the Department of Health and Human Services document, "Healthy People 2020," 3 and the "Surgeon General's Call to Action to Improve the Health and Wellness of Persons with Disabilities." ${ }^{4}$ These recommendations are consistent with the professional obligations of physical therapists in promoting wellness, improving immediate health, and preventing secondary complications of chronic disease. ${ }^{5-7}$

Although physical therapists may not routinely offer tobacco cessation counseling (TCC), individualized, patient-centered education is a hallmark of effective rehabilitation and preventive management, and TCC guidelines are closely compatible with existing professional standards. ${ }^{7}$ Ongoing communication throughout an episode of care enables physical therapists to build a strong rapport and become familiar with unique aspects of each patient's life. These practice traits provide valuable opportunities for physical therapists to initiate and tailor tobacco cessation advice to best suit an individual's unique needs, resources, and personal goals. Surveys shows that patient education by physical therapists carries considerable impact: $83.8 \%$ of patients reported a change in knowledge and $86.5 \%$ reported behavioral changes as a result of education regarding self-management and improved physical function. ${ }^{8}$

Within physical therapy treatment environments, there are several factors that are conducive to TCC. The Joint Commission on Accreditation of Hospital Organizations (JCAHO) requires tobacco screening and counseling for all patients admitted with pneumonia, myocardial infarction, and congestive heart failure, ${ }^{9}$ diagnoses commonly encountered by physical therapists. Patients confronted by an episode of serious illness may be more motivated to quit, ${ }^{10}$ and may have recently experienced a period of forced abstinence due to smoking restrictions within hospitals and rehabilitation facilities. This break in habit provides an opportunity for physical therapists to encourage successful long-range cessation. ${ }^{11}$

Despite scientific advances and the availability of evidence-based interventions, deficits in the treatment of tobacco use persist. According to the United States Ambulatory Health Survey, $32 \%$ of patient charts were missing information regarding smoking status, and less than $20 \%$ of smokers received cessation assistance during their most recent medical visit. ${ }^{12}$ When compared with their non-disabled peers, people with disabilities are even less likely to be screened for tobacco use, ${ }^{1}$ or receive specific smoking cessation advice. ${ }^{13}$ Smoking leads to suboptimal physical therapy treatment outcomes in all four physical therapy practice areas: musculoskeletal, neuromuscular, cardiopulmonary/ vascular, and integumentary health, ${ }^{5}$ but only $17 \%$ of physical therapists routinely offer tobacco cessation advice during patient 
encounters. ${ }^{6}$ These statistics highlight the need for further research regarding effective application of evidence-based smoking interventions in physical therapist practice and education.

The Agency for Healthcare Research and Quality (AHRQ) developed evidence-based TCC parameters, commonly known as the " $5 \mathrm{~A}$ 's and $5 \mathrm{R}$ 's," which are widely recognized as the "gold standard" for smoking cessation treatment. ${ }^{14,15}$ Studies have shown that training increases implementation of the AHRQ guidelines, ${ }^{4,16-18}$ thereby increasing the likelihood that patients who smoke will receive effective treatment. ${ }^{12}$ Therefore, TCC training for all healthcare professionals, including physical therapists, is endorsed by The United States Public Health Service. ${ }^{4}$

Although many healthcare providers possess a desire to assist patients who smoke, many lack confidence in their ability to provide successful tobacco cessation interventions. ${ }^{19}$ Other barriers towards the application of TCC as a routine component of patient care include lack of available resources, uncertainties in professional roles and scope of practice, doubts regarding the efficacy of TCC, and anticipated patient resistance towards cessation advice. ${ }^{20}$ By addressing these factors, TCC education can ultimately improve knowledge, skill, and implementation of evidence-based guidelines. While training for practicing physical therapists will also be needed, student physical therapists represent the future of the profession, and a continued lack of training in entry-level curricula will only perpetuate the dearth of effective TCC within physical therapy treatment settings. ${ }^{4,12,16,17}$ Given these factors, there is a need for the design, implementation, and assessment of an evidence-based TCC training specifically tailored for student physical therapists.

Training during entry-level education allows opportunity for repetition and feedback within the classroom setting, and fosters the development of skills and knowledge required in the application of TCC during subsequent clinical practice. In research involving pharmacy students, 94\% ranked their TCC abilities as good, very good, or excellent following tailored education, and $97 \%$ believed the training would increase the quality of their patient interactions. ${ }^{4}$ Another study using patient survey data showed that chiropractic interns were eight times more likely to provide cessation advice after completing TCC training. ${ }^{17}$ Among dentists and dental hygienists, practitioners trained as students were more than twice as likely to provide counseling when compared to colleagues lacking entry-level education. ${ }^{21}$ Approximately $40 \%$ of patients who are counseled will make a cessation attempt, ${ }^{22}$ and chances of success are doubled when patients receive TCC from more than one type of provider, ${ }^{23}$ further demonstrating the importance of TCC by physical therapists as part of an interdisciplinary approach.

Barriers to TCC training in the healthcare professions include the absence of a uniform curriculum, lack of required competencies for professional practice and education, and 
perceived lack of value in addressing smoking cessation as a professional priority. ${ }^{24}$ According to a prior study by our group, TCC training is absent in approximately $60 \%$ of entry-level physical therapist programs in the United States and Puerto Rico (unpublished data). Factors positively associated with curricular inclusion were faculty familiarity with evidence-based TCC guidelines, prior training in TCC, self-rated knowledge and skill in applying guidelines, a belief that brief TCC can be effective, and favorable opinions towards TCC as a component of physical therapy practice. While there are many factors to consider regarding implementation and assessment, it should be recognized that smoking cessation efforts reflect the educational mission of the American Physical Therapy Association (APTA) and are congruent with elements of health promotion and wellness advocated by the Guide to Physical Therapist Practice, ${ }^{25}$ the Normative Model for Physical Therapy Education, ${ }^{26}$ professional core values, ${ }^{27}$ the Clinical Performance Instrument, ${ }^{28}$ and the Commission on Accreditation in Physical Therapy Education (CAPTE) criteria. ${ }^{29}$ Furthermore, TCC training in entry-level physical therapist education is an important issue because greater involvement within the profession has the potential to increase the likelihood that people with disabilities, as an at-risk population, will receive evidence-based interventions to reduce smoking prevalence and smoking-related impact on morbidity, mortality, and diminished quality of life. ${ }^{27}$ Therefore, the purpose of this study was to determine if a TCC workshop, specially designed for physical therapy students, could be effectively delivered within a standard educational curriculum, and if participation in the workshop had a positive impact on students' knowledge, beliefs, and intention to employ TCC in their future professional practice.

\section{Study Design}

This study used a pre-test/ post-test, single group design without control group. The study was repeated at two sites in order to assess reliability, and was approved by the Institutional Review Boards at each participating university. Pre-tests and post-tests were administered using an anonymous, online format (Qualtrics Online Survey Platform, Provo, Utah).

\section{Participants and Recruitment}

Two universities agreed to allow pilot testing within their entry-level doctor of physical therapy educational programs. Recruitment of students at each participating university occurred via electronic mail, flyers, and brief face-to-face meetings describing the purpose of the study, inclusion and exclusion criteria, and benefits/ risks of participation. Participation was voluntary, and was not linked to the students' grades or academic standing. A $\$ 25.00$ gift card and certificate of completion were presented at the end of the workshop in appreciation of participants' time and effort. 


\section{Educational Intervention}

The pilot curriculum designed for this study was 3 hours long: 2 hours of didactic material followed by 1 hour of case-based discussions and role-playing exercises. Design of this pilot training curriculum centered on evidence-based AHRQ TCC parameters, i.e. - the " 5 A's and 5 R's." ${ }^{30}$ The "5 A's: Ask, Advise, Assess, Assist and Arrange," refer to recommendations used to promote cessation in patients receptive towards changing their smoking behavior within the next 30 days. The "5 R's: Relevance, Risks, Rewards, Roadblocks, Repeat," refer to recommendations that practitioners can employ to encourage further consideration of cessation in patients who are unable or unwilling to commit to quitting within the near future. These AHRQ TCC guidelines have been effectively employed in dental education, ${ }^{31,32}$ physician education, ${ }^{33,34}$ pharmacy education, ${ }^{16,35}$ chiropractic education, ${ }^{18}$ and nursing education. ${ }^{23}$

In applying the " $5 \mathrm{~A}^{\prime} \mathrm{s}$ " and " $5 \mathrm{R}$ 's" to entry-level physical therapist education, the first step was to define training objectives. ${ }^{31}$ Objectives were based on the rationale for TCC as a component of physical therapist practice, ${ }^{5}$ and skills required to successfully implement AHRQ TCC Guidelines during typical patient encounters. Prior to the design of this pilot training program, educational needs were assessed using a cross-sectional survey of accredited physical therapist educational programs throughout the United States. This survey was performed by our group in order to obtain preliminary data (unpublished). Additional data were obtained through a literature review of content, objectives, and educational outcomes for TCC training in other health professions. This preliminary information was used to develop a curricular blueprint, specifically designed for entry-level physical therapists. Educational content included epidemiologic data regarding tobacco use $\mathrm{e}^{4,36,37}$ and high risk groups with the most difficulty in achieving successful cessation, ${ }^{38,39}$ as well the scientific rationale for professional involvement in TCC, 5,38 the consequences of smoking, the benefits of quitting, and the impact of tobacco use on all areas of physical therapy practice. ${ }^{5,40}$ Participants were instructed in how to obtain a smoking history, screen for nicotine addiction, assist patients in quitting, and identify community resources for patient referral. ${ }^{30,41}$

In order to encourage active student engagement, didactic content was augmented by casebased role playing exercises which enabled performance feedback by peers and the faculty moderator. ${ }^{34}$ Active student engagement provided data for formative assessment, allowing the students and instructor to focus on material that required further clarification or additional skills practice during training. ${ }^{42}$ Each case study included patient characteristics described by the Transtheoretical Model of Behavior, which defines readiness to change through use of 5 stages. ${ }^{43}$ Skills practice focused on counseling in the pre-contemplation/ contemplation, preparation and action stages, although factors related to relapse and long-term abstinence during maintenance phase were also discussed. For each case, workshop participants assumed 
the role of patient, practitioner, or observer. Observers used a checklist based on criteria deemed essential for competent application of the AHRQ evidence-based TCC guidelines. Specific to TCC skills, role playing has also been shown to increase provider performance by promoting self-reflection and improved self-efficacy. ${ }^{44}$ (See Table 1 for a list of training objectives and instructional methods).

Based on research assessing the TCC behaviors of dental hygiene students and successful training of family medicine physicians and staff, student physical therapists were provided with a handbook, treatment algorithm, patient education guidelines, and a guide to assessing patient readiness to change. ${ }^{45}$ Workshop participants were also given an objective screening instrument for nicotine addiction and a laminated pocket reference outlining the AHRQ TCC guidelines.

\section{Outcome Assessment}

Results of training were assessed using several methods, as shown in Table 1. An anonymous online survey was used to assess change in designated learning objectives, including whether participation increased knowledge, improved self-efficacy, and resulted in favorable opinions and intention towards the provision of TCC during clinical practice. Most responses were structured using a 5 point Likert-type scale (strongly agree, agree, neither agree nor disagree, disagree, strongly disagree). Student opinions and attitudes were assessed using items incorporating common barriers and facilitators described by prior research, including beliefs regarding the efficacy of TCC, time constraints within the patient care settings, and perceptions regarding scope of practice and professional obligations. ${ }^{47,18}$ The survey was also used to gather demographic information including respondents' age, sex, race/ethnicity, tobacco use, and current year of study in the physical therapy program.

In order to ensure a coherent relationship between the survey instrument and underlying behavioral theories, construct validity was examined using existing literature and expert consultation. ${ }^{48}$ The assessment instrument was based on the Theory of Reasoned Action, ${ }^{49}$ in which knowledge, attitudes, and intention are viewed as proximal determinants of behavior. ${ }^{50}$ The scale to measure respondents' intention to apply TCC in a clinical setting was based on the Transtheoretical Model, using the Stages of Change, which can be applied to clinician behaviors as well as patient actions. ${ }^{51}$ Similar methods have been employed in examining the impact of tobacco cessation training on other health professions students. ${ }^{18,34,52}$

According to The Theory of Reasoned Action, behavioral intentions are a product of outcome expectations, or the anticipated results of the prescribed action, as well as the estimated likelihood of desired results based on perceived barriers, facilitators, and personal control (selfefficacy). ${ }^{53}$ To best reflect components of the theory, scoring for the pre-test/ post-test was 
based on 6 subscales: knowledge, outcome expectations, anticipated barriers, anticipated facilitators, self-efficacy, and intention to utilize the evidence-based guidelines within clinical practice. Items reflecting subscales were reviewed by an educational psychologist with expertise in theory-based assessment.

Content validity, i.e. - how well items on the test reflect the intended subject material, was examined using data regarding the relevance of TCC to physical therapy outcomes and practice. ${ }^{5}$ Prior to use, the survey was reviewed by three content experts in cardiopulmonary physical therapy, a content expert in patient education and substance use, a biostatistician, and three physical therapy faculty members, including a program chair and director of research. Modifications included edits for wording consistent with the Guide to Physical Therapist Practice, ${ }^{25}$ item organization to promote complete responses, and the inclusion of open-ended follow-up questions.

Prior to research, the survey was also given to a small sample of current physical therapist students $(\mathrm{N}=5)$, recent graduates $(\mathrm{N}=3)$, and practicing clinicians $(\mathrm{N}=2)$. Based on feedback, minor adjustments were made to descriptors for race/ ethnicity. In addition, items concerning clinical guidelines were edited to include a full listing of the " 5 A's: Ask, Advise, Assess, Assist and Arrange" as well as the " 5 R's: Relevance, Risks, Rewards, Roadblocks, and Repetition."

Program assessment also included observable behaviors, ${ }^{54}$ i.e. - role play activities and checklists used to provide structured feedback from the student's peers and faculty mentor. At the end of the workshop, participants were asked to complete a course evaluation based on research which showed that learners' satisfaction with training can also have an impact on implementation. ${ }^{55}$ The course evaluation requested student input on content, organization of materials, teaching methods, and quality of instruction.

\section{Data Analysis}

Data analysis centered on the initial research question: does tailored TCC training for entrylevel physical therapist students increase the likelihood of the application of evidence-based guidelines in professional practice? Goals were to assess changes in knowledge, attitudes, and intentions to apply TCC guidelines following workshop participation. Intention was used as a measure of subsequent clinical behavior. ${ }^{49}$

Due to relatively small sample sizes, the intervention was repeated twice, at different programs, in order to assess reliability. Demographics and survey scores were analyzed using frequency counts, percentages, means, medians, standard deviations (SD) and interquartile range (IQR). Due to the ordinal nature of the pre-test/ post-test scores, comparison of training results (i.e. - change in the median comprehensive scores for knowledge, perceived barriers, perceived facilitators, outcomes expectations, and intention) at each site was accomplished 
using the Wilcoxon Signed Rank Test. Comparison of baseline scores for students at Site 1 versus Site 2 was accomplished using the Wilcoxon Two-Sample Test. A comparison of the change in scores following training at each individual site was also performed using a nonparametric one-way analysis of variance (Mann-Whitney $U$ test). Due to limited individual sample sizes and multiple pairwise comparisons, statistical significance for each of these procedures was defined as $p \leq 0.01$, using the Bonferroni correction. ${ }^{56}$ Analyses were completed using SPSS software, Version 16 (IBM Corporation, Armonk, NY) and SAS software, Version 9.3 (SAS Institute, Cary, NC).

\section{Results}

The first workshop was held at an entry-level doctor of physical therapy program at a public university in the Middle Atlantic region. ${ }^{29}$ This program is on a smoke-free campus, in a nontobacco growing state, and has a total of 180 students. The TCC pilot training at Site 1 involved 16 participants: 12 completed both pre-test and post-test surveys. Average age of participants was 26 years (SD 1.24, range 22-27), 85\% ( $N=7$ ) were male, and 83\% were student members of the American Physical Therapy Association (APTA). By self-report, $100 \%$ of participants were non-smokers, although $17 \%(\mathrm{~N}=2)$ had previously smoked. Students in their first year of physical therapist training accounted for $67 \%$ of the sample $(\mathrm{N}=8)$, and the remaining $33 \%(\mathrm{~N}=4)$ were in year 2 . None of the participants reported any prior training in TCC techniques, or were previously familiar with the AHRQ TCC guidelines, although $58 \%(\mathrm{~N}=7)$ reported prior education regarding effects of smoking on cardiovascular health, $33 \%(\mathrm{~N}=4)$ reported training on effects of smoking on musculoskeletal and neuromuscular health, and $42 \%(\mathrm{~N}=5)$ reported training on effects of smoking on integumentary health/ wound healing. (See Table 2 for a summary of descriptive statistics).

The second workshop was held at an entry-level doctor of physical therapy program at a public university within the South Atlantic region. ${ }^{29}$ This program has a total 105 students and is part of a smoke-free campus in a tobacco growing state. The TCC pilot training program at Site 2 involved 19 participants, 17 completed both pre-test and post-test surveys. The average age was 23 years (SD 1.24, range $22-27), 88 \%$ of were female $(N=15)$, all were completing their first year, and $29 \%$ were student members of the APTA. All of the pre-test respondents were nonsmokers, although $12 \%(\mathrm{~N}=2)$ had previously smoked. In terms of prior training, $12 \%(\mathrm{~N}=2)$ reported previous education in tobacco cessation, and one had some prior knowledge regarding the AHRQ clinical guidelines. For other related topics, $29 \%$ of the sample $(N=5)$ reported prior training on the effects of smoking on cardiovascular health, and $12 \%(\mathrm{~N}=2)$ reported prior training on the effects of smoking on musculoskeletal, neuromuscular, and integumentary health. (See Table 2 for a summary of descriptive statistics). 
A baseline comparison showed the initial scores for participants at Site 1 and 2 were equivalent for outcome expectations and perceived facilitators $(p<0.01)$. However, scores at baseline for all other categories, including knowledge, perceived barriers, self-efficacy, and intention were different for participants at Site 1 and Site 2 (See Table 3). Therefore, results of training at each site were analyzed separately, rather than combining the samples.

Following training, participants at both sites demonstrated statistically significant gains in all categories, with the exception of Site 1 where a 4.5 point improvement in perceived barriers did not meet the selected criterion for significance $(p=0.03)$. Participants at Site 2 showed a 6.0 point gain in score for perceived barriers $(p<0.01)$. (Please note that the grading scale for perceived barriers is reversed - i.e. - higher scores represent a lower number of perceived barriers to TCC). The largest effect was a 13.0 gain in self-efficacy at Site 2, and a 6.5 point gain at Site $1(p<0.01)$. Participants at both sites displayed a 5.0 gain in median score for knowledge; participants at Site 1 exhibited a 3.5 point gain in the median score for outcomes expectations, with a 2.0 point gain observed at Site $2(p<0.01)$. The median score for perceived facilitators rose by 2.0 points for participants at Site 1 and 4.0 points at Site $2(p<0.01)$ (See Table 4 and Figure 1 for a comparison of training results.)

A review of the checklists used to provide feedback during case studies discussion and skills practice showed competency in all areas outlined in the AHRQ TCC guidelines. The majority of participants indicated that counseling was most challenging when the patient was resistant to change, and easiest when the patient had already decided to quit and was seeking additional resources.

Participant feedback reflected a high level of satisfaction with training (mean rating 5/5). Participants were unanimous in indicating a belief that the content included in the TCC training would help improve their practice, and that TCC was clearly related to other topics covered during their physical therapist education. Participants' suggestions for future improvements included video demonstration of counseling techniques for patients with varied levels of readiness for change, and a greater number of case discussions interspersed with didactic content.

\section{Discussion}

This study demonstrated the positive impact of a tailored educational intervention in improving knowledge, outcome expectations, attitudes, and intentions of entry-level physical therapist students towards the application of evidence-based TCC guidelines in future clinical practice. Results of this study are similar to results obtained when researchers examined the impact of TCC training for entry-level baccalaureate dental hygienists, ${ }^{57}$ first year medical students, ${ }^{33}$ and pharmacy students. ${ }^{16}$ In dentists and hygienists trained as students, follow-up studies 
investigating the long-term results of training on clinical behaviors found a $23 \%$ increase in provision of TCC, and a $12 \%$ increase in patient education regarding the consequences of tobacco use. ${ }^{58}$ Further research is required to determine whether comparable long-term results can be obtained as a result of TCC training in entry-level student physical therapists. Factors to consider include recall and retention, as well as the ability to successfully negotiate barriers to TCC in the clinical environment. The impact of TCC delivered by physical therapists trained as students will also require further investigation to determine whether counseling has a positive effect on patient behavior. In one study, patients treated by dental students who had been trained in brief TCC demonstrated a $20 \%$ quit rate. ${ }^{59}$ In a second study, TCC delivery by dental students yielded a $22 \%$ quit rate, with an additional $14 \%$ of patients reducing the amount of tobacco use following TCC as a component of routine dental care. ${ }^{60}$ Given the results obtained in the present study showing gains in knowledge, attitude, and intentions toward employing TCC guidelines in clinical practice, it is likely that TCC counseling by physical therapists trained as students can have comparable impact on patient behavior.

Based on a relatively small investment of time and resources, TCC training for entry-level student physical therapists is feasible and effective in fostering knowledge, outcome expectations, self-efficacy, and other characteristics known to facilitate TCC behaviors of health care practitioners. Student physical therapists expressed satisfaction with the training experience, along with increased intention to apply evidence-based TCC guidelines in subsequent clinical practice. While evidence is strengthened by the application of this pilot workshop in two different samples, certain limitations should be noted. There were a relatively small number of participants, and due to scheduling conflicts, only first and second year doctor of physical therapy students were enrolled. Research has shown that opinions of dental students regarding their professional role in TCC varied by year of training. ${ }^{61}$ Therefore, future assessments may wish to include third-year physical therapist students and/ or an examination of the role of TCC training as a component of student clinical experiences. To the extent that content in TCC may be time-sensitive, curricula for physical therapist students will require revision as new information becomes available.

Although the number of students at each institution was small, both samples reflect demographics described in aggregate program data provided by CAPTE. ${ }^{29}$ However, further testing should include private universities with larger class sizes in other region of the country in order to enhance external validity. Also, since it is important to include opportunities for students to apply TCC techniques when working with patients in conjunction with the supervision and feedback of experienced clinical mentors, educators may also wish to consider the use of community-based activities such as health fairs and school-based group interventions aimed at high-risk youth as additional venues for continued student practice. ${ }^{15}$ 
Research is also needed to assess curricular design and implementation of tailored TCC training for experienced practitioners. It is likely that the educational needs of practicing physical therapists differ from the needs of student physical therapists. Therefore, preliminary investigations should assess the beliefs of practicing physical therapists towards professional roles and use of evidence-based TCC guidelines within the current scope of practice. Research should also examine other factors that may potentially influence the intention to integrate evidence-based TCC as a routine component of patient care. As the role of physical therapists in TCC continues to expand, further studies should explore potential challenges and solutions in the practical application of TCC within physical therapy patient care settings. In addition to patient quit rates, studies are needed to evaluate the impact of smoking cessation on healing rates, strength, function, and susceptibility to future injury among physical therapy clientele.

In summary, TCC training is consistent with professional values espoused by physical therapists. By increasing access to effective counseling, the profession can promote autonomy and function in people with disabilities who use tobacco. Efforts to promote health and wellness, as well as optimal rehabilitative outcomes, must include the integration of evidence-based TCC guidelines in clinical practice and education. 


\section{References}

1. Armour B, Campbell, V., Crews, J., Malarcher, A., Maurice, E., Richard, R. State-Level Prevalence of Cigarette Smoking and Treatment Advice, by Disability Status, United States, 2004. Preventing Chronic Disease: Public Health Research, Practice and Policy. 2007;4(4):1-11.

2. Sheffer C, Barone, C., Anders, M. Training Health Care Providers in the Treatment of Tobacco Use and Dependence: Pre- and Post-Training Results. Journal of Evaluation in Clinical Practice. 2009;15:607-613.

3. United States Department of Health and Human Services. Healthy People 2020. 2013; http://www.healthypeople.gov/2020/default.aspx. Accessed 4/4/13, 2013.

4. United States Department of Health and Human Services. The Surgeon General's Call to Action to Improve the Health and Wellness of Persons with Disabilities. Washington, DC2005.

5. Pignataro R, Ohtake P, Swisher A, Dino G. The Role of Physical Therapists in Smoking Cessation: Opportunities for Improving Treatment Outcomes. Physical Therapy. 2012;92:757-766.

6. Rea B, Marshak, H., Neish, C., Davis, N. The Role of Health Promotion in Physical Therapy in California, New York and Tennessee. Physical Therapy. 2004;84(6):510-523.

7. Bodner M, Dean, E. Advice as a Smoking Cessation Strategy: A Systematic Review and Implications for Physical Therapists. Physiotherapy Theory and Practice. 2009;25(56):369-407.

8. Jensen G, Gwyer J, Shepard K, Hack L. Expert Practice in Physical Therapy. Physical Therapy. 2000;80:28-43.

9. Tremblay M, Cournoyer, D., O'Loughlin, J. Do the Correlates of Smoking Cessation Counseling Differ across Health Professional Groups? Nicotine \& Tobacco Research. 2009;11(11):1330-1338.

10. Gahimer J, Domholdt E. Amount of Patient Education in Physical Therapy Practice and Perceived Effects. Physical Therapy. 1996;76:1089-1096.

11. Schroeder S. What to Do with a Patient Who Smokes. Journal of the American Medical Association. 2005;294(4):482-487.

12. Mitra M, Chung, M., Wilber, N., Walker, D. Smoking Status and Quality of Life: A Longitudinal Study Among Adults with Disabilities. American Journal of Preventive Medicine. 2004;27(3):258-260.

13. Rimmer J, Rowland, J. Health Promotion for People with Disabilities: Implications for Empowering the Persona and Promoting Disability-Friendly Environments. American Journal of Lifestyle Medicine. 2008:1-12.

14. Prochaska J, Fromont S, Hudmon K, Cataldo J. Designing for Dissemination: Development of an Evidence-Based Tobacco treatment Curriculum for Psychiatry Training Programs. Journal of the American Psychiatric Nurses Association. 2009;15(1):24-31.

15. Geller A, Zapka, J., Brooks, K., Dube, C., Powers, C., Rigotti, N., O'Donnell, J., Ockene, J. Tobacco Control Competencies for US Medical Students. American Journal of Public Health. 2005;95(6):950-955. 
16. Corelli R, Kroon, L., Chung, E., Sakamoto, L., Gundersen, B., Fenlon, C., Hudmon, K. Statewide Evaluation of a Tobacco Cessation Curriculum for Pharamacy Students. Preventive Medicine. 2005;40:888-895.

17. Bernstein S, Boudreax E, Cabral L, et al. Efficacy of a Brief Intervention to Improve Emergency Physicians' Smoking Cessation Counseling Skills, Knowledge, and Attitudes. Substance Abuse. 2009;30:158-181.

18. Evans M, Hawk C, Strasser S. An Educational Campaign to Increase Chiropractic Intern Advising Roles on Patient Smoking Cessation. Chiropractice and Osteopathy. 2006;14(24):1-9.

19. Guilmette T, Motta, S., Shadel, W., Mukand, J., Niaura, R. Promoting Smoking Cessation in the Rehabilitation Setting. American Journal of Physical Medicine and Rehabilitation. 2001;80(8):560-562.

20. An L, Foldes, S., Alesci, N., Bluh, J., Bland, P., Davern, M., Schillo, B., Ahluwalia, J., Manley, M. The Impact of Smoking-Cessation Intervention by Multiple Health Professionals. American Journal of Preventive Medicine. 2008;34(1):54-60.

21. Pedersen L, Blumenthal D, Dever A, McGrady G. A Web-Based Smoking Cessation and Prevention Curriculum for Medical Students: Why, How, What and What Next. Drug and Alcohol Review. 2006;25:39-47.

22. Victoroff K, Dunkulich-Huryn T, Haque S. Attitudes of Incoming Dental Students Toward Tobacco Cessation Promotion in the Dental Setting. Journal of Dental Education. 2004;68(5):563-568.

23. Matten P, Morrison, V., Rutledge, S., Chen, T., Chung, E., Wong, S. Evaluation of Tobacco Cessation Classes Aimed at Hospital Staff Nurses. Oncology Nursing Forum.

2011;38(1):67-73.

24. Barker G, Williams K, Taylor T, Barker B. Practice Behaviors of Alumni Trained as Students in Tobacco Use Cessation Interventions. The Journal of Dental Hygeine. 2001;75(11):165-169.

25. American Physical Therapy Association. Guide to Physical Therapist Practice: Second Edition2003.

26. American Physical Therapy Association. A Normative Model of Physical Therapist Professional Education: Version 2004. Alexandira, Virginia2004.

27. American Physical Therapy Association. Professionalism in Physical Therapy: Core Values. Vol BOD P05-04-02-032003.

28. American Physical Therapy Association. Physical Therapist Clinical Performance Instrument. Alexandria, VA2006.

29. Commission on Accreditation in Physical Therapy Education. Accredited Physical Therapist Education Programs 2010; http://apps.apta.org/Custom/wscapte.cfm?cfml=accreditedschools/Index.cfm\&cfmltitle =Accredited\%20Schools\&process=3\&type=PT\&navID=10737421958. Accessed November 18, 2011, 2011.

30. Fiore M, Bailey W, Cohen S. Treating Tobacco Use and Dependence: Quick Reference Guide for Clinicians. In: Services USDoHaH, ed. Rockville, Maryland: Public Health Service; 2000. 
31. Davis J, Ramseier, C., Mattheos, N., Schoonheim-Klein, M., Compton, S., Al-Hazmi, N., Polychronopoulou, A., Suvan, J., Antohe, M., Forna, D., Radley, N. Education of Tobacco Use Prevention and Cessation for Dental Professionals - A Paradigm Shift. International Dental Journal. 2010;60:60-72.

32. Davis J, Stockdale, M., Cropper, M. Evaluation of a Comprehensive Tobacco Cessation Curriculum for Dental Hygeine Programs. Journal of Dental Education. 2010;74(5):472479.

33. Brown R, Pfeifer J, Gjerde C, Seibert C, Haq C. Teaching Patient-Centered Tobacco Intervention to First-Year Medical Students. Journal of General Internal Medicine. 2004;19:534-539.

34. Cornuz J, Humair, J., Seematter, L., Stolanov, R., van Melle, G., Stadler, H., Pecoud, A. Efficacy of Resident Training in Smoking Cessation: A Randomized, Controlled Trial of a Program Based on Application of Behavioral Theory and Practice with Standardized Patients. Annals of Internal Medicine. 2002;136:429-437.

35. Hudmon K, Prokhorov, A., Corelli, R. Tobacco Cessation Counseling: Pharmacists' Opinions and Practices. Patient Education and Counseling. 2006;61:152-160.

36. Adler N, Rehkopf D. US Disparities in Health: Descriptions, Causes and Mechanisms. Annual Reviews in Public Health. 2008;29:235-252.

37. Becker $\mathrm{H}$, Brown A. Disparities in Smoking Behaviors Among Those With and Without Disabilities From 2001 to 2005. Public Health Nursing 2008;25(6):526-535.

38. Jones A, Lollar, D. Relationship Bewteen Physical Disabilities or Long-Term Health Problems and Health Risk Behaviors or Conditions Among US High School Students. Journal of School Health. 2008;78(5):252-257.

39. Centers for Disease Control and Prevention. Health Disparities Persist Among People with Disabilities2007.

40. Hudmon K, Corelli, R., Chung, E., Gundersen, B., Kroon, L., Sakamoto, L., Hemberger, K., Fenlon, C., Prokhorov, A. Development and Implementation of a Tobacco Cessation Training Program for Students in the Health Professions. Journal of Cancer Education. 2003;18:142-149.

41. Fiore $M$, Croyle R, Curry S, et al. Preventing 3 Million Premature Deaths and Helping 5 Million Smokers Quit: A National Action Plan for Tobacco Cessation. American Journal of Public Health. 2004;94(2):205-210.

42. Scal P, Hennrikus D, Ehrlich L, Ireland M, Borowsky I. Preparing Residents to Counsel About Smoking. Clinical Pediatrics. 2004;43(703-708).

43. Prochaska J, DiClemente C. Stages and Processes of Self-Change of Smoking: Toward an Integrative Model of Change. Journal of Consulting and Clinical Psychology. 1983;51(3):390-395.

44. Hayward L, Cairns M. Physical Therapist Students' Perceptions of and Strategic Approaches to Case-Based Instruction: Suggestions for Curriculum Design. Journal of Physical Therapy Education. 1998;12(2):33-42.

45. Johns T, Lawrence E, Martini L, Dunn G, Thompson Z, Zwygart K. Smoking Cessation in Family Medicine: Effects of an Area Health Education Center Training Program. Journal of Graduate Medical Education. 2010:283-287. 
46. Brown D, Wise H. Service Learning to Facilitate ATtainment of Professional Practice Expectations in Prevention and Health Promotion. Journal of Physical Therapy Education. 2007;21(3):59-64.

47. Jenkins K, Ahijevyk K. Nursing Students' Beliefs About Smoking, Their Own Smoking Behaviors, and Use of Professional Tobacco Treatment Intervention. Applied Nursing Research. 2003;16(3):164-172.

48. Leong S, Lewis, P., Curry, W., Gingrich, D. Tobacco World: Evaluation of a Tobacco Cessation Training Program for Third-Year Medical Students. Academic Medicine. 2008;83(10):S25-S28.

49. Ajzen I, Madden T. Prediction of Goal-Directed Behavior: Attitudes, Intentions, and Perceived Behavioral Control. Journal of Experimental Social Psychology. 1986;22:453474.

50. Ajzen I. The Theory of Planned Behavior. Organizational Behavior and Human Decision Processes. 1991;50:179-211.

51. Green J. Taregting, Tailoring and Stages of Change. IUHPE - Promotion and Education. 2001;VIII:4-7.

52. Barta S, Stacy R. The Effects of a Theory-Based Training Program on Nurses' Self-Efficacy and Behavior for Smoking Cessation Counseling. The Journal of Continuing Education in Nursing. 2005;36(3):117-123.

53. Ajzen I, Fishbein M. Understanding Attitudes and Predicting Social Change. Englewood Cliffs, New Jersey: Prentice Hall; 1980.

54. American Educational Research Association, American Psychological Association, National Council on Measurement in Education. Standards for Educational and Psychological Testing. Washington, DC: American Psychological Association; 1985.

55. Richmond R, Zwar N, Taylor R, Hunnisett J, Hyslop F. Teaching About Tobacco in Medical Schools: A Worldwide Study. Drug and Alcohol Review. 2009;28:484-497.

56. Agresti A. An Introduction to Categorical Data Analysis. Hoboken, New Jersey: John Wiley \& Sons; 2007.

57. Boyd L, Fun K, Madden T. Initiating Tobacco Curricula in Dental Hygeine Education. Substance Abuse. 2006;27:53-60.

58. Gelsky S. Impact of a Dental/ Dental Hygeine Tobacco-Use Cessation Curriculum on Practice. Journal of Dental Education. 2002;66(9):1074-1078.

59. Schoonheim-Klein M, Gresnigt $C$, van der Velden U. Influence of Dental Education in Motivational Interviewing on the Efficacy of Interventions for Smoking Cessation. European Journal of Dental Education. 2012:106.

60. Shilby O. Effect of Tobacco Counseling by Dental Students on Patient Quitting Rate. Journal of Dental Education. 2009;74(2):140-148.

61. Cannick G, Horowitz A, Reed S, Drury T, Day T. Opinions of South Carolina Dental Students Toward Tobacco Use Interventions. Journal of Public Health Dentistry. 2006;66(1):44-48. 
Table 1 - Learning Objectives, Teaching Methods and Assessment Measures

\begin{tabular}{|l|l|l|}
\hline \multicolumn{2}{|l|}{$\begin{array}{l}\text { Upon completion of this learning module, participants will be able to } \\
\text { meet the following objectives: }\end{array}$} & METHOD \\
\hline OBJECTIVE & $\begin{array}{l}\text { Lecture, visual aids, workbook, } \\
\text { reading assignment, class } \\
\text { evidence-based tobacco-cessation } \\
\text { counseling as a component of } \\
\text { physical therapy practice }\end{array}$ & Survey, class discussion \\
\hline $\begin{array}{l}\text { Identify and apply techniques } \\
\text { designed to screen physical } \\
\text { therapy patients for tobacco use } \\
\text { and nicotine addiction. }\end{array}$ & $\begin{array}{l}\text { Lecture, visual aids (laminated } \\
\text { treatment guide, workbook), } \\
\text { written resources - Fagerstrom's } \\
\text { Questionnaire, case discussion/ } \\
\text { role play }\end{array}$ & $\begin{array}{l}\text { Survey } \\
\text { Case based role play }\end{array}$ \\
\hline $\begin{array}{l}\text { Assess a patient's readiness for } \\
\text { tobacco cessation using the } \\
\text { Stages of Change. }\end{array}$ & $\begin{array}{l}\text { Lecture, visual aids, written } \\
\text { resources - Stages of Change } \\
\text { Questionnaire, case discussion/ } \\
\text { role play }\end{array}$ & $\begin{array}{l}\text { Survey } \\
\text { Case based role play } \\
\text { (observation) }\end{array}$ \\
\hline $\begin{array}{l}\text { Apply the AHRQ/ USDHHS clinical } \\
\text { practice guidelines for tobacco } \\
\text { cessation counseling, based on } \\
\text { Stages of Change. }\end{array}$ & $\begin{array}{l}\text { Lecture, visual aids (laminated } \\
\text { treatment guide, workbook, } \\
\text { patient education materials, case } \\
\text { discussion/ role play }\end{array}$ & $\begin{array}{l}\text { Survey } \\
\text { Case based role play } \\
\text { (observation) }\end{array}$ \\
\hline
\end{tabular}


Table 2-Descriptive statistics

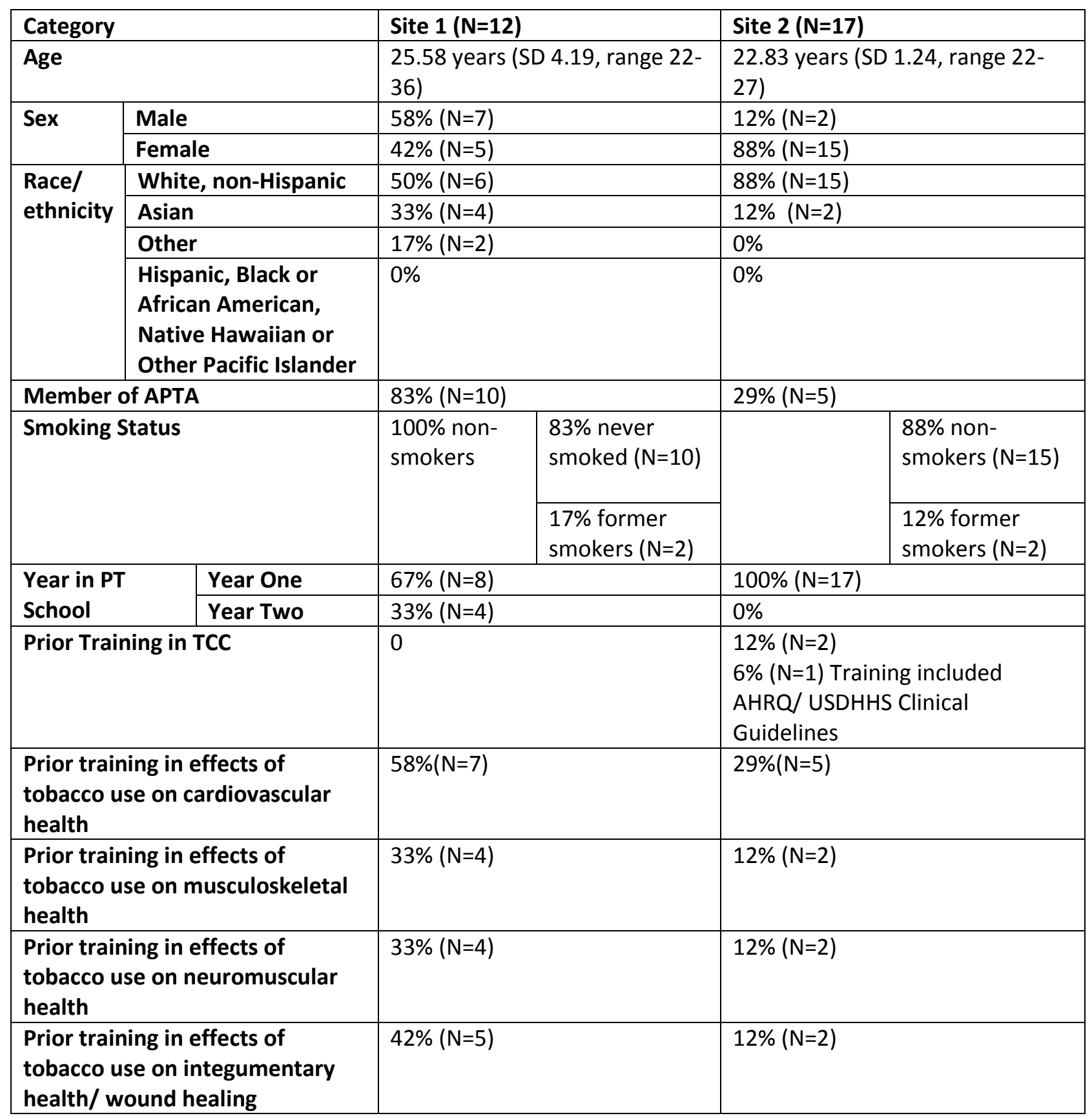


Table $\mathbf{3}$ - Scores Comparison, Sites 1 and 2

\begin{tabular}{|l|l|l|l|l|l|}
\hline \multirow{2}{*}{ Category } & \multicolumn{2}{|l|}{$\begin{array}{l}\text { Pre-Test } \\
\text { Median Score }\end{array}$} & \multirow{2}{*}{$\begin{array}{l}\text { Between Group } \\
\text { Comparison - }\end{array}$} & \multicolumn{2}{l|}{$\begin{array}{l}\text { Post-Test } \\
\text { Median Score }\end{array}$} \\
\cline { 2 - 3 } & Site 1 & Site 2 & Pre-Test Scores & Site 1 & Site 2 \\
\hline Knowledge & 6.0 & 6.0 & $\mathrm{P}=0.98$ & 10.5 & 12.0 \\
\hline $\begin{array}{l}\text { Outcome } \\
\text { Expectations }\end{array}$ & 6.0 & 8.0 & $\mathrm{P}<0.01^{*}$ & 9.0 & 10.0 \\
\hline Perceived Barriers & 13.0 & 12.0 & $\mathrm{P}=0.07$ & 18.0 & 18.0 \\
\hline $\begin{array}{l}\text { Perceived } \\
\text { Facilitators }\end{array}$ & 12.0 & 10.0 & $\mathrm{P}<0.01^{*}$ & 14.0 & 15.0 \\
\hline Self-Efficacy & 26.0 & 25.0 & $\mathrm{P}=0.38$ & 32.0 & 38.0 \\
\hline Intention & 3.0 & 3.0 & $\mathrm{P}=0.80$ & 4.0 & 4.0 \\
\hline
\end{tabular}

¥Wilcoxon Mann-Whitney $U$ test

*results statistically significant $p \leq 0.01$ 
Table 4 - Results of Training

\begin{tabular}{|l|l|l|l|l|l|l|l|}
\hline Category & \multicolumn{3}{|c|}{ Site 1 } & \multicolumn{3}{c|}{ Site 2 } & $\begin{array}{c}\text { Between } \\
\text { Groups } \\
\text { Comparison } \\
\text { of Results }\end{array}$ \\
\cline { 2 - 8 } & $\begin{array}{l}\text { Median } \\
\text { Change } \\
\text { in Score }\end{array}$ & IQR & $\begin{array}{l}\text { Level of } \\
\text { Significance }\end{array}$ & $\begin{array}{l}\text { Median } \\
\text { Change } \\
\text { in Score }\end{array}$ & IQR & $\begin{array}{l}\text { Level of } \\
\text { Significance }\end{array}$ & $\begin{array}{l}\text { Overall } \\
\text { Change in } \\
\text { Score } \diamond\end{array}$ \\
\hline $\begin{array}{l}\text { Comprehensive } \\
\text { Knowledge }\end{array}$ & 5.0 & $3.0,6.5$ & $\mathrm{P}<0.01^{*}$ & 5.0 & $5.0,7.0$ & $\mathrm{P}<0.01^{*}$ & $\mathrm{P}=0.30$ \\
\hline $\begin{array}{l}\text { Outcomes } \\
\text { Expectations }\end{array}$ & 3.5 & $2.0,5.0$ & $\mathrm{P}<0.01^{*}$ & 2.0 & $1.0,2.0$ & $\mathrm{P}<0.01^{*}$ & $\mathrm{P}=0.01^{*}$ \\
\hline $\begin{array}{l}\text { Perceived } \\
\text { Barriers }\end{array}$ & 4.5 & $0.5,7.0$ & $\mathrm{P}=0.03$ & 6.0 & $3.0,8.0$ & $\mathrm{P}<0.01^{*}$ & $\mathrm{P}=0.49$ \\
\hline $\begin{array}{l}\text { Perceived } \\
\text { Facilitators }\end{array}$ & 2.0 & $0.5,3.0$ & $\mathrm{P}<0.01^{*}$ & 4.0 & $3.0,5.0$ & $\mathrm{P}<0.01^{*}$ & $\mathrm{P}<0.01^{*}$ \\
\hline Self-efficacy & 6.5 & $2.0,8.0$ & $\mathrm{P}<0.01^{*}$ & 13.0 & $11.0,17.0$ & $\mathrm{P}<0.01^{*}$ & $\mathrm{P}<0.01^{*}$ \\
\hline $\begin{array}{l}\text { Intention to } \\
\text { Provide } \\
\text { Cessation } \\
\text { Counseling }\end{array}$ & 1.0 & $0,1.0$ & $\mathrm{P}<0.01^{*}$ & 1.0 & $0,1.0$ & $\mathrm{P}<0.01^{*}$ & $\mathrm{P}=0.16$ \\
\hline
\end{tabular}

‡ Wilcoxon Signed-Rank Test

$\checkmark$ Mann-Whitney U

*results statistically significant $p \leq 0.01$ 
Figure 1 - Change in Scores, by Group

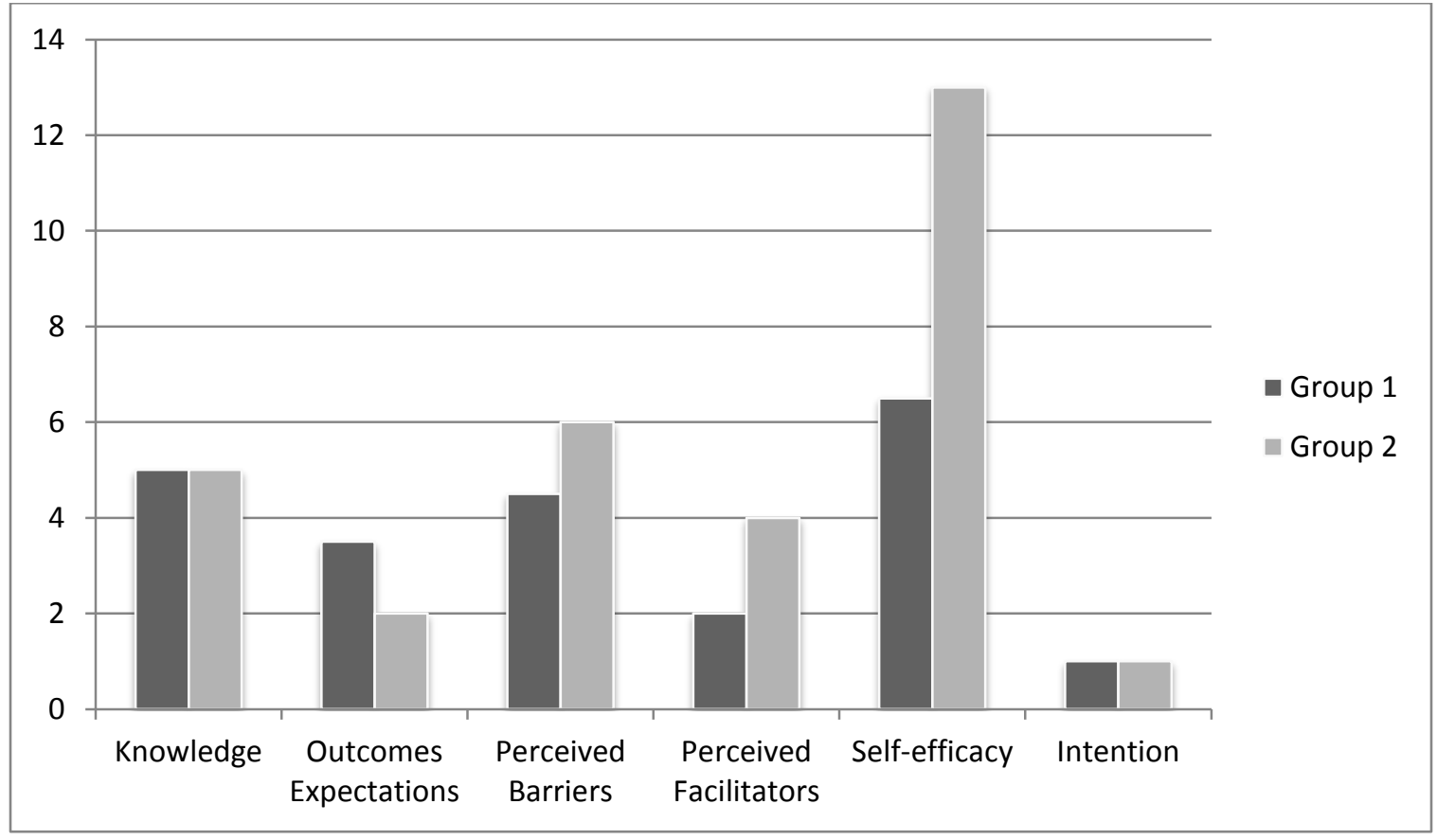


Chapter 5 


\section{Summary and Conclusions}

Tobacco use constitutes one of the greatest threats to public health worldwide. ${ }^{1}$ Within the United States, tobacco use results in approximately 8,600,000 cases of illness, and 443,000 deaths each year through direct exposure and second-hand smoke. ${ }^{2}$ According to the National Commission on Prevention Priorities, tobacco cessation interventions are the most important clinical preventive services a health care professional can offer. ${ }^{3}$ Evidence-based clinical guidelines for tobacco cessation counseling (TCC) established by the Agency for Health Care Quality and Research (AHRQ) were first released in 1996, and are considered the "gold standard" for non-pharmacologic treatment to end smoking. According to these guidelines, every patient should be screened for tobacco use during the medical encounter, and those who smoke should receive tailored cessation advice based on readiness to quit. Despite these recommendations, the most recent United States Ambulatory Health Survey found that 32\% of medical records were missing documentation of patients' smoking status, and fewer than $20 \%$ of patients reported receiving cessation advice during their last visit with a health care provider. ${ }^{4}$ However, it has been estimated that national implementation of AHRQ TCC Guidelines would result in 5 million new quitters each year, with prevention of more than 3 million premature deaths. ${ }^{5}$ In fact, $70 \%$ of current smokers report that they would like to quit and are amenable to recommendations and input from health care professionals. ${ }^{6}$ As instrumental members of the health care team, it is essential for physical therapists to join the public health initiative to reduce chronic morbidity and premature mortality resulting from tobacco use. Given higher rates of smoking among people with disabilities, ${ }^{7}$ along with greater consequences of tobacco use in exacerbating existing impairments, ${ }^{8}$ tobacco cessation counseling as a component of physical therapy practice could have a substantial impact in reducing premature mortality and chronic disease for populations in greatest need.

This doctoral dissertation was devoted to research regarding the application of AHRQ evidencebased TCC guidelines within physical therapy practice:

- Chapter 1 outlines the rationale, goals, and objectives for each of the three papers contained within the dissertation.

- $\quad$ Chapter 2 describes how smoking impacts physical therapy treatment outcomes in all areas of practice, and highlights the need for TCC among special populations due to epidemiologic data showing higher smoking rates and elevated health consequences of smoking among people with disabilities. Chapter 2 also outlines the use of the AHRQ TCC guidelines within the context of physical therapy assessment and treatment.

- Chapter 3 constitutes an educational needs assessment for TCC training in entrylevel physical therapist programs within the United States.

- $\quad$ Chapter 4 describes the design, evaluation, and outcomes of a pilot TCC training curriculum specifically tailored for student physical therapists. 
This final chapter will provide a summary and recommendations for continued research and development regarding the role of physical therapists in TCC as it relates to a component of health promotion and wellness.

According to available research, only $17 \%$ of physical therapists currently engage in tobacco screening and counseling as a component of standard practice. ${ }^{9}$ As seen in Chapter 3 , the opinions of physical therapists regarding their professional role in providing TCC includes debate regarding scope of practice and the relevance of TCC with respect to goals of treatment. However, a review of available literature (Chapter 1) provides a strong scientific rationale for TCC as a component of physical therapy practice based on the detrimental effects of smoking on all systems of the body, along with the potential for smoking cessation to result in better treatment outcomes across all areas of physical therapy practice, including cardiopulmonary and vascular health, musculoskeletal and neuromuscular health, and integumentary conditions. ${ }^{10}$ Tobacco cessation can enhance functional outcomes through better healing rates, decreased pain, and improved strength, balance, and endurance, and should therefore be included as an important element of physical therapy patient education. ${ }^{6,10}$ Furthermore, there is a greater need for TCC within typical physical therapy clientele. For example, among people with disabilities, smoking prevalence is nearly 10 points higher than the general population (30.5\% versus $21.7 \%$, respectively). ${ }^{11}$ People with disabilities also have a tendency to smoke at a higher intensity than their non-disabled peers, ${ }^{7}$ and are less likely to receive tailored smoking cessation advice during routine healthcare, particularly when their disability encompasses impairments in mobility. ${ }^{7,11,12}$ In addition, the impact of smoking may be magnified in people with disabilities due to clustering of other health risk factors, including higher prevalence of sedentary lifestyle, obesity, and limited access to health care. ${ }^{11}$ Physical therapists and physical therapist assistants are uniquely positioned to offer TCC services as outlined by the AHRQ clinical guidelines. TCC is closely compatible with existing patterns of physical therapy practice: physical therapists and physical therapist assistants have a long history of offering tailored patient education geared towards behavioral change as a means of enhancing patient autonomy, physical function, and quality of life. This collaborative approach to enhancing personal wellness is further strengthened by the close rapport that develops between the patient and clinician during multiple encounters throughout a single episode of physical therapy care. Frequent communication enables the physical therapist and assistant to become intimately familiar with many aspects of a patient's life, including support systems, environments, and other factors that may act as resources in promoting better health. These aspects of physical therapy provide opportunities for clinicians to assist patients in recognizing the personal relevance of smoking cessation based on the risks and benefits of behavioral change specific to their individual diagnosis and impairments, as well as the patient's own goals for regaining independence and optimal wellness, and can be used to assist patients in identifying and implementing effective smoking cessation strategies, thereby enhancing the likelihood of a successful quit attempt and long-term abstinence.

Although some may question the efficacy of $\mathrm{TCC}^{13}$ past studies have shown that patients who receive advice from their physician are 1.6 times more likely to quit smoking than those who have not received similar intervention, ${ }^{14}$ and are 3 times more likely to maintain abstinence at 2 
month follow-up. ${ }^{15}$ An interdisciplinary approach enhances the chances of successful cessation: patients who receive TCC from more than one health care professional are twice as likely to quit. ${ }^{16}$ In a health care environment plagued by escalating expenses, scarce resources, and increasing rates of chronic disease and disability, increased involvement of physical therapy professionals is essential in preventing tobacco-related illness and promoting improved outcomes. TCC is an important component of health care reform. Medical costs for smokers are approximately $\$ 1041$ per year greater than costs for non-smokers. ${ }^{17}$ Cost savings as a result of effective TCC are estimated at approximately $\$ 883$ - \$3590 per year of life preserved. ${ }^{3}$

The overarching goal of the research contained within this dissertation was to promote smoking cessation, particularly among people with disabilities, through increased application of AHRQ evidence-based TCC guidelines in physical therapy practice. Theoretical underpinnings for the research questions and methods were provided, in part, by the Theory of Reasoned Action, first proposed by Fishbein and Azjen. ${ }^{18}$ The Theory of Reasoned Action provides a comprehensive framework for examining the interrelationships between personal attitudes, opinions, self-confidence or perceived control, and the motivation to pursue certain goals and intended outcomes. Although this theory is most often applied to health-related behaviors of patients, such as dietary change, physical activity, or smoking cessation, it can also be a valuable resource in assessing factors that influence decision making and treatment strategies selected by health care providers, such as the decision to integrate evidence-based guidelines as a component of clinical practice.

In and of itself, scientific evidence has no influence on disease rates or improvements in public health unless the evidence can be used to promote changes in professional practice. Barriers to the translation of evidence, such as the application of evidence-based TCC guidelines, include a lack of knowledge, as well as doubt regarding the efficacy of the recommended treatment in achieving the purported results. ${ }^{22}$ Evidence-based TCC guidelines developed by the AHRQ have been in place for more than two decades, yet entry-level training for health care practitioners in the clinical application of these parameters remains deficient. According to the Global Health Professions Survey, although the majority of third-year students enrolled in dental, medical, nursing, and pharmacy school believed that they should play a role in promoting a reduction in patient's health risk behaviors, less than $40 \%$ reported that they had received training in smoking cessation as a component of their professional education. ${ }^{23}$ The inadequacies in training are reflected in patient statistics which show that less than $20 \%$ of smokers received TCC services during their most recent visit with a health care provider. ${ }^{4}$ Specific to physical therapist practice, $90 \%$ of practitioners surveyed reported that they were unfamiliar with the " 5 $A^{\prime} s^{\prime \prime}$ behavioral intervention program and $40 \%$ were unfamiliar with national health priorities listed in the United States Department of Health and Human Services document, "Healthy People 2020." ${ }^{24}$ It is important to note that these deficiencies are not a result of insufficient motivation. Physical therapists have a long history of meeting public need, particularly among people with disabilities, ${ }^{25}$ and are acutely aware of their professional obligations. A prior survey of physical therapy practitioners demonstrated $100 \%$ agreement that physical therapists should play a primary role in health promotion and prevention. ${ }^{24}$ 
One of the greatest impediments to the application of AHRQ TCC guidelines is failure to recognize the importance of smoking cessation with respect to one's professional role and priorities. ${ }^{33}$ As previously stated, without perceived clinical relevance, there is little motivation to encourage adoption of guidelines as a component of direct patient care. Therefore, the first objective of this dissertation research, as outlined in Aim 1.0 was to establish a clinical rationale for the inclusion of TCC as an important element of physical therapy practice and education. This clinical rationale was constructed based on scientific data demonstrating the impact of smoking on musculoskeletal, neuromuscular, cardiovascular, pulmonary and integumentary pathologies and associated impairments. Data were abstracted from a comprehensive, structured review of the literature, and were used to compose an evidencebased position paper which appeared in Physical Therapy, May 2012. ${ }^{10}$ Physical Therapy is the official scientific journal of the American Physical Therapy Association (APTA) and the Royal Dutch Society for Physical Therapy (KNGF). This journal has an impact factor of 3.113, is ranked number 3 among all 82 rehabilitation journals, and has a national and international circulation of 80,000 readers. Through its policy and perspectives papers, Physical Therapy seeks to inform and advance professional practice through the translation of clinically relevant scientific evidence.

By providing the clinical rationale for evidence-based TCC to enhance physical therapy treatment outcomes, Study 1 of the dissertation formed the basis for further inquiry. It is known that provider training increases rates of TCC interventions. In order to promote widespread use of evidence-based TCC guidelines in physical therapist practice and education, it was important to consider factors involved in professional decision making within academic, administrative, and clinical environments. According to the Theory of Reasoned Action, the antecedents of a particular behavior include perceived barriers or facilitators towards achieving the intended results. ${ }^{19}$ Further research was required in order to develop a better understanding of the proximal determinants of clinical decision making, as well as other factors that may potentially promote or inhibit the dissemination and adoption of TCC by physical therapists, as well as other health care professionals invested in the entry-level training of future rehabilitative professionals. By soliciting the opinions and attitudes of faculty members with regards to academic preparation and clinical practice in physical therapists, Study 2 captured need for further training, but also delineated factors that may promote the integration of evidence-based TCC guidelines within professional education. This information was then be used to inform the design of a research-based TCC curriculum, as a primary means of facilitating the translation of evidence into practice. ${ }^{20,21}$ Ultimately, it will be important for future studies to verify that this translation of evidence results in improved patient outcomes and quality of care.

Student physical therapists represent the next generation of providers, and entry-level education is a key resource in promoting change in clinical practice. Training entry-level health care professionals in the use of evidence-based tobacco interventions increases the likelihood of application during subsequent patient management, ${ }^{26}$ and is consistent with recommendations of the United States Public Health Service (USPHS). The USPHS encourages training in treatment of tobacco use and dependence for all students entering a health-related 
field. ${ }^{27}$ Studies examining results of training show that professionals trained as students are more likely to apply TCC during typical patient encounters: chiropractic interns trained in TCC were eight times more likely to address a change in habit for patients who smoke. ${ }^{28}$ Similar effects have also been shown among pharmacy students, ${ }^{27}$ dental students, ${ }^{29}$ nursing students, ${ }^{30}$ medical students, ${ }^{31}$ and medical residents. ${ }^{32}$ The application of AHRQ TCC practice recommendations in professional education involves unique challenges. Training can be enhanced through tailored curricular development specifically designed to address potential barriers and facilitators in the application of TCC guidelines for professional education and practice. ${ }^{22}$ In order to be successful in promoting a change in professional practice, tailored educational initiatives must include explicit, objective goals shaped by factors known to influence subsequent behavioral intentions. ${ }^{22}$ These factors include the individual characteristics of each provider, such as personal opinions and attitudes towards his or her professional role in assisting patients who smoke, as well as elements of the practice environment that can either encourage or inhibit the transfer of knowledge in a clinical setting. ${ }^{22}$

Past research has shown that implementation of TCC training in entry-level health professions students can be facilitated through the development of a curricular template. ${ }^{34}$ In keeping with the tenets of evidence-based practice, curricular design should also be shaped by the application of relevant research. Therefore, goals of this dissertation research included program development and assessment of a tailored TCC training workshop, specifically designed for use with student physical therapists. Since previous studies have shown that the design of an effective training program should begin with an assessment of existing academic resources, ${ }^{35}$ development of a TCC curricular template designed for student physical therapists was preceded by a needs assessment, shaped by the following research questions:

1) What is the current state of TCC training in entry-level physical therapist education programs throughout the United States?

2) What are the perceived barriers and facilitators influencing the inclusion of evidencebased TCC within entry-level physical therapist education?

These research questions formed the basis for Study 2. Data obtained in Study 2 were instrumental in achieving Aim 2.0: Determine the current state of TCC education in entry-level physical therapist programs, i.e. - prevalence of training, scope of content, and instructional format, including opportunities to apply TCC skills in a clinical setting.

Aim 2.0 was attained using research described in Chapter 3 of the dissertation. Data collection occurred via a cross-sectional survey of faculty at all entry-level physical therapist programs recognized by the Committee on Accreditation of Physical Therapy Education (CAPTE), and yielded a $71.5 \%$ response rate. Data analysis showed that $60 \%$ of respondents from entry-level physical therapist programs in the United States lack curricular content specific to the application of evidence-based TCC guidelines. Results also indicated that the likelihood of training was highest when faculty had prior knowledge and training in TCC, and possessed 
favorable views towards the efficacy of TCC and the professional roles of physical therapists in providing TCC for patients who smoke.

During similar inquiry regarding the state of TCC training in physician education, researchers found that the lack of a curricular model can discourage programs from including TCC content. ${ }^{36}$ Studies also found that better care for underserved populations, such as the provision of TCC for people with disabilities, can be facilitated by providing an evidence-based rationale for changes in practice. ${ }^{37}$ This rationale should include epidemiologic data regarding incidence, prevalence, and mortality rates for people and groups who are most in need of services. ${ }^{37}$ Training should also include criteria for successful screening, as well as patient counseling approaches designed to encourage a change in personal health-related behaviors. ${ }^{37}$ Clinicians' knowledge and counseling skills can be enhanced through further education promoting the use of appropriate communication methods as well as other aspects related to patient-centered advocacy. ${ }^{37}$

Commonalities exist within the professional education of all health care providers. However, physical therapy is a unique, autonomous entity with distinct curricular requirements for competent practice. $^{38}$ Therefore, it was essential to tailor curricular design for TCC in order to promote dissemination and adoption of AHRQ TCC practice guidelines within the distinct context of rehabilitative care. Due to the nature of graduate education, it was also essential for the tailored educational approach to incorporate principles of adult learning, such as factors known to influence the motivation to acquire and apply new knowledge. ${ }^{39}$

Several facilitators foster the implementation of AHRQ TCC guidelines in physical therapist education and practice. The physical therapy profession has consistently placed a strong emphasis on patient education, as reflected in professional documents such as the Core Values, ${ }^{40}$ and Normative Model of Physical Therapist Professional Education. ${ }^{41}$ Tailored, individualized interventions are viewed as essential methods in enhancing patient autonomy, and limiting the impact of functional impairments. ${ }^{42}$ When considering the patterns outlined in the Guide to Physical Therapist Practice, ${ }^{43}$ the perceived value of interpersonal communication is clearly evident. The interactions between physical therapy providers and patients typically involve close rapport which permits insight into the unique aspects of each person's life. These close relationships enable the physical therapist to implement AHRQ TCC guidelines by offering tailored advice that best suits each individual's goals, resources, and potential challenges. ${ }^{6}$

The goal of TCC training within physical therapist education is to increase patient access to evidence-based smoking cessation interventions, particularly among people with disabilities. However, the adoption of TCC guidelines is related to many factors and extends beyond the individual knowledge and skill level of each provider. Curricular design must take into account additional factors which may influence the implementation of practice guidelines with in patient care settings. Teaching methods and content should be designed to address characteristics delineated by the Theory of Reasoned Action (TRA) which may potentially promote or inhibit the intention to treat using the evidence-based approach to smoking cessation endorsed by the AHRQ. ${ }^{18}$ While it is true that behavioral intention is largely influenced by knowledge and 
awareness of the clinical guidelines, there are other proximal determinants that factor into decision making, including the perceived likelihood of anticipated results (i.e. - outcome expectations), potential barriers and facilitators, and self-confidence in one's level of skill (also known as self-efficacy). With these factors in mind, study 3 of the dissertation sought to answer the following research questions:

1) Is tailored training in evidence-based TCC effective in increasing the knowledge, skills, and self-efficacy of student physical therapists?

2) Does training result in improved outcome expectations and a corresponding increase in the intention to provide TCC in a clinical setting?

These questions are the focus of Aim 3.0: Assess the knowledge, attitudes, self-efficacy, and intentions of physical therapy students towards TCC before and after a specifically-tailored educational module to teach TCC skills.

\section{A: Conduct baseline survey of physical therapy students (pre-test)}

\section{B: Develop and deliver a tailored educational module for PT students}

\section{C: Conduct post-educational survey of physical therapy students (post-test)}

Goals outlined in Aim 3.0 were achieved in study 3 of the dissertation, presented in Chapter 4. Results of Study 3 show that tailored TCC training for entry-level physical therapists can lead to significant increases in the antecedents of TCC behaviors which favor the implementation of AHRQ evidence-based TCC clinical guidelines in subsequent professional practice. Student physical therapists who participated in the 3-hour interactive TCC training workshop demonstrated $36 \%$ gains in knowledge and related skills, a $20 \%$ increase in positive outcome expectations, a $20 \%$ improvement in perceived barriers and facilitators, a $23 \%$ increase in selfefficacy towards the implementation of TCC guidelines, and a $23 \%$ increase in intention to adopt tobacco screening and intervention as a component of routine patient management.

While these findings are indeed promising, studies are needed to verify the translation of knowledge into long-range clinical practice. These studies should include an assessment of the retention of knowledge and the application of acquired skills once physical therapists trained as students complete their entry-level education and become fully engaged in direct patient care. In addition, research efforts must go beyond entry-level education to address the need for post-professional training. Such efforts will potentially involve a whole new set of questions regarding the design and effectiveness of continuing education in TCC, including development and testing of a separate, distinct educational blueprint designed to best meet the needs and interests of experienced practitioners. Other concerns include time and cost required for training, determining the best delivery methods to enhance knowledge and promote adoption of guidelines, and the development of effective feedback mechanisms to ensure continued professional growth. Performance data are required in order to assess and improve the adoption, adaptation, and implementation of TCC services. ${ }^{17}$ Feedback should also include the 
impact of provider behavior in achieving superior treatment outcomes for patients who receive evidence-based TCC.

Past studies have also shown that the TCC behaviors of trained clinicians can be further enhanced through the application of systems prompts and other changes in the practice environment. ${ }^{3}$ Beneficial modifications within health care settings may include the use of standardized forms and patient education materials, ${ }^{44}$ as well as a professional "champion," or recognized leader in the field who will continue to advocate and encourage greater professional involvement in health promotion efforts and services. ${ }^{44,45}$ Other factors which may promote adherence to clinical guidelines include a uniform referral source, such as the use of a telephone quitline or the assistance of a referral coordinator, as well as a recognized billing code which can be used for reimbursement of TCC services. ${ }^{46}$ One study evaluating the effectiveness of these types of systems prompts found an $18 \%$ increase in identification of patients who smoke, and a $100 \%$ increase in implementation of assessment planning for patients prepared to quit. Overall, patients who were screened for tobacco use under the revised systems were $80 \%$ more likely to receive the full scope of TCC as outlined in the AHRQ/ USDHHS clinical guidelines, as compared with patients seen prior to this change. ${ }^{47}$ Ultimately, the goal of TCC is to decrease smoking prevalence and improve patient outcomes by reducing chronic disease rates, disability, and premature mortality. In pursuit of these goals, further clinical translational research designed to assess the implementation and impact of TCC within the actual context of physical therapist practice is needed. ${ }^{57}$ Practice-based studies will enable realistic assessment of fidelity to AHRQ/ USDHHS guidelines within the context of challenges and barriers presented by the current health care environment. Over time, experienced providers may adapt certain aspects of the guidelines to best fit their skill set and desired outcomes. As widespread dissemination of evidence-based TCC guidelines within clinical practice occurs, additional data may reveal additional methods for reducing smoking behaviors among physical therapy clientele, helping to further efforts to reduce the impact of tobacco use on people with disabilities, and prevent premature mortality and diminished health related quality of life among the public as a whole. ${ }^{57}$

Although the application of AHRQ/ USDHHS TCC guidelines is an important step in addressing health-related problems and premature mortality attributable to tobacco use, reducing the damaging effects of smoking requires investment by all primary stakeholders within the healthcare environment. ${ }^{5}$ In addition to the behaviors of individual health care practitioners, administrative behaviors must also be considered. Before TCC can become a recognized aspect of appropriate patient management, policy makers will need to establish new criteria for competent practice. Potential administrative changes include the establishment and dissemination of new benchmarks consisting of specific TCC performance goals, as well as systems to gather performance feedback in order to monitor and facilitate continued quality improvement.

Feedback to providers, administrators and third-party payers should incorporate practice-based research regarding efficacy and impact of TCC, forming an additional avenue for future study. Data demonstrating the value of improved implementation of the AHRQ evidence-based 
guidelines can be used to continue to promote and maintain positive outcome expectations with regards to the practitioner's professional role in counseling patients who smoke. Increases in positive outcome expectations can help sustain efforts to promote the continued application of TCC guidelines, as well as further dissemination and adoption of TCC by a practitioner's peers and colleagues. ${ }^{52}$ Use of the electronic medical record could provide an avenue for gathering and evaluating practice-based data. ${ }^{45,53}$ Other data collection methods have included direct observation or audiotaped recordings of patient encounters, ${ }^{54}$ and/or surveys and informative interviews with staff, ${ }^{5}$ provider, ${ }^{54}$ and patients, ${ }^{5}$ as well as direct observation or audiotaped recordings of patient encounters during tobacco screening and counseling. Previous research has shown that interdisciplinary collaboration is essential for optimal success in addressing tobacco use. Therefore, with regard to physical therapist practice, future outcomes assessment should include joint efforts between rehabilitative clinicians and other potential collaborators, such as physicians, nurses, social workers, psychologists, and others who may be involved in comprehensive patient management.

Data regarding provider performance and the results of TCC can also be valuable in advocating for improved reimbursement through private health plans and third party payers. ${ }^{55,56}$ For instance, research regarding dental practice found that payment for TCC was often hampered by insurers' concerns for return on investment. ${ }^{56}$ By substantiating the cost-effectiveness of TCC relative to medical costs of associated morbidity and functional decline, practice-based data in physical therapy can be used to promote better coverage and payment for necessary services. It has also been suggested that reimbursement for TCC could be enhanced by demonstrating an increased demand for services by plan members (i.e. - patients) and health program purchasers, such as employers and benefits managers. ${ }^{56}$

Within the physical therapy profession, it is likely that widespread changes in practice with regard to implementation of evidence-based TCC guidelines may require sponsorship by a respected authority, such as the American Physical Therapy Association (APTA). Involvement at a national level can assist in promoting the development of new expectations and norms, including standardized training and certification in TCC. ${ }^{48}$ Efforts can be advanced using a sound scientific rationale which highlights the consistency between TCC quality improvement measures and the overall mission of the physical therapy profession. ${ }^{17}$ Although smoking is typically associated with cardiovascular and pulmonary health, it is important to continue to emphasize the influence of smoking on outcomes in all areas of physical therapist practice, so that the perceived relevance of TCC in keeping with the goals of the profession become clear. An example of this approach can be found in the position statement released by the American Society of Health-Systems Pharmacists (ASHP), endorsing tobacco screening and TCC as a component of routine patient care. ${ }^{49}$ To a certain extent, although not specific to physical therapy, changes in health care norms are already evidenced by tobacco cessation as a recognized accreditation standard (for example, criteria for TCC established by the Joint Commission for Accreditation of Healthcare Organizations), ${ }^{50,51}$ resulting in policies that promote TCC. $^{45}$ 
While access to TCC is an essential consideration in limiting the impact of smoking, there are additional factors which may facilitate successful quit attempts. Future studies should incorporate these factors in order to gain a broader perspective of tobacco control as it relates to public health. In addition to TCC, changes in public policy, such as smoking bans and higher taxation for the purchase of tobacco products, can have a cumulative impact by limiting access to tobacco products. Through their effects on the smokers' environment, including limitations in smoking within public spaces, public policies can assist individual cessation efforts and help reduce the chance of relapse. ${ }^{58}$ Smoking cessation may also be assisted through interventions which address multi-substance use, due to known associations between cigarettes and alcohol consumption, and links between stress and smoking as an unhealthy coping mechanism. ${ }^{58}$

Within the practice of physical therapy, aids for smoking cessation may go beyond counseling to include exercise-based interventions. A recent systematic review revealed higher cessation rates and better abstinence at 3-month and 12-month follow-ups for smokers who engaged in physical activity as an adjunct to cessation treatment. ${ }^{59}$ Exercise may assist smoking cessation by helping to manage withdrawals and cravings, ${ }^{59}$ and may help mitigate associated weight gain. ${ }^{60}$ However, further studies are needed to assess optimal treatment parameters, including the recommended exercise "dose," i.e. - intensity and timing of physical activity, as well as measures of adherence. ${ }^{59}$

Physical therapy professionals have an established history of providing tailored patient educations and have considerable leverage in promoting behavioral change, whether through education regarding activities of daily living, the use of assistive devices, exercise prescription or smoking cessation. The application of evidence-based TCC guidelines enhances existing efforts to promote patient autonomy by facilitating improved self-management of the disease risks presented by tobacco use. Smoking cessation reduces the chances of premature mortality, disability, and diminished health related quality of life. In this regard, TCC fits well with existing patterns of physical therapist practice, offering a cost-effective mechanism for appropriate use of resources within an overburdened medical system. Barriers to widespread implementation of evidence-based TCC guidelines within the physical therapy profession include a lack of knowledge and skills, as well as limited confidence in offering assistance for patients who smoke. Entry-level physical therapist education can provide an avenue for initiating change by improving TCC training and fostering attitudes and beliefs which promote the application of TCC as an element of routine clinical practice. As practitioners trained as students to offer TCC enter the workforce, further research regarding the effect of evidencebased guidelines in promoting smoking cessation should also be considered. Practice-based data regarding cessation rates and improved clinical outcomes specific to physical therapy can be used to substantiate further involvement of the profession through continuing education for experienced practitioners. By demonstrating the impact of patient education by physical therapists in addressing behavioral risk factors for disease and disability, implementation of counseling strategies for tobacco cessation may be extended to other health risk behaviors such as sedentary lifestyle and poor nutrition. Like tobacco use, these personal behaviors increase physical impairments and challenge treatment outcomes through elevated incidence of obesity, hypercholesterolemia, and impaired glycemic control. Each of these conditions 
increase risk for cardiovascular disease, cerebrovascular disease, musculoskeletal and neuromuscular impairments, and disability. While physicians are currently the largest group represented in studies examining tobacco cessation interventions, ${ }^{6}$ it is known that an interdisciplinary approach enhances quit rates. ${ }^{16}$ Physical therapy professionals have a strong history in addressing needs of people with disabilities. Their involvement in reducing the impact of tobacco use is essential in light of epidemiologic data that show that smoking disproportionately affects people with mobility impairments and other physical conditions. ${ }^{61}$ These effects are compounded by higher intensity of smoking, limited access to care, and higher risk of associated co-morbidities when people with disabilities are compared with their non-disabled peers.

In preparation for the future, the American Physical Therapy Association (APTA) recently held meetings with key stakeholders. Qualitative data from these focus group meetings were used to compile a list of key themes geared towards continued improvements in addressing public need ("Revision to Vision 2020"). Data analysis revealed a list of professional priorities including the pursuit of research and changes in professional practice which would facilitate recognition of physical therapists and physical therapist assistants as "national leaders in implementing evidence-based strategies for health promotion." These goals will require greater professional involvement in the public health sector in order to shift the focus of health care from disease management to disease prevention. Within the physical therapy profession, continued professional action is needed in order to generate greater awareness of critical public health issues. Further dialogue will enable researchers, clinicians and educators to work together in uncovering additional avenues geared towards continued improvements in patient outcomes, particularly by addressing health disparities through interventions designed to promote autonomy, health, and optimal physical functioning in people with disabilities. Implementation of evidence-based TCC within physical therapy practice matches the priorities outlined in the APTA 2013 Strategic Plan. This plan includes a revised vision statement that strives towards "doctors of physical therapy .... as the practitioners of choice to whom consumers have direct access for the diagnosis of, interventions for, and prevention of impairments, functional limitations, and disabilities related to movement, function and health." Goals contained within the Strategic Plan include increasing the prevalence of physical therapists providing prevention and wellness services, and the implementation of innovative models of patient-centered services. Training for entry-level physical therapists in the use of AHRQ TCC guidelines will enhance the "effectiveness of care" by increasing use and adherence of research-based information. Greater professional involvement in tobacco cessation efforts through tailored tobacco cessation advice for people who smoke will also increase recognition for physical therapists as "leaders in delivery of patient-centered care." Furthermore, it will foster the growth and development of physical therapists and assistants in achieving "high standards of professional and intellectual excellence." 


\section{$\underline{\text { References }}$}

1. Fiore $\mathrm{M}$, Croyle R, Curry S, et al. Preventing 3 Million Premature Deaths and Helping 5 Million Smokers Quit: A National Action Plan for Tobacco Cessation. American Journal of Public Health. 2004;94(2):205-210.

2. United States Department of Health and Human Services. Ending the Tobacco Epidemic: A Tobacco Control Strategic Action Plan for US Department of Health and Human Services2010.

3. Curry S, Keller P, Orleans C, Fiore M. The Role of Health Care Systems in Increased Tobacco Cessation. Annual Reviews in Public Health. 2008;29:411-428.

4. Sheffer C, Barone, C., Anders, M. Training Health Care Providers in the Treatment of Tobacco Use and Dependence: Pre- and Post-Training Results. Journal of Evaluation in Clinical Practice. 2009;15:607-613.

5. An L, Bluhm J, Foldes S, et al. Clinical System Elements and Patient Reports of Tobacco Cessation Counseling. Journal of Clinical Outcomes Management. 2008;15(10):485-492.

6. Bodner M, Dean, E. Advice as a Smoking Cessation Strategy: A Systematic Review and Implications for Physical Therapists. Physiotherapy Theory and Practice. 2009;25(56):369-407.

7. Armour B, Campbell, V., Crews, J., Malarcher, A., Maurice, E., Richard, R. State-Level Prevalence of Cigarette Smoking and Treatment Advice, by Disability Status, United States, 2004. Preventing Chronic Disease: Public Health Research, Practice and Policy. 2007;4(4):1-11.

8. Rimmer J, Chen M, Hseih K. A Conceptual Model for Identifying, Preventing and Managing Secondary Conditions in People with Disabilities. Physical Therapy. 2011;91(12):1728-1739.

9. Rea B, Marshak, H., Neish, C., Davis, N. The Role of Health Promotion in Physical Therapy in California, New York and Tennessee. Physical Therapy. 2004;84(6):510-523.

10. Pignataro R, Ohtake P, Swisher A, Dino G. The Role of Physical Therapists in Smoking Cessation: Opportunities for Improving Treatment Outcomes. Physical Therapy. 2012;92:757-766.

11. Rimmer J, Rowland, J. Health Promotion for People with Disabilities: Implications for Empowering the Persona and Promoting Disability-Friendly Environments. American Journal of Lifestyle Medicine. 2008:1-12.

12. Moorhouse M, Pomeranz, J., Barnett, T., Yu, N., Curbow, B. Tobacco Cessation Intervention for People with Disabilities: Survey of Center for Independent Living Directors. Rehabilitation Counseling Bulletin. 2011;54(2):118-121.

13. Pignataro R. Tobacco Cessation Counseling Training in US Entry-Level Physical Therapy Curricula: A Cross-Sectional Survey. Unpublished Data: West Virginia University, School of Public Health; 2013.

14. Caplan L, Stout C, Blumenthal D. Training Physicians to Do Office-Based Smoking Cessation Increases Adherence to PHS Guidelines. Journal of Community Health. 2011;36:238-243. 
15. Katz D, Muehlenbruch D, Brown R, Fiore M, Baker T. Effectiveness of Implementing the Agency for Healthcare Research and Quality Smoking Cessation Clinical Practice Guideline: A Randomized, Controlled Trial. Journal of the National Cancer Institute 2004;96(8):594-603.

16. An L, Foldes, S., Alesci, N., Bluh, J., Bland, P., Davern, M., Schillo, B., Ahluwalia, J., Manley, M. The Impact of Smoking-Cessation Intervention by Multiple Health Professionals. American Journal of Preventive Medicine. 2008;34(1):54-60.

17. March A. The Business Care for Tobacco Cessation Programs: A Case Study of Group Health Cooperative in Seattle2003.

18. Ajzen I, Fishbein M. Understanding Attitudes and Predicting Social Change. Englewood Cliffs, New Jersey: Prentice Hall; 1980.

19. Burnkrant R, Page T. The Structure and Antecedents of the Normative and Attitudinal Components of Fishbein's Theory of Reasoned Action. Journal of Experimental Social Psychology. 1988;24:66-87.

20. Perkins M, Jensen, P., Jaccard, J., Gollwitzer, P., Oettinger, G., Pappadopulous, E., Hoagwood, K. Applying Theory-Driven Approaches to Understanding and Modifying Clinicians' Behaviors: What Do We Know? Psychiatric Services. 2007;58(3):342-348.

21. Godin G, Belanger-Gravel, A., Eccles,M., Grimshaw, J. Healthcare Professionals' Intentions and Behaviors: A Systematic Review of Studies Based on Social Cognitive Theories. Implementation Science. 2008;3(36):1-12.

22. Spring B. Health Decision Making: Lynchpin of Evidence-Based Practice. Medical Decision Making. 2008;28(6):866-874.

23. Warren C, Jones N, Chauvin J, Peruga A. Tobacco Use and Cessation Counselling: CrossCountry Data from the Global Health Professions Student Survey (GHPSS), 2005-2007. Tobacco Control. 2008;17(4):238-247.

24. Johnson S. Health Promotion and Wellness: Knowledge, Beliefs, and Practices of Physical Therapists and Physical Therapy Students2006, Nova Southeastern University.

25. American Physical Therapy Association. Who We Are \& What We Do. 2011. Accessed 9/21/11, 2011.

26. Richmond R, Zwar N, Taylor R, Hunnisett J, Hyslop F. Teaching About Tobacco in Medical Schools: A Worldwide Study. Drug and Alcohol Review. 2009;28:484-497.

27. Corelli R, Kroon, L., Chung, E., Sakamoto, L., Gundersen, B., Fenlon, C., Hudmon, K. Statewide Evaluation of a Tobacco Cessation Curriculum for Pharamacy Students. Preventive Medicine. 2005;40:888-895.

28. Evans M, Hawk C, Strasser S. An Educational Campaign to Increase Chiropractic Intern Advising Roles on Patient Smoking Cessation. Chiropractice and Osteopathy. 2006;14(24):1-9.

29. Koerber A, Crawford J, O'Connell K. The Effects of Teaching Dental Students Brief Motivational Interviewing for Smoking Cessation Counseling: A Pilot Study. Journal of Dental Education. 2003;67(4):439-447.

30. Shishani K, Stevens K, Dotson J, Reibe C. Improving Nursing Students' Knowledge Using Online Education and Simulation to Help Smokers Quit. Nurse Education Today. 2012;in press(in press):in press. 
31. Leong S, Lewis, P., Curry, W., Gingrich, D. Tobacco World: Evaluation of a Tobacco Cessation Training Program for Third-Year Medical Students. Academic Medicine. 2008;83(10):S25-S28.

32. Cornuz J, Humair, J., Seematter, L., Stolanov, R., van Melle, G., Stadler, H., Pecoud, A. Efficacy of Resident Training in Smoking Cessation: A Randomized, Controlled Trial of a Program Based on Application of Behavioral Theory and Practice with Standardized Patients. Annals of Internal Medicine. 2002;136:429-437.

33. Sarna L, Bialous, S., Rice, V., Wewers, M. Promoting Tobacco Dependence Treatment in Nursing Education. Drug and Alcohol Review. 2009;28:507-516.

34. Rankin K, Jones D, Crews K. Tobacco Cessation Education for Dentists: An Evaluation of the Lecture Format. Journal of Cancer Education. 2010;25:282-284.

35. Davis J, Ramseier, C., Mattheos, N., Schoonheim-Klein, M., Compton, S., Al-Hazmi, N., Polychronopoulou, A., Suvan, J., Antohe, M., Forna, D., Radley, N. Education of Tobacco Use Prevention and Cessation for Dental Professionals - A Paradigm Shift. International Dental Journal. 2010;60:60-72.

36. Spangler J, George G, Foley K, Crandall S. Tobacco Intervention Training: Current Efforts and Gaps in US Medical Schools. Journal of the American Medical Association. 2002;288(9):1102-1109.

37. Allan J, Barwick T, Cashman S, et al. Clinical Prevention and Population Health: Curriculum Framework for Health Professions. American Journal of Preventive Medicine. 2006;27(5):471-476.

38. Broberg C, Aars M, Beckmann K, et al. A Conceptual Framework for Curriculum Design in Physiotherapy Education - An International Perspective. Advances in Physiotherapy. 2003;5:161-168.

39. Bryan R, Kreuter M, Brownson R. Integrating Adult Learning Principles Into Training for Public Health Practice. Health Promotion and Practice. 2009;10(4):557-563.

40. American Physical Therapy Association. Professionalism in Physical Therapy: Core Values. Vol BOD P05-04-02-032003.

41. American Physical Therapy Association. A Normative Model of Physical Therapist Professional Education: Version 2004. Alexandira, Virginia2004.

42. Jensen G, Gwyer J, Shepard K, Hack L. Expert Practice in Physical Therapy. Physical Therapy. 2000;80:28-43.

43. American Physical Therapy Association. Guide to Physical Therapist Practice: Second Edition2003.

44. Crabtree B, Miller W, Tallia A, et al. Delivery of Clinical Preventive Services in Family Medicine Offices. Annals of Family Medicine. 2005;3:430-435.

45. Bellows N, McMenamin S, Halpin H. Adoption of Systems Strategies for Tobacco Cessation by State Medicaid Programs. Medical Care. 2007;45(4):350-356.

46. Holtrop J, Malouin R, Weismantel D, Wadland W. Clinician Perceptions of Factors Influening Referrals to a Smoking Cessation Program. BMC Family Practice. 2008;9(18).

47. McCullough A, Fisher M, Goldstein A, Kramer K, Ripley-Moffitt C. Smoking as a Vital Sign: Prompts to Ask and Assess Increase Cessation Counseling Journal of the American Board of Family Medicine. 2009;22:625-632. 
48. Muramoto M, Connolly $T$, Strayer $L$, et al. Tobacco Cessation Skills Certification in Arizona: Application of a State Wide, Community Based Model for Diffusion of Evidence Based Practice Guidelines. Tobacco Control. 2000;9:408-414.

49. Hudmon K, Corelli R. ASHP Therapeutic Position Statement on the Cessation of Tobacco Use. American Journal of Health Systems Pharmacy. 2009;66:291-307.

50. Ladapo J, Jaffer F, Weinstein M, Froelicher E. Projected Cost-Effectiveness of Smoking Cessation Interventions in Patients Hospitalized with Myocardial Infarction. Archives of Internal Medicine. 2011;171(1):39-45.

51. Fiore M, Keller P, Curry S. Health System Changes to Facilitate the Delivery of TobaccoDependence Treatment. American Journal of Preventive Medicine. 2007;33(6S):S349356.

52. Manfredi C, Cho Y, Warnecke R, Saunders S, Sullivan M. Dissemination Strategies to Improve Implementation of the PHS Smoking Cessation Guideline in MCH Public Health Clinics: Experimental Evaluation Results and Contextual Factors. Health Education Research. 2011;26(2):348-360.

53. Boyle R, Solberg L, Fiore M. Use of Electronic Health Records to Support Smoking Cessation. The Cochrane Library. 2011(12).

54. Conroy M, Majchrzak N, Silverman C, et al. Measuring Provider Adherence to Tobacco Treatment Guidelines: A Comparison of Electronic Medical Record Review, Patient Survey, and Provider Survey. Nicotine \& Tobacco Research. 2005;7(Suppl 1):S35-S43.

55. Reif S, Horgan C, Garnick D, McLellan D. Systems-Level Smoking Cessation Activities by Private Health Plans. Preventing Chronic Disease: Public Health Research, Practice and Policy. 2011;8(1):1-10.

56. Shelley D, Wright S, McNeely J, et al. Reimbursing Dentists for Smoking Cessation Treatment: Views from Dental Insurers. Nicotine \& Tobacco Research. 2012;14(10):1180-1186.

57. Glasgow R, Magid D, Beck A, Ritzwoller D, Estabrooks P. Practical Clinical Trials for Translating Research to Practice: Design and Measurement Recommendations. Medical Care. 2005;43(6):551-557.

58. Reid R, Mullen K, Pipe A. Systematic Approaches to Smoking Cessation in the Cardiac Setting. Current OPinion in Cardiology. 2011;26:443-448.

59. Ussher M, Taylor A, Faulkner G. Exercise for Smoking Cessation. Mental Health and Physical Activity. 2012;5:99-100.

60. Filozof C, Pinilla M, Fernandez-Cruz A. Smoking Cessation and Weight Gain. Obesity Reviews. 2004;5(2):95-103.

61. Adler N, Rehkopf D. US Disparities in Health: Descriptions, Causes and Mechanisms. Annual Reviews in Public Health. 2008;29:235-252. 